University of Louisville

ThinkIR: The University of Louisville's Institutional Repository

Electronic Theses and Dissertations

$12-2011$

\title{
Towards an improved measure of intrinsic/extrinsic religious motivation.
}

Aaron W. Banister

University of Louisville

Follow this and additional works at: https://ir.library.louisville.edu/etd

\section{Recommended Citation}

Banister, Aaron W., "Towards an improved measure of intrinsic/extrinsic religious motivation." (2011). Electronic Theses and Dissertations. Paper 67.

https://doi.org/10.18297/etd/67

This Doctoral Dissertation is brought to you for free and open access by ThinkIR: The University of Louisville's Institutional Repository. It has been accepted for inclusion in Electronic Theses and Dissertations by an authorized administrator of ThinkIR: The University of Louisville's Institutional Repository. This title appears here courtesy of the author, who has retained all other copyrights. For more information, please contact thinkir@louisville.edu. 


\title{
TOWARDS AN IMPROVED MEASURE OF INTRINSIC/EXTRINSIC RELIGIOUS MOTIVATION
}

\author{
By \\ AARON W. BANISTER \\ B.A., Johnson Bible College, 1996 \\ M.Ed., University of Louisville, 2008
}

\author{
A Dissertation \\ Submitted to the Faculty of the \\ College of Education and Human Development of the University of Louisville \\ in Partial Fulfillment of the Requirements \\ for the Degree of \\ Doctor of Philosophy \\ Department of Educational and Counseling Psychology \\ University of Louisville \\ Louisville, KY
}

December, 2011 
Copyright 2011 by Aaron W. Banister

All Rights Reserved 


\section{TOWARDS AN IMPROVED MEASURE OF INTRINSIC/EXTRINSIC RELIGIOUS MOTIVATION}

By

AARON W. BANISTER

B.A., Johnson Bible College, 1996

M.Ed., University of Louisville, 2008

A Dissertation Approved on

November 29, 2011

by the following Dissertation Committee:

Patrick Possel, Dissertation Co-Chair

Jill L. Adelson, Dissertation Co-Chair

Kathleen Rudasill

Mark Leach

Namok Choi 


\title{
DEDICATION
}

\author{
"Trust in the Lord with all of your heart \\ And lean not on your own understanding; \\ acknowledge Him in all of your ways, \\ and He will direct your paths" \\ Proverbs 3:5-6
}

This dissertation work is dedicated to my beautiful Joy, and our little fire Aiden, who have been on this journey from its genesis. It is also dedicate to two beautiful little girls, Maggie and Aubrie, who have joined us along the way.

It is also dedicated to my Father. Thank you for never giving up on me. I hope I have made you proud. 


\section{ACKNOWLEDGMENTS}

I would like to thank the many that have prepared me for this journey and have traveled alongside. I would like to begin by thanking my dissertation co-chairs, Dr. Patrick Pössel and Dr. Jill Adelson. Your guidance, support, challenge, time and effort have been greatly appreciated. Thank you for molding me into an effective researcher and helping me to discover my confidence in the process. I would also like to thank my dissertation committee members, Dr. Namok Choi, Dr. Kathleen Rudasill, and Dr. Mark Leach. You all have added something different for me over the course of my graduate studies and I am grateful for your investment in me.

I would also like to thank my professional mentors that loaned to me their wisdom, offered their guidance and support, and encouraged me along the way. Thank you to Dr. David Reece, Dr. Stan McDaniel, Dr. Jeff Valentine, Dr. Kirsten Sundell, Dr. Natalie Kosine, Dr. Nancy Cunningham, Dr. Terri White and Dr. Kai Kirby. I appreciate the genuineness that you shared with me along the way.

I would like to thank the staff at the University of Notre Dame Counseling Center for your encouragement and belief in me. Also, thank you to Dr. Ming Jung Doh for the support as we finished our internship and dissertation journeys together.

I would also like to thank Eric Banister, Kathy Mullis, Randy Prewitt, Dr. Nate Mitchell, Dr. Erica Adams, Dr. Amanda Wyrick, Dr. Amy Gonshak, Natalie Pickering, Shon Goodwin, Mike Whitten, Jamie White, Mrs. Jane Goodwin, Mrs. KD Faubion, Butch and Nancy Sowder, Sherry and Jerry Umphress, Phil McDonald, Denny and Reida Cummings, Elisa Beyers, Rikki and Terry Willoughby, David and Susan Fry, David Legg, Dr. John Croasdell, Paul Walker, Matt Craig, Johnson University, the "Guthrie Gang”, Wonder Valley Camp, Mundell Christian Church and Hillcrest Christian Church. 
You all are loved and have helped me to become a stronger believer, a better friend, and I am better for you having been a part of my life.

I cannot express enough appreciation to Dr. Dennis Kaufman. Your belief in me was life changing. Thank you for showing me the power of what this field can do.

Finally, my family: thank you and I love you! I know that the reason I have been able to achieve this degree of education, as a first generation college student, is only because generations before me have set the example of hard work and perseverance. Your spirit and courage in life has inspired me to live my life to the fullest.

Thank you mom for being all that you were, all that you are, for introducing me to my faith, to taking us to the "Book-Mobile", involving us in scouts and church. I know the road was not easy but I am lucky that you were in my life. You have given me this chance.

Joy, Aiden, Maggie and Aubrie: I love you. Thank you for your sacrifices for me. 


\section{ABSTRACT \\ TOWARDS AN IMPROVED MEASURE OF INTRINSIC/EXTRINSIC RELIGIOUS MOTIVATION}

Aaron W. Banister

November 22, 2011

Religious motivation is a construct that has been the focus of decades of research. The "Religious Orientation Scale" (ROS) and variations of it, including the "Age Universal Intrinsic-Extrinsic Scale-12" (AUIES-12), are the most commonly used measures of religious motivation. But from the initial use of these measures there has been questions concerning their theoretical foundation and scale reliabilities.

The purpose of this dissertation was to 1) test the factor structure of the AUIES12 and investigate its scale reliabilities; 2) investigate, through CFA, the factor structure of a new measure of religious motivation, the "Measure of Religious Motivation" (MRM), which introduces a fourth factor of religious motivation, Extrinsic-Rules Keeping, to be considered; and 3) test the theory of Extrinsic-Rules Keeping religious motivation by examining the relationship between Extrinsic-Rules Keeping and Stage Two of Fowlers Theory of Faith Development (1981; 1991; 2004), of which the theory of Extrinsic-Rules Keeping was built. The Extrinsic-Rules Keeping factor identifies individuals that use their religion as a set of "celestial rules", by which they are rewarded by God if they obey them and punished if they break them. In the development of the MRM additional items for the Extrinsic-Personal and Extrinsic-Social scales were included, as recommended, to increase scale reliabilities.

A sample of 961 participants drawn from an online questionnaire were divided into two randomly split samples. Analyses using both samples indicated that the AUIES12 was indeed a three-factor structure. However, as has been the case historically, only the Intrinsic scale held an acceptable reliability level. The MRM was supported through CFA as a four-factor model. The additional items added to the Extrinsic-Personal and Extrinsic-Social scales increased scale reliabilities to acceptable levels. Furthermore, the 
Extrinsic-Rules Keeping scale was found to have a positive relationship with Stage Two of Fowlers Theory of Faith Development, providing construct validity.

The end result of this dissertation was the support for a 27 item measure of religious motivation that is psychometrically sound, theoretically supported, identifies four distinct types of religious motivation, and allows for reliable score and valid inferences from all scales. 


\section{TABLE OF CONTENTS}

PAGE

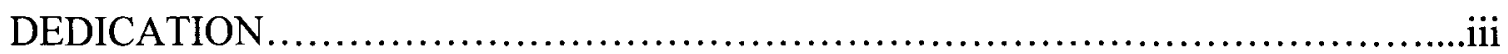

ACKNOWLEDGEMENTS............................................................

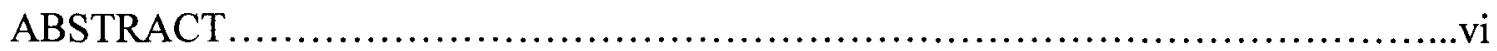

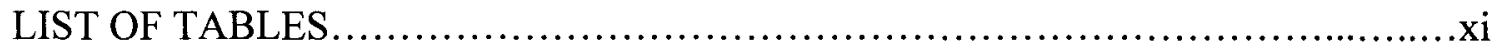

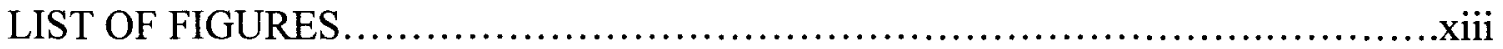

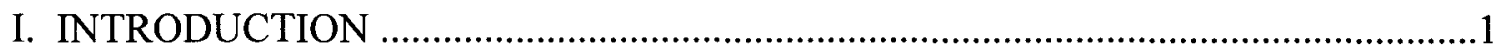

Definitions of Religiosity, the Need for Further Refinement

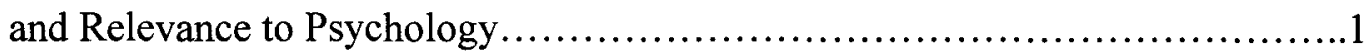

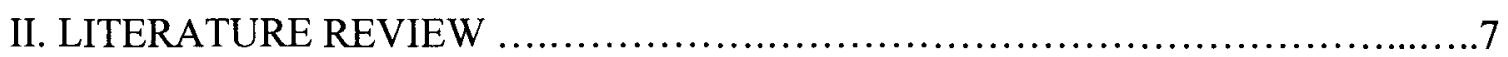

Moral Development.....................................................

Religious Development...................................................15

Allport's Concept of Intrinsic and Extrinsic Religious Motivation

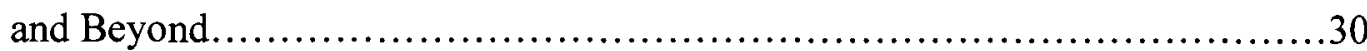

Measure of Intrinsic/Extrinsic Religious Motivation: Development

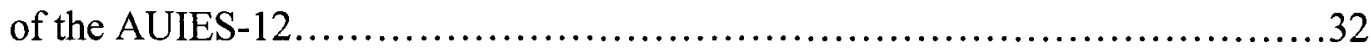

Appropriateness of Use of Intrinsic/Extrinsic Measures among Religious and

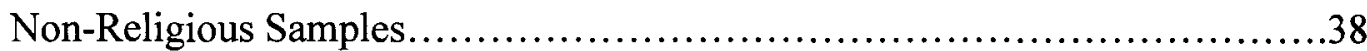

A New Measure of Intrinsic/Extrinsic Religious Motivation: Development of the

Measure of Religious Motivation...............................................40

Towards Defining and Refining the Study of Intrinsic/Extrinsic

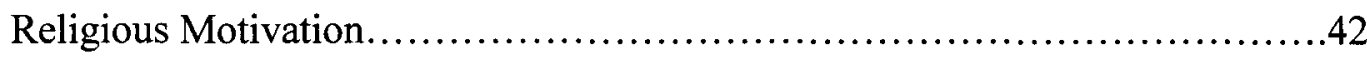




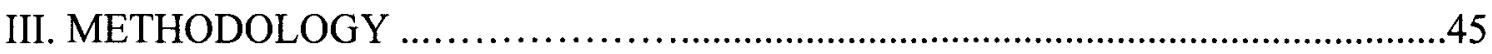

Research Questions and Hypotheses......................................43

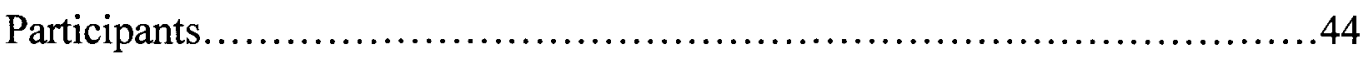

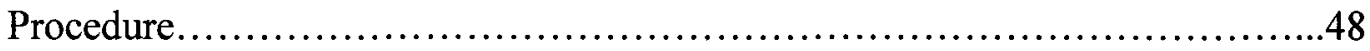

Statistical Analysis Plan....................................................49

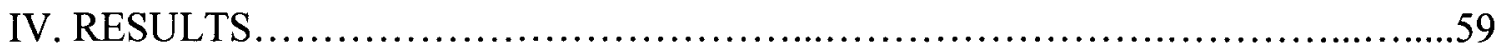

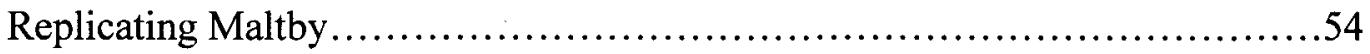

Analyzing the AUIES-12 with New Methods...................................56

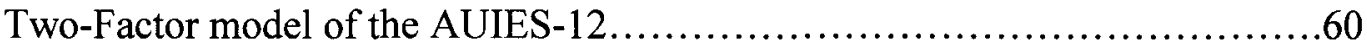

Three-Factor model of the AUIES-12 .......................................65

Model One: Initial Four-Factor Model of the MRM..........................68

Model One-B: Initial Four-Factor Model of the MRM with Correlations

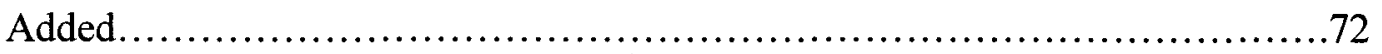

Model Two: Four-Factor Model of the MRM with all AUIES-12

Items Included ......................................................... 76

Model Two-B: Final Four-Factor Model of the MRM with Subsample 1........80

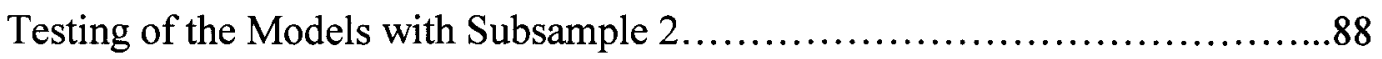

Testing of Hypothesis Three......................................... 92

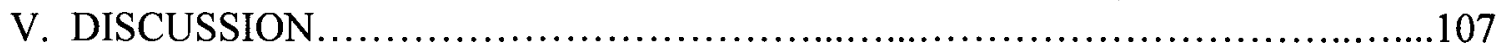

Research Question 1: Determining the Factor Structure of the AUIES-12 _.......98

Research Question 2: Determining the Factor Structure of the MRM...........104

Research Question 3: Relationship between the Extrinsic-Rules Keeping

Scale and Fowler's Theory of Faith Development.............................109 
Summary and Conclusions......................................... 112

Limitations and Future Direction.........................................115

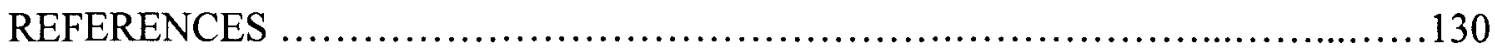

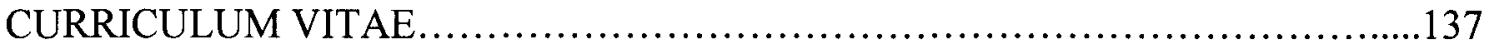




\section{LIST OF TABLES}

\section{TABLE}

1. Sample Demographic Information.

2. Pattern Coefficients from the PCA and PAF with direct oblimin rotation for the 12

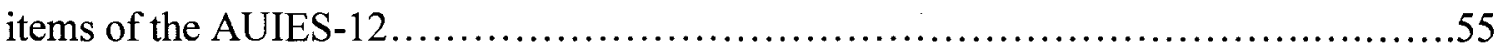

3. Eigenvalues and Parallel Analysis Results for AUIES-12 .......................57

4. Standardized Pattern Coefficients for Two Confirmatory Factor Analysis Models of

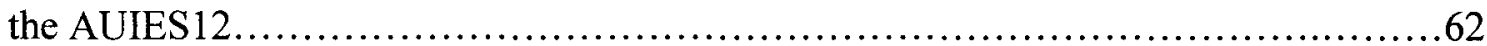

5. Fit Statistics: Confirmatory Factor Models of the AUIES-12......................64

6. Standardized and Unstandardized Pattern Coefficients for Confirmatory Factor Analysis of the Measure of Religious Motivation.................................... 70

7. Pearson Correlation Matrix for Factor Correlation of the Measure of Religious

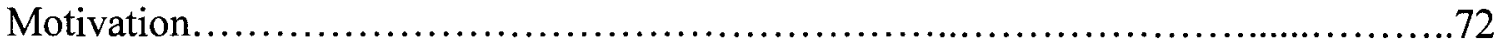

8. Fit Statistics for All Confirmatory Factor Analysis Models of the Measure of Religious Motivation............................................................. 75

9. Standardized Pattern Coefficients for Confirmatory Factor Analysis Four-Factor Model of the MRM with all AUIES-12 Items...................................... 78

10. Pearson Correlation Matrix for Four-Factor Model of the MRM with all AUIES-12 Items.

11. Standardized Pattern Coefficients for Confirmatory Factor Analysis of the Measure of Religious Motivation: Final Model..............................................85 
12. Pearson Correlation Matrix for Factor Correlation of MRM Final Model with

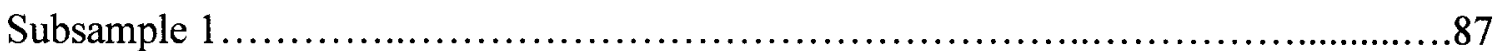

13. Pearson Correlation Matrix for Factor Correlation of MRM Final Model with

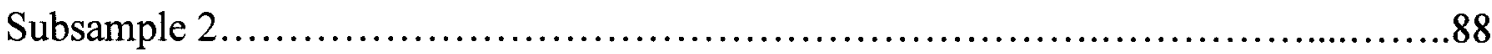

14. Pearson Correlations between Extrinsic-Rules Keeping and Stage 2 through Stage 5 of Fowlers Theory of Faith Development as Measured by the FDSS......................91

15. Characteristics of Sample from the Pilot Study ...................................93 


\section{LIST OF FIGURES}

\section{FIGURE}

1. Scree Test from PCA with Maltby's Methods..................................54

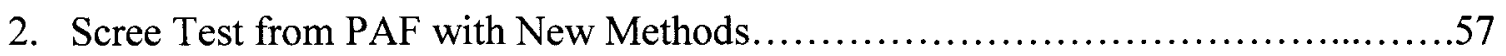

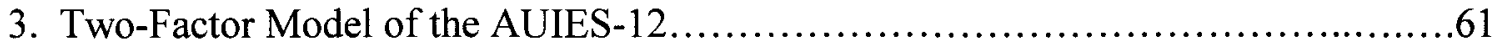

4. Two-Factor Model of the AUIES-12 with Correlated Items.......................64

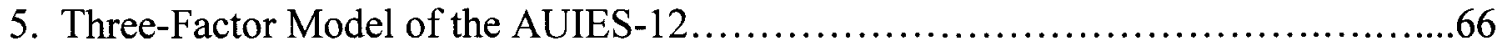

6. CFA of Model One of the MRM...............................................69

7. CFA of Model One-B of the MRM .......................................... 74

8. CFA of Model Two of the MRM............................................ 77

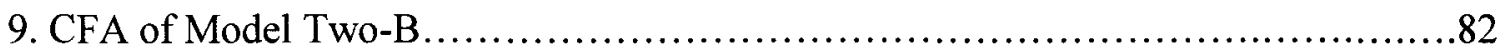

10. Scatterplot of Extrinsic-Rules Keeping and Stage 2 of Fowler's Theory of Faith

Development................................................................95 


\section{INTRODUCTION}

\section{Definitions of Religiosity, the Need for Further Refinement and Relevance to Psychology}

There has been a considerable amount of research dedicated to the subject of religiosity and its influence on human development, human behavior, psychological wellbeing, and physiological health (Idler, 1987; Johnson \& Mullins, 1989; McClure \& Loden, 1982; St. George \& McNamara, 1984; Siegel, Anderman, \& Schrimshaw, 2001). However, religiosity has had various definitions across studies. Religiosity has been defined as the quality of being formally structured and identified with religious institutions and prescribed theology and rituals (Zinnbauer et al., 1997); as the state of being religious to the degree to which an individual believes and is committed to their faith or religious system (Kahoe, 1985); an individual's spiritual beliefs, religious practices, and participation with a faith community (Lambert \& Dollahite, 2006); and the motivation behind why one engages in religious behaviors (Allport, 1950). Koenig, McCullough, and Larson (2001) defined religiosity as an individual's behavior and attitude that reflects an organized system of beliefs, rituals, and/or symbols designed to facilitate closeness to the sacred or transcendent and promote an understanding of their relationships and responsibilities to others in living together in a community. A summation of the differing definitions of religiosity can be conceptualized as a term that encompasses one's religious beliefs, further adherence to prescribed behavioral attributes 
associated with religion, and the significance that religion plays in an individual's day-today motivations, behaviors, and attitudes.

A difficulty in scientifically investigating religiosity lies in the precise defining and measuring of such broad terms (e.g., religiosity, spirituality, faith) (Batson \& Ventis, 1982; Dittes, 1969; Genia \& Shaw, 1991; Spilka, Hood, \& Gorsuch, 1985). Ellis (2000) reported that a reason for his earlier dogmatism towards religiosity was rooted in what he described as the ambiguous terms that he believed were difficult to pin down to prescribed definitions. A testament to the varying definitions of religiosity can be observed in the number of measures that have been designed to measure some aspect of it. Hill and Hood (1999) reported, over a decade ago, that there were over 100 measures designed specifically for the objective research of religiosity, with Allport and Ross' Religious Orientation Scale (ROS) being the most frequently used. Among these measures, several aspects of religiosity are measured, including the degree of religious belief and practices, religious attitudes, religious orientation, religious commitment, religious experience, morality related to religion, spirituality and mysticism, concepts of God, religious fundamentalism, institutional religious affiliation, and religious motivation (among others). For a more focused investigation into the potential risk and protective factors that are associated with religiosity, a clearly defined construct of what religiosity consists of and a valid measure of those domains are needed.

The broader term of religiosity has a history of detractors and advocates among psychological theorists. Freud (1939) and Ellis (1983) were both doubtful that any benefit towards psychological well-being could derive from an individual ascribing to religious beliefs. Freud believed that religiosity was an expression of underlying 
psychological neuroses and as an attempt to control the Oedipal complex, an infantile delusion and an attempt to control the outside world. Freud wrote in his 1939 work Moses and Monotheism that "religion is an attempt to get control over the sensory world, in which we are placed, by means of the wish-world, which we have developed inside us as a result of biological and psychological necessities. If one attempts to assign to religion its place in man's evolution, it seems not so much to be a lasting acquisition, as a parallel to the neurosis which the civilized individual must pass through on his way from childhood to maturity" (p. 43). Ellis (1983) believed that devout religiosity was antithetical to good mental health and emotionally harmful ${ }^{1}$. However, Jung (1933) believed that religiosity was beneficial and valuable to humanity, bringing meaning to individuals' lives.

Regardless of the differing camps that have existed in the realm of psychology since its beginnings, there has been an increase in the perception of the legitimacy of how religiosity can both harm and benefit an individual. Weaver, Pargament, Flannelly, and Oppenheimer (2006) conducted a systematic review that revealed that over a 35 year period, between 1965 and 2000, there had been a dramatic increase in the number of empirical studies that focused on the broader domains of religion, spirituality, and health. During the period between 1965 and 2000 Weaver et al. (2006) found 1,100,300 articles that addressed some aspect of health as well as religion, spirituality or both. They found that from 1965-1969 articles addressing some aspect of health and both religion and spirituality occurred at an average rate of 64 articles per 100,000 articles, increasing to a

\footnotetext{
${ }^{1}$ Ellis (2000) later clarified his statement by stating: "My view now is that religious and non religious beliefs in themselves do not help people to be emotionally "healthy" or "unhealthy." Instead, their emotional health is significantly affected by the kind of religious and nonreligious beliefs that they hold" (p. 30).
} 
rate of 362 per 100,000 between 1996 and 2000, with 2,153 per 100,000 focusing on some aspect of religion, spirituality, or an amalgamation of both.

This increase in empirical studies concerning religious matters is a tribute to the changing perception of religiosity in the field of psychology. This expanding research of religiosity acknowledges that there are types of religiosity that seem to be helpful and certain types that seem to be harmful (Clay, 1996). For example, research has found that there are both positive and negative relationships between religiosity and depression (Pössel, Martin, Garber, Banister \& Pickering, 2011; Smith, McCullough, \& Poll, 2003), psychological well-being (Francis \& Kaldor, 2002; Hackney \& Sanders, 2003), substance use (D’Onofrio et al., 1999; Kendler, Gardner, \& Prescott, 1997), life satisfaction (Cohen, 2002; Cohen et al., 2005; Dorahy et al., 1998) and physiological health (Benjamins \& Brown, 2004; Koenig, McCullough, \& Larson, 2001; Reyes-Ortiz, Palaez, Koenig, \& Mulligan, 2007; Yeager et al, 2006). Furthermore, intrinsic religious motivation (an individual that has internalized their religious beliefs and lives them in their everyday life) and extrinsic religious motivation (someone involved in religious activities for some ulterior, self-centered purpose) have been correlated to both negative and positive associations concerning mental health. Traditionally, intrinsic religious motivation has been found to be associated with better mental health (Chatters, 2000; Forthun, Pidcock, \& Fischer, 2003; Genia, 1996; Koenig, 1995; Maltby, Lewis, \& Day, 1999) whereas extrinsic religious motivation has been considered to be a risk factor for depression and anxiety (Baker \& Gorsuch, 1982; Park, Cohen, \& Herb, 1990). These findings have further altered the perception of the legitimacy of religiosity as a viable psychological construct to be explored. 
This ever changing perception has ushered in an acknowledgment that the study of the multidimensional concept of religiosity is appropriate and benefits the field of psychology. It can be argued that the study of spirituality/religiosity represents an understudied, or even veiled, core dimension that should be considered in the research of human development (Benson, 2004), a dimension that is deserving of further scientific inquiry. Frame (2003) stated that theoretical models oriented around religious and spiritual development are valuable to psychologists because they provide frameworks for understanding how clients incorporate their faith into everyday living. The literature on the effects of religiosity on mental health among adults has produced a voluminous amount of literature ("Handbook of the Psychology of Religion and Spirituality", Paloutzian \& Park, 2005). However, there are vastly fewer studies concerning the effects of religiosity on the mental health of adolescents (Schapman \& Inderbitzen-Nolan, 2002). With knowledge of the empirically supported risk /protective factors associated with religiosity among adults (Gartner, Larson, \& Allen, 1991; Hackney \& Sanders, 2003; Koenig Larson, \& Larson, 2001), similar investigations should be made across the life span. A move towards this endeavor would be to examine the construct of religiosity across the life span, investigating if the known elements of religiosity are applicable to all age groups, or to find what specific differences may exist between age groups, and the implications that has on mental health. To enable this pursuit instruments measuring the different aspects of religiosity that allows for valid inferences is needed. The following dissertation will focus on the aspect of religious motivation. 


\section{LITERATURE REVIEW}

\section{Considering Moral Development and Faith/Religious Development Theories}

In order to investigate religious motivation more clearly, a review of several influential theories concerning moral development and faith/religious development is needed. Below are several influential theories in both moral and faith/religious development.

\section{Moral Development}

Moral judgment concerns how people define one or another course of action in a situation as morally right or fair (Schlaefli, Rest, \& Thoma, 1985). Moral judgment includes (a) defining what constitutes moral issues, (b) deciding how conflicts can be adjudicated, and (c) the principle reasoning for choosing a specific set of actions (Rest, Thoma, \& Edwards, 1997). Below are four influential theories concerning the process and/or stages by which moral judgment develops.

Jean Piaget. Piaget, considered a pioneer of moral development theory, is credited with conducting the most influential early research concerning the moral development of children. To investigate the development of moral judgment in children, Piaget (1948) explored children's thinking concerning justice by analyzing their attitudes towards game rules and stories of stealing and lying. Piaget's research led him to the conclusion that children's social interaction leads them to new levels of moral understanding (Bergman, 2002). Piaget's study of the attitudes of children with regard to 
rules of games suggested that, in the beginning stages of moral development, children feel constrained by the game rules; they believe the rules reflect parental authority and must be obeyed without question. Piaget referred to this belief as the morality of constraint. However, over time through social interaction, children begin to learn that rules are not absolute. Social consensus can alter the rules, making rules no longer an external limitation to be revered, but rather social creations derived through a process of free decision deserving of mutual respect and consent. Piaget referred to this belief as the morality of cooperation.

Piaget (1948) believed that children move from a heteronomous morality (morality of restraint) to an autonomous morality. Individuals in heteronomous morality do not question the rules, they simply obey them. They believe that rules are absolute and unchallengeable, handed down by an omniscient authority (i.e. parent, teacher, law official, God) who will always know if a rule is broken and enact immediate punishment. Piaget referred to this immediate, swift punishment as immanent justice. Moving towards autonomous morality, a child's conception of fairness and justice begins to alter, developing a sense of reciprocity. Autonomous morality occurs when the child no longer believes that rules are handed down to them, but rather that moral beliefs exist within each individual. Autonomous morality also has a cooperative element, based on mutual decisions that consider others feelings and input as well.

Piaget's (1948) story-based research, in which he presented children with moral dilemmas in which they had to derive a solution, provided further insights into the reasoning behind the moral judgments of children. Piaget found that children first base moral judgments on the consequences of transgressions, and he categorized this type of 
moral judgment as objective judgment. A second type of moral judgment is subjective judgment. Subjective judgment develops later than objective judgment and considers intentions and motives as well. Therefore, a child operating from objective judgment would believe everyone who breaks the rules deserved the same consequences, regardless of the circumstances, whereas a child operating from subjective judgment would not administer a one-size-fits-all consequence, but would take each case individually. In summation, Piaget (1948) believed that as children grow they became more cognitively sophisticated. Coupled with being immersed in an ever more complex social world, children begin to progress in their understanding and perception of morality and justice. Piaget believed that children moved from a morality of constraint to a morality of cooperation, passing from heteronomous morality (morality of constraint) to autonomous morality, and moving from objective to subjective judgments. Even though not all of Piaget's conclusions have been substantiated by more current research, his ideas formed the theoretical foundation for the later research of moral development.

Lawrence Kohlberg. Kohlberg (Kohlberg 1958, 1963, 1966, 1969; Kohlberg \& Gilligan, 1971; Kohlberg \& Kramer, 1969; Kohlberg \& Turiel, 1972) took the work of Piaget and expanded upon it to develop his own theory of moral development that extended beyond childhood. Like Piaget, Kohlberg was not concerned with what an individual actually does when facing a moral dilemma, or the statements they make about whether their actions are wrong or right. What Kohlberg was interested in was the reasons given for making moral decisions or moral judgments -the motivation for or reasons why a moral decision was made. Kohlberg believed that if someone could 
explain a person's moral judgment stage, they would have further insight into their motivations, sensitivities and potential for action (Narvaez, in press).

Kohlberg (1963) studied 72 males, ranging in age from 10 to 16 years, by interviewing them every three years for an 18 year period. Kohlberg presented each subject with 10 moral dilemmas. Each dilemma involved a person(s) caught in a specific moral dilemma (e.g. the Heinz dilemma ${ }^{2}$ ) where an act of disobedience to legal-social rules or the instructions of authority figures conflicted with the welfare or need of others. Each subject was presented two potential acts and asked which was more moral, and the reason why it was more moral. Through this method of interviewing Kohlberg explored the thought process by which an individual comes to arrive at a specific moral judgment. Through his longitudinal research (Kohlberg 1958, 1963, 1966, 1969, 1970; Kohlberg \& Gilligan, 1971; Kohlberg \& Kramer, 1969; Kohlberg \& Turiel, 1972), Kohlberg came to believe that moral reasoning progresses in stages and identified three major levels of moral development containing six distinguishable stages (two stages per level).

Level 1 of Kohlberg's theory of moral development is Preconventional Moral Reasoning, containing Stage 1, Obedience and Punishment Orientation, and Stage 2, Individualism and Exchange. Next is Level 2, Conventional Morality, consisting of Stage 3, Good Interpersonal Relationships and Stage 4, Maintaining the Social Order.

\footnotetext{
${ }^{2}$ In Europe, a woman was near death from a special kind of cancer. There was one drug that the doctors thought might save her. It was a form of radium that a druggist in the same town had recently discovered. The drug was expensive to make, but the druggist was charging ten times what the drug cost him to make. He paid $\$ 200$ for the radium and charged $\$ 2,000$ for a small dose of the drug. The sick woman's husband, Heinz, went to everyone he knew to borrow the money, but he could only get together about $\$ 1,000$ which is half of what it cost. He told the druggist that his wife was dying and asked him to sell it cheaper or let him pay later. But the druggist said: "No, I discovered the drug and I'm going to make money from it." So Heinz got desperate and broke into the man's store to steal the drug-for his wife. Should the husband have done that? (Kohlberg, 1963, p. 19)
} 
Finally, Level 3, Post-Conventional Morality, is made up of Stage 5, Social Contract and Individual Rights and Stage 6, Universal Principles.

In Preconventional Morality's first stage, Obedience and Punishment Orientation, individuals believe that if they do not obey the rules, they will be punished for their disobedience. Their motivation for doing what is right is to avoid being punished. The second stage of Kohlberg's first level of moral development is Individualism and Exchange, in which an individual views what is right as following the rules only when doing so is to his or her immediate advantage. An individual in this stage acts to meet his or her own interests and needs and lets others do the same. In the Individualism and Exchange stage, what is right is also viewed as a perception of fair exchange or fair deals (Crain, 2005), or as an agreement (Colby, Kohlberg, Gibbs, \& Lieberman, 1983). At this stage of moral development decisions are based on external control, attempting to avoid punishment or gain reward from some external source.

In the second level, Conventional Morality, stage three (Good Interpersonal Relationships) is where good behavior is that which helps or pleases others and is contingent on external approval. The fourth stage, Maintaining the Social Order, is concerned with law and order. This is an orientation towards authority, maintaining social order, and fixed rules. Doing "right" is when one does their duty and shows respect for authority, in turn maintaining the social order of things. At this stage of moral development decisions are based from both an external control and internal control.

The third level of Kohlberg's theory of moral development is Post-Conventional Morality. Stage five, Social Contract and Individual Rights, has utilitarian overtones. At this level there is more flexibility in the understanding that rules are obeyed because they 
are necessary for social order; however, the rules could be altered if there were more fitting alternatives. In the sixth stage, Universal Principles, behavior begins conforming to internal principles to avoid self-condemnation, violating society's rules if necessary. At this stage of moral development, the basis of moral decision-making is no longer concerned with external control, but has moved to internal control resulting from the internalization of individuals' moral values and belief systems. Individual's, at this stage, base their behavior on or the benefits that it will have on others around them, and less so on choosing behavior that solely benefits themselves.

Although Kohlberg (1981) later acknowledged that not every individual actually reached the highest level of his model, he still believed that individuals progressed through each stage, making it necessary to pass through one before reaching another. $\mathrm{He}$ also believed that these stages were universal, transcending gender, ethnicity and culture.

Kohlberg's theory of moral development has attracted numerous critics. Vine (1986) believed that Kohlberg's theory was culturally biased. Turiel $(1983,1997)$ thought that Kohlberg confused the moral domain with the social cognitive domain. Eisenberg (1995) believed that the dilemmas in the Moral Judgment Interview (MJI), developed by Kohlberg to measure moral development, were unrealistic, requiring the subject to make decisions concerning scenarios that were about authority and justice. However the sharpest criticism came from Gilligan (1982), who believed that Kohlberg's theory was gender-biased. This criticism of gender-bias launched a new line of research concerning moral development and gender differences.

Carol Gilligan. Gilligan, a student of Kohlberg, did not endorse his theory of moral development because of her belief that it was gender-biased (Crain, 2005; Gilligan, 
1982). In her book A Different Voice, Gilligan (1982) asserted that females deal with moral dilemmas differently than males because they are more caring, less abstract, and more sensitive in nature. She based her dissatisfaction with the theory on the fact that Kohlberg (1958) conducted his research on exclusively male subjects. This fact, in Gilligan's opinion, made it inappropriate to generalize his theory of moral development to females. In addition, Gilligan questioned the validity of applying his theory to a female population due to the scoring method for the MJI having been developed from male only responses (Jorgensen, 2006). The average adolescent female scored at a Stage 3, whereas their male counterparts scored at Stage 4, a full stage higher.

Gilligan (1982) proposed that there was a difference between males and females concerning moral development, but that it was not a matter of either sex being more advanced. Gilligan believed that the difference arose from differing perspectives of moral issues. She believed males rely more heavily on a legalistic orientation focusing on justice, preserving rights, rules, and principles, whereas females emphasize a caring orientation, demonstrating concern and empathy for others and sensitivity to their feelings and rights (Muss, 1988). Kohlberg conceived that the concept of care, as described by Gilligan, was subsumed in justice (Kohlberg, Levine, \& Hewer, 1983).

However, research has demonstrated that the MJI is not biased against women (Greeno \& Maccoby, 1986) and that female and male operate from both a justice orientation and caring orientation (Walker \& Taylor, 1984). White (1999), using the MJI, actually found that female members of the U.S. Coast Guard scored higher than their male counterparts on measures of moral judgment, again providing research that does not support Gilligan's claim of gender-bias. Critics of Gilligan state that the open- 
ended interview technique employed during her research left for extensive interpretation of the answers by the researcher, allowing for bias (Colby \& Damon, 1983).Walker (1991) found that both females and males demonstrated a more legalistic orientation when confronted with impersonal issues, and operated from a caring orientation when confronted with more personal concerns.

James Rest. Rest, a student of Kohlberg as well, also focused on how a person reaches a decision based on moral reasoning. He supported Kohlberg's developmental model but suggested that the inner process of moral development was more complicated than Kohlberg originally believed (Rest et al., 1997). Rest proposed that moral judgment should be thought of as containing four inner processes or components, all of which must perform adequately to produce moral behavior and all of which involve cognitiveaffective interaction (Bergman, 2002). Building upon, but diverging somewhat from Kohlberg's theory, Rest (1986) then developed the Four-Component Model of Moral Behavior. The four components of the model are 1) Moral Sensitivity, 2) Moral Judgment, 3) Moral Motivation, and 4) Moral Virtue.

In Component One, Moral Sensitivity, a person must be able to make some degree of interpretation to a particular situation in terms of what actions are possible, who (including themselves) each course of action would affect, and how those involved would regard such consequence on their personal welfare. In Component Two, Moral Judgment, the individual must be able to make a judgment concerning which course of action is morally right or fair, identifying one possible course of action as what a person, morally, should do in the given situation (Rest, 1986). In Component Three, Moral Motivation, the individual must prioritize acting morally above other personal values, deciding to 
carry through what is deemed moral (Rest, 1986). Component Four, Moral Character, is concerned with one's ability to follow through on reflected convictions. Rest believed it necessary that individuals must have ample perseverance, ego strength, and implementation skills to be capable of following through on their decision to behave morally, remain steadfast and overcome difficulties (Rest 1986).

Rest's Four-Component Model is not a stage theory, nor general traits of people that develop from maturation; rather, the components represent processes by which a person may engage in moral reasoning. Rest (1986) pointed out that the components may not always exist in a linear sequence, but that the four processes are present in logical sequence and serve as an analytical framework for processing thoughts in order for moral behavior to be generated. Rest (1986) held that individuals at differing points of development interpret moral dilemmas differently; possessing differing intuitions about what is right and fair in any given situation. Rest viewed these intuitions as a more common-sense, behind-the-scenes process, rather than a subjective system of rules. Rest developed the Defining Issues Test (DIT), closely aligned with Kohlberg's theory, to measure cognitive moral development. The numerous studies that have utilized the DIT have provided support for Kohlberg's stages, although the age ranges are different than what Kohlberg expected. Research results have fortified the fact that there are moral developmental stages and that people tend to develop through a certain sequence of these stages according to chronological age and educational level (Jorgensen, 2006). Although Rest has articulated more complex stages than Kohlberg, the research has a strong corroboration of Kohlberg's stage theory. It should be noted that there are no items on the DIT to measure the first stage of Kohlberg's theory. 


\section{Conclusion}

Although Kohlberg, as well as the idea of stage theories in general, have received criticism, his theory of moral development is still utilized in current research (i.e., Narvaez, in press). Rest (1997) progressed Kohlberg's line of research, providing corroborating evidence for stages of moral development. Although there has been heavy criticism that Kohlberg's theory of moral development is gender-biased (Gilligan, 1982), there has been no empirical support to back those claims. There has actually been evidence that the claim of gender-bias is inaccurate (Green \& Maccoby, 1986; Walker, 1984; White, 1999). Kohlberg's theory still survives as seemingly the predominant theory of moral development.

Although Kohlberg's stages of moral development were not conceived as a model of the development of intrinsic/extrinsic religious motivation, his theory may be appropriately applied and extended to the development of intrinsic/extrinsic religious motivation. Several researchers (Duriez, \& Soenens, 2006; Glover, 1997; Sapp \& Gladding, 1989) noted that these two constructs are indeed very closely linked. Duriez and Soenens (2006) found that the manner in which an individual processes moral content is predictive of the way that he or she deals with religious content. They found that being religious had no significant impact on moral reasoning ability, however, the way in which religious content is processed was critical. Kohlberg's theory also served as a springboard for several models of faith/religious development.

\section{Religious Development}

As with several corners of literature concerning theories and research into religious fronts, several terms are used to seemingly describe very similar, if not the 
same, constructs. Although I will discuss several faith/religious development theories that may use different terms, all view religion not as a static belief, but rather a continually evolving construct. Each theory of faith/religious development discussed below also addresses how individuals grow and change in relation to their religious faith.

Only theories of faith development that incorporate Kohlberg's (1958, 1963, $1966,1969,1970)$ theory of moral development are presented below. The one exception is Allport's (1950) theory, which preceded Kohlberg's work. This theory is relevant because it became the foundation of his later work in which the ROS (1967) was developed (which will be later discussed). This is salient because the ROS is the forefather of the AUIES-12, from which I attempt to derive an improved measure of religious motivation.

\section{Allport's Theory of Faith Development. Allport (1950) was the first} contemporary psychologist to present a theory of faith development (Frame, 2003). Allport's (1950) first stage of faith development is raw credulity, which is viewed as an authority-based stage of faith (Worthington, 1989). According to Allport (1950), preadolescents believe everything they hear concerning religion and spirituality that comes from their parents and other authority figures (Frame, 2003). At this first stage preadolescents begin to feel an intense desire to belong to and identify with the in-group (Allport, 1950). Resulting from this bond to their in-group children, without examination or question, hold unswervingly to their religious in-group beliefs (Frame, 2003). Allport (1950) stated that at this stage a child that identifies with any denominational in-group, or any other chosen denomination, will likely hold animosity towards any other religious group simply based on the perception that they do not belong to their chosen in-group, 
despite similarities in beliefs or morals. It is possible for children to move into adulthood without critically examining their beliefs and denominational allegiance, thus never surpassing this first stage of faith development. Allport stated that this type of immature religion is largely concerned with magical thinking, personal comfort, and selfjustification.

The second stage of Allport's theory, satisfying rationalism, generally begins in adolescence. At this stage teenagers begin to question their belief system that developed in childhood (Allport, 1950; Frame, 2003; Worthington, 1989). Individuals begin to seek their own unique identity, separate from their parents. This leads to questioning and possible rejection of their parents religious teachings.

Religious maturity, Allport's final stage, is described as a disposition forged through experience, and capable of responding in a favorable manner to conceptual objects and principles that the individual regards as of having supreme importance in their own lives (Allport, 1950). Religious maturity is marked by a connection to their religious traditions and beliefs following a critical examination of them, maintaining those beliefs that are helpful and hold meaning, and rejecting those beliefs that are not. Religious beliefs at this stage have a liberating, rather than oppressive quality, acting as a positive and motivating energy in an individual's life (Frame, 2003). Allport noted that not all that held religious beliefs would reach religious maturity.

Allport's (1950) model of faith development later was incorporated into the development of the ROS (Allport \& Ross, 1967), where he viewed an extrinsic religious motivation to be spawned from an immature faith and an intrinsic religious motivation to be the product of a mature belief system. Allport did not give a theoretical foundation to 
his ideas or show any empirical support, but simply hypothesized what he believed to be observable. However, Allport's general concept of mature versus immature (intrinsic religious motivation versus extrinsic religious motivation) faith has become a cornerstone in a large portion of the research that has been done over the past several decades (e.g., Baker \& Gorsuch, 1982; Benjamins \& Brown, 2004; Brewczynski \& McDonald, 2006: Chatters, 2000; Cohen, 2002; Cohen et al., 2005; D’Onofrio et al., 1999; Donahue, 1984; Francis \& Kaldor, 2002; Forthun et al., 2003; Genia, 1996; Hackney \& Sanders, 2003; Kendler , 1997; Koenig, 1995, 2001; Leak \& Fish, 1989; Leak \& Randall, 1995; Maltby et al., 1999; Park et al., 1990; Pössel et al., 2011; Reyes-Ortiz et al., 2007; Smith et al., 2003; Yeager et al., 2006).

Fowler's Stages of Faith Development. Fowler, influenced by the psychosocial ego psychology of Erickson (Fowler, 1981; 1991), Piaget's cognitive development theory (Frame, 2003; Gathman \& Nessan, 1997), and Kohlberg's theory of moral development (Gathman \& Nessan, 1997), presented faith development as a parallel construct to moral development (Wallwork, 1980). Believing that religious growth is a gradual process through stages of reasoning about ultimate reality (Leak, Louks, \& Bowlin, 1999), Fowler $(1981,1991,2004)$ presents several stage-like positions in the development of an individual's religious faith. The stages of faith are Primal faith, Intuitive-Projective faith, Mythic-Literal faith, Synthetic-Conventional faith, Individuative-Reflective faith, Conjunctive faith, and Universalizing faith. Some refer to Fowler's model as a six-stage model, placing Primal faith as a pre-stage, as opposed to a full stage to be considered (Frame, 2003). However, in his 2004 article, "Stages of Faith and Identity: Birth to Teens," Fowler included Primal faith as a stage to consider in faith development. 
Fowler's model will be referenced throughout this dissertation as the traditional six-stage model due to its more frequent use throughout the faith development literature.

Fowler (1981) claimed that the stages are invariant and hierarchical and that each stage must be passed through sequentially. Fowler viewed his theory as universal, applying to all cultures and belief systems. Although no stage could be skipped, Fowler did allow for overlap of stages and acknowledged that individuals could remain in one stage for a lengthy period of time (Frame, 2003).

Fowler $(1981,1991,2004)$ believed that the pre-stage of faith development, primal faith, prevailed from infancy to two years of age. This earliest form of faith, developing before language, is a total emotional orientation of trust offsetting mistrust. Primal faith forms in the mutuality of one's relationship with parents and others around them. This primal faith enables one to overcome the anxieties resulting from separations that occur during infant development. Fowler stated that primal faith does not necessarily determine the course of our later faith, but it establishes the foundation where faith is later built upon (Fowler, 1991). This stage of faith development parallels Erickson's age appropriate developmental task of the development of a basic sense of trust in those of whom the child is in closest contact (Erickson, 1963).

Fowler's first stage, Intuitive-Projective faith, becomes visible between toddlerhood (approximately age two) and early childhood, although some adolescents and adults could still demonstrate features of this stage (Frame, 2003). In this stage symbols, gestures and stories that are not yet controlled by logical thinking are created from the child's imagination. These symbols, gestures and stories are combined with the child's feelings and perceptions to create long-lasting faith images (Fowler, 1981, 1991, 
2004). Represented by these images are both the protective and threatening powers that exist in the child's life. The child's representation of God emerges from these developed faith images, as well as the child's experiences with their parents and other adults with whom they are emotionally attached.

Mythical-Literal faith, the second stage, takes shape from middle childhood and beyond. The emergence of logical thinking enables the child to begin to order the world with categories of space, time, causality, and number (Fowler, 1991). With this emergence of concrete-operational thinking comes the ability to discern real from makebelieve, and see others' perspectives, enabling the ability to capture meanings from narrative and stories (Fowler 1991, 2004). There is a propensity for individuals in this stage to act as if God patrols as a cosmic ruler who rewards goodness, punishes evil and demands moral behavior (Gold, 2010). Gold (2010) adds that an individual's beliefs may be manifested by behaviors towards perfection due to expectations of reward and avoidance of punishment. This behavior, which manifests from the development of concrete-operational thinking, allows for the ability for thoughts to be reversed, making cause-and-effect thinking available. This new feature of thinking allows the individual to experience its world as linear and predictable (Fowler, 1981). The individual constructs images of God as a cosmic ruler that controls the universe, is a caring, just ruler that rewards goodness and punishes badness (Fowler, 1981). Whether a child, adolescent or adult at this stage, there is an emerging belief that this is a "quick-payoff" world, where good things happen to good people, and bad things happen to bad people. Fowler (1987) pointed out that entire fundamentalist sects, sects that are focused on avoiding hell, or eternal damnation and punishment, or praying/reading religious texts as a rule to obey 
strictly, can remain in this stage, never progressing. The perception of God as the enforcer and judge shapes their behaviors to where decisions are based on celestial consequence for breaking the rules or commandments of their belief system.

Synthetic-Conventional faith begins to take shape in early adolescence and beyond. This third stage of Fowler's faith development puts forth that identity is developed largely based on the integration of how the adolescent perceives their roles and relationships. This stage coincides with the adolescents' development of formal operational thinking. The development of formal operational thinking allows for reliance on abstract ideas and concepts, aiding in making sense of the world around them (Fowler, 1991), allowing for mutual, interpersonal perspective taking. The formation of SyntheticConventional faith requires the individual to form a set of beliefs, commitments, and values that provides motivation for living. The sculpting of these beliefs, commitments, and values occurs as individuals have experiences with people and contexts that provide role-models and beliefs that can fuel their imaginations and desire for adult truth. At this stage the function of faith is to provide a unifying means of synthesizing values and information. In addition, at this stage faith also serves as a principal element to forge an enduring identity and world view (Frame, 2003). This development creates a desire for a relationship with God where one feels known and deeply loved (Fowler, 1991).

Fowler's fourth stage, Individuative-Reflective faith, comes forth in young adulthood. There are two prerequisites to reaching this stage of faith. The first prerequisite is the critical examination of the values, beliefs, and faith images that had previously been forged. This critical examination moves held beliefs from tacit (unconsidered, unexamined, uncritically accepted) commitments to explicit (consciously 
chosen and critically supported) commitments. Resulting from the pilgrimage from tacit commitments to explicit commitments the symbols, gestures and stories are translated into conceptual formulations providing clarity and understanding, allowing for greater articulation of the held beliefs. However, with the increased clarity and understanding comes a dulling in the power of the symbols, gestures and stories (Fowler, 1991; Fowler $\&$ Dell, 2004).

The second prerequisite Fowler referred to as the claiming of an executive ego (Fowler, 1991). Fowler stated that the task of this stage is to establish an executive ego, the "I" that manages and possesses all these roles and relations but is not identical with any single one of them. The task then is to take charge of one's own life. This is achieved by moving away from an identity defined by their roles and relationships, as is found in the previous stage, and moves to an identity formed by coming to understand who the "l" is that holds those roles and relationships. Most individuals never progress beyond this stage of faith development (Fowler, 1981).

Conjunctive faith (formally referred to as paradoxical-consolidative faith), the fifth stage, involves the embracing and integration of polarities in an individual's life. These polarities are seen in the understanding that God is both personal and abstract; one can be both old and young, masculine and feminine, and constructive and destructive simultaneously. Alertness to this newly discovered paradox and the need for multiple interpretations of reality mark this stage (Fowler \& Dell, 2004). In this stage, along with this alertness to paradox, comes a willed naiveté that allows the symbols and stories from their own tradition, as well as others traditions, to become newly appreciated as a means of expressing truth. Following the critical examination of one's beliefs, and movement 
towards a more solid conceptual understanding, one begins to desire a deeper relationship with what the symbols mediate (Fowler, 1991). Most people do not reach this stage, with only one in six obtaining it (Lownsdale, 1997).

The sixth and final stage of Fowler's stages of faith is Universalizing faith. This stage is reached by only three of every one-thousand people (Lownsdale, 1997). Occurring around midlife, this stage represents the completion of a process of decentration from one's self that is initiated with the emergence of simple perspective taking in the Mythic-Literal stage (Fowler, 1991). At this stage the individual is grounded in oneness with the power of God. Fowler describes an individual in this stage as being freed by their visions and commitments for a passionate, yet detached, spending of their self in love, devoted to overcoming division, oppression, and violence, and living in an a community of justice and love (Fowler, 1991).

Fowler (1981) developed his theory over several years, conducting hundreds of interviews and analysis of his theory. Fowler and Dell (2004) reported that there was no gender-bias among the sample used to forge his theory and that there was a wide range of Christian denominations represented. Barnes, Doyle and Johnson (1989) found in replicated studies that individuals did appear to fall in the faith stages hypothesized by Fowler. Parker (2010) concluded that Fowler's theory of faith development did have adequate empirical support, noting that the structural-developmental dimensions of the theory had greater empirical support than the psychosocial dimensions. A criticism of Fowler's stages of faith is that the construct of faith is defined too broadly, allowing for most all beliefs systems to qualify (Wallwork, 1980). Fowler has also received criticism for trying to apply his theory to all belief systems, not just Christianity. Critics believe 
that this is an invalid generalization due to the Western paradigm from which it is drawn (Streib, 2002).

Genia's Model of Religious Development. Genia (1990) constructed a fivestage theory of religious development that took into consideration the perspectives of psychodynamic and object relations theories. Genia believed that Fowler's model as well as other models of faith/religious development appeared consistent with cognitive, moral, and psychosocial development but excluded the contributions that psychodynamic and object relations theories had contributed to understanding the religious development of people (Gold, 2010). Genia's model is not necessarily linear, and trauma and other psychological stressors can cause an individual to regress to a more immature level.

Genia (1990) labeled the first stage of the model as Egocentric faith. Egocentricity is the overwhelming characteristic of this stage. Individuals in stage one are likely to display the first two stages of Kohlberg's theory of moral development. In this stage, the individual bases "wrong or right" on reward or punishment. Also, God is viewed anthropomorphically, becoming an extension of oneself. At this stage prayer is petitionary and reflects magical thinking that accompanies weak ego strength and confession springs from fear of punishment (Genia, 1990, 1995). At this stage, individuals attempt to maintain perfection to remain in favor with God (Gold, 2010). Religion, at this stage, functions also as a source of comfort (Frame, 2003).

Stage two, Dogmatic faith, is based on fixed rules of fairness and defined duties and obligations in conforming to the beliefs of one's reference group (Genia, 1990). Individuals hastily devote themselves to earning God's love and approval (Gold, 2010), exhibiting strict adherence to religious codes (Frame, 2003). This stage of religious 
development is also predominately marked by egocentricity; however, there is a budding sense of the rights and needs of others. Where the egocentrics of stage one attempts to appease a vengeful God, stage two dogmatics seek to please God so they will be rewarded and eternally blessed (Frame, 2003; Genia, 1995). The religious dogma that characterizes this second stage provides the rules for reciprocal exchange between an individual and God. Needing clear guidelines, the individuals at the Dogmatic faith stage interpret scripture literally and view it as absolute. Moral and religious judgments are made based on obedience to this literal interpretation of absolute truth without taking situational context into consideration. Prayer is concerned with personal favors or the reassurance of God's love and confession is motivated from a fear of losing God's love.

Transitional faith, the third stage of Genia's model, parallels the identity crisis typically experienced by adolescents (Genia, 1990). Individuals in this stage experiencing a questioning of their faith, and begin to wrestle with doubts concerning their beliefs. This wrestling leads to a deconstruction of their previous beliefs and a construction of a more sophisticated articulation of their beliefs. Individuals in the Transitional faith stage may experience a period of testing other religious beliefs and rebellion against their perceived religious authorities (Genia, 1990, 1995; Gold, 2010). This critical examination of beliefs that brings clarification and deeper commitment is close to the movement from tacit commitments to explicit commitment as found in Fowlers Individuative-Reflective faith (Fowler, 1981, 1991, 2004).

Stage four, Reconstructed Internalized faith, provides religious ideology that gives the individual a sense of purpose and meaning. From internalizing their beliefs, the defensive functions of scripture and religious doctrine that are present in the Dogmatic 
stage begin to dissipate. Scripture is taken less literally and prayer becomes thanksgiving, praise and devotion. Although diversity in belief is not condemned, an individual in this stage makes no effort to expand their own belief system or integrate or incorporate any ideology from any belief system other than their own.

Stage five, Transcendent faith, has considerable overlap with stage four, however Transcendent faith has more porous psycho-spiritual boundaries and is more flexibly guided by a universally principled morality (Genia, 1990). Individuals at this stage live in-step with their chosen values, have overcome their egocentricity, and are open to diversity of religious beliefs and systems. Individuals can be steadfast to specific religious ideas or doctrine but feel secure in maintain unanswered questions or doubts (Gold, 2010). This stage is rarely reached (Genia, 1990).

Gibson's Levels of Christian Spiritual Maturity. Gibson (2004) utilized Kohlberg's theory of moral development to construct a model of Christian (Catholic and Protestant) spiritual development. Three of the four levels of this model parallel Kohlberg's theory of moral development. Gibson contended that a proper perspective on spiritual maturation could not be based solely on reasoning, as Kohlberg contended, but rather needed to take into account affective and volitional maturation as well. As with Kohlberg's model, each level of Gibson's model corresponded with specific ages (Hernandez, 2006) centered on a primary concept. Kohlberg centered on justice, whereas Gibson centered on obedience to God. For an individual to reach a higher level, he or she must have passed through the lower levels.

Level one, accommodation to God's law, parallels Kohlberg's first level, Preconventional Morality. At this level in Gibson's model, individuals' have a self- 
centered source of authority. They accommodate God's rules because they fear punishment or hope to gain reward. Hence, a Christian's motivation for responding to God at level one is driven by self-interest. There is no motivation stemming from a regard of the rules as being a personal belief. Scriptural or denominational decrees are simply viewed as rules that will bring a wanted reward or result in punishment if broken.

Respect for and obedience to God's law, the second level, is parallel to Kohlberg's second level of moral development; Conventional Morality. At this level the individual is transitioning from accommodating the rules from a consequence-oriented perspective, to a level of obedience that is others-centered rather than self-centered. At this level the individual is concerned with how they are perceived by their Christian social groups and other influential role-models. The individual begins to model their own behavior to match the behavior of the Christians around them.

Level three, principle-centered commitment to a Christian worldview, parallels Kohlberg's Post-Conventional Morality, the final level of his model. At this level the individual begins to move from accommodating God's rules because they want those of the same faith to respect them, to internalizing and owning the rules as their own personal beliefs. This movement toward individuation that takes place simulates the internalization of one's own moral values and commitments (Gibson, 2004). This is the same type of movement that is found in Fowler's fifth faith stage (IndividuativeReflective faith), moving from tacit to explicit commitments. The individual moves from being others-centered to being principle-centered. Gibson described this stage in Christian language as where "individuals reach a third level of spiritual development when they internalize the Christian worldview, which grows out of a personal 
commitment to Christ" (p. 301) and his teachings. It would seem that this stage is where the intrinsic motivation described by Allport (1950) emerges. In this stage there is no longer a motivation driven by consequences or for social gain. At this level the individual begins "living" their religion.

The fourth and highest level of the model is the Kingdom-centered commitment to God's glory. Gibson states that at this level individuals move beyond a principlecentered focus to an action-centered focus, moving from focusing on their individual spirituality to actively promoting the spirituality of others. In other words, someone at this level would act in ways to fulfill the Great Commission, strive to live in Christian communality, to endeavor to help the less fortunate, strive to achieve equality, to confront oppressive economic systems and to fully capture the principles of love, care and justice as taught in Christ's teachings.

Gibson's model (2004) should be considered more cautiously than the theories of Fowler and Genia due to the lack of empirical support or additional criticism. Until empirical research is conducted this model should only be viewed as a theoretical offering to be considered in future research. With its formation drawing heavily from Kohlberg's theory, and its logical fit with Fowler's model, Gibson's model does seem to have reason to be considered. Moroney (2006) criticizes Gibson's model, asserting that Kohlberg's theory is flawed and should not be seen as valid to build a theory of spiritual maturity upon.

\section{Conclusion}

Each of these stage models of faith/religious development addresses the development of an individual as passing through stages, journeying from an immature to 
a mature faith. However, each model also allows for an individual to remain in any given stage for a long period of time, never progressing forward in their hierarchical models. This macro-approach to faith/religious development provides key insights into the growth of faith and how/why one moves forward. However, there are also aspects of religious individuals that are deserving of a more micro-investigation of faith/religious development. One such component is religious motivation; why someone adheres to their belief system and how the function of their religious beliefs dictates such motivation. For this reason, the closer examination of the function of religious motivation, rather than an examination of the content of religious beliefs, stage models have been focused upon. Seeing that religion functions in our world as a multifaceted system with various content to each denomination and belief system, it is practical to examine the function that religious beliefs, religious commitment, and religious motivations serve individuals in present day, as well as societies and cultures. In light of the vast history of religious movements and shifting doctrines there is little chance of covering all aspects of religious development in a single theory, or group of cohesive theories, of faith development that stands universal across belief systems (Huber, Reich, \& Schenker, 2003; Roehlkepartain, 2005). Therefore, the theories considered here do not fully consider the phenomenon of religion as a whole, but rather the function that religion and religious belief serve within the development of individuals' faith (Subbotsky, 2000). It should be noted that the theories of Genia, outside of her own work, and Gibson have little or no empirical support or criticism. The remainder of this dissertation will focus on the aspect of religious motivation and developing an instrument to measure religious motivation in more detail. The aim is to develop an instrument that can be used to further examine the 
function of religious motivation in individuals' lives and what bearing, if any, it has on overall mental health.

\section{Allport's Concept of Intrinsic and Extrinsic Religious Motivation and Beyond}

A crucial cog in the advanced study of religious orientation is a clearly defined theory and understandable definition. The theoretical concept of intrinsic/extrinsic religious orientation among Christians (Protestant/Catholic), originally developed by Allport (1950), has been continually researched and refined (Banister, Pössel, \& Adelson, 2011a, 2011b; Gorsuch, 1988; Gorsuch \& McPherson, 1989; Gorsuch \& Venable, 1983; Kahoe, 1985; Kahoe \& Meadow, 1981; Leong \& Zachar, 1990; Maltby, 1999; Maltby \& Lewis 1996; Spilka, Kojetin, \& McIntosh, 1985) to better define the constructs of intrinsic/extrinsic religious orientation and improve the focus of the research to further advance the study of religious motivation. Allport's theory of intrinsic/extrinsic religious orientation, conceptualized as a construct of religious motivation (Brewcyzynski \& Mac Donald, 2006; Flere \& Lavric, 2008; Gorsuch \& McPherson, 1989) has endured for nearly six decades as the dominant theory of religious motivation among Christians (Brewcyzynski \& Mac Donald, 2006; Flere \& Lavric, 2008), contributing a more narrowed view of the construct of religiosity. Allport recognized two types of religious motivation: intrinsic and extrinsic. Intrinsic religious motivation, a mature commitment to religious ideals (Genia \& Shaw, 1991), is the motivation to use religion as a meaningendowing framework in terms of which all aspects of life is understood (Rychlak, 1977). By contrast, extrinsic religious motivation, an immature commitment, is the motivation to use religion for comfort and social convention, in a self-serving, instrumental manner shaped to suit oneself (Donahue, 1985). Kahoe (1985) described extrinsic religious 
motivation as individuals, without turning away from themselves, turn to God, lightly holding to their religious creed and selectively shaping it to fit their more primary needs. The intrinsically motivated religious individual internalizes religious beliefs and lives them, whereas the extrinsically motivated religious individual uses religion as a means to his or her own personal gain (Allport \& Ross, 1967).

Bridging the theories of Fowler $(1981 ; 1991 ; 2004)$, Genia (1990) and Gibson (2004) to the concepts of Extrinsic (immature) religious motivation and Intrinsic (mature) religious motivation as defined by Allport and Ross (1967), each of the theories of faith development contain immature and mature levels/stages. Stages 1 through 3 of Fowler, Stages 1 through 3 of Genia and Level 1 and 2 of Gibson's theories are viewed as immature levels of faith, where the chosen belief systems has not yet been internalized. Stages 4 through 6 of Fowler, Stages 4 and 5 of Genia, and Levels 3 and 4 of Gibson's theories are viewed as mature levels/stages of faith where religious beliefs have been internalized and are lived in daily behaviors and interactions.

Allport and Ross (1967) identified intrinsic and extrinsic as the two extremes of religious motivation but did not discuss the "in-betweens." In their' 1967 landmark study Personal Religious Orientation and Prejudice, Allport and Ross encountered the limitations of measuring only the two extremes, finding that some participants in their religious sample were "consistently intrinsic" (p. 437), endorsing intrinsically worded items and rejecting the extrinsically worded items, whereas some participants were "consistently extrinsic," agreeing with extrinsically stated items on the extrinsic subscale (p. 437). They also discovered that measuring only these extremes resulted in many subjects being "provokingly inconsistent," repeatedly endorsing any or all items that 
seemed favorable to religion in any regard. Their responses, therefore, are "indiscriminately pro-religious" (p. 437). This "indiscriminately pro-religious" group consisted of nearly $31 \%$ of their sample, with both the intrinsic and extrinsic groups comprising just over $34 \%$ each. With nearly one-third of the sample falling between the two extremes, Allport and Ross "reformulated their approach" and included the indiscriminately pro-religious category into their statistical analysis. ${ }^{3}$ The indiscriminately pro-religious group was not a defined intrinsic/extrinsic construct, but served more as a "catch-all" for those participants that did not fall into either the intrinsic or extrinsic categories. This large proportion not fitting either extreme suggests a limitation to Allport and Ross's measuring of the two extremes.

One cannot help but wonder what other factors are represented in the “indiscriminately pro-religious" group that Allport and Ross (1967) discovered. As noted, although they included this group in their analyses, Allport and Ross did not specify further characteristics of this group nor offer any theoretical reasoning for its existence. Kahoe and Meadow's (1981) suggested that identifying those factors that make up the "indiscriminately pro-religious" group would enlarge and benefit the literature concerning intrinsic/extrinsic religious motivation. Such focused additions would enable researchers to consider how these different factors affect human behavior, psychological well-being, and overall human development, if at all, by defining how each separate factor may characteristically differ. To identify these factors, a clear definition of the construct of intrinsic/extrinsic religious motivation and overt theoretical underpinnings must be present. Then a measure of intrinsic/extrinsic religious motivation

\footnotetext{
${ }^{3}$ Although Allport and Ross identified the indiscriminate groups after they measured for intrinsic-extrinsic religious motivation, they did not provide any hypothesis as to why so many participants fell into the indiscriminate groups.
} 
that produces reliable scores and allows for valid inferences, which is needed for research on these constructs to proceed, can be produced. Possessing these elements (clear definition, theoretical underpinnings, and a measure that produces reliable scores and allows for valid inferences) would enable researchers to investigate the various factors identified and examine their relationship with known variables that are impacted by intrinsic/extrinsic religious motivation (e.g., psychological wellbeing, substance use, life satisfaction, physiological health) and determine how each factor differs among the constructs.

\section{Measure of Intrinsic/Extrinsic Religious Motivation: Development of the AUIES-12}

Allport's original measure of intrinsic/extrinsic religious motivation, the ROS;

1967 , and variations of it, has been one of the most widely used instrument to measure intrinsic and extrinsic religious motivation (Brewcyzynski \& Mac Donald, 2006; Donahue, 1985; Hill \& Hood, 1999). The ROS is a 20-item self-report questionnaire containing nine items measuring intrinsic religious motivation and 11 measuring extrinsic religious motivation. However, the ROS requires an advanced reading level and is only appropriate for use among adult populations (Gorsuch, 1988). Also, the ROS has been criticized for its poor psychometric properties (Brewcyzynski \& Mac Donald, 2006; Genia, 1993; Hoge, 1972). In light of these limitations, Gorsuch and Venable (1983) modified the ROS to make it suitable for use with children aged five and older as well as adult populations by decreasing the reading difficulty of the original instrument. With the resultant Age Universal Intrinsic/Extrinsic Scale (AUIES), Gorsuch and Venable also sought to investigate developmental questions regarding religious orientation and to use the AUIES as a tool to identify shifts from extrinsic to intrinsic religious motivation as a 
person of religion grows older. It should be noted, however, that Gorsuch and Venable did not provide any theoretical framework for identifying these shifts.

Maltby and Lewis (1996), in a modification of the AUIES, changed its response categories from a 5-point to a 3-point Likert-scale $(1=$ Yes; $2=$ Not Sure; $3=$ No $)$, finding this adaptation resulted in improved psychometric properties. Following a factor analysis of the AUIES that replicated earlier studies (Genia, 1993; Gorsuch \& McPherson, 1989, Kirkpatrick, 1989; Leong \& Zachar, 1990), Maltby and Lewis also separated the single extrinsic scale into two extrinsic scales: Extrinsic-Social and Extrinsic-Personal. Extrinsic-Social was defined as using religion as a source of social gain, whereas Extrinsic-Personal was defined as using religion as a source of comfort. Although suggested by earlier studies to be statistically appropriate (Genia, 1993; Gorsuch \& McPherson, 1989, Kirkpatrick, 1989; Leong \& Zachar, 1990), Maltby and Lewis gave no theoretical reasoning for splitting the extrinsic scale into the two new factors. Maltby (1999) preformed a follow-up study using a principal component analysis (PCA) with an oblimin rotation, using only the scree test (Cattell, 1966) as factor to retain criteria, finding again that the extrinsic scale separated into two separate factors: Extrinsic-Personal and Extrinsic-Social. No reliability statistics for the individual scales were provided. From these results Maltby created the Age Universal Intrinsic/Extrinsic Scale-12 (AUIES-12). Kirkpatrick (1989) and Kirkpatrick and Hood (1990) argued that the separation of the extrinsic scale was the result of poor measurement of the construct, not the emergence of two separate extrinsic factors. The AUIES-12 (Maltby 1999) incorporated 12 items from Gorsuch and Venable's earlier AUIES measure with the aforementioned changes to the response format and the bifurcation of the extrinsic scale. 
Maltby also deemed the use of the AUIES-12 suitable for use among non-religious populations. To this point the ROS and its derivatives were predominantly used with religious, Christian populations.

It should also be noted that Maltby and Lewis (1996) and Maltby (1999) retained three factors (Intrinsic, Extrinsic-Social and Extrinsic-Personal) based solely on the use of a scree test (Cattell, 1966) and using PCA. This is problematic for several reasons. First, the scree test tends to overestimate the number of factors to retain (Hayton, Allen, \& Scarpello, 2004). Zwick and Velicer (1986) concluded that the use of the scree test alone retained an appropriate amount of factors only $57 \%$ of the time, and when it was in error over $90 \%$ of the errors were an overestimation of the number of factors to retain. Second, there is no objective definition of a cutoff point between the important and trivial factors, leaving it open to subjectivity (Ledesma \& Valera-Mora, 2007). Third, there are more accurate methods to use (i.e., parallel analysis) to determine factor structure (Hayton et al., 2004; Ledesma \& Valero-Mora, 2007). And lastly, random error is included in PCA because there is no differentiation between common and unique variance. Therefore, a potential pitfall of PCA is to mistakenly determine that components share variance when in reality the intercorrelations have been attenuated by random error. Another potential hazard of using PCA is, due to the inclusion of random error, conclusions are drawn that components are distinct when in fact they are not (Brown, 2006). With one of the most important decisions in factor analysis being that of how many factors to retain (Preacher \& MacCallum, 2003), these decisions made with solely the scree test, and utilizing PCA, are called into question. 
In a partial replication of Maltby's (1999) study to determine the factor structure of the AUIES-12, Banister et al. (2011a) performed a PCA with an oblimin rotation on data collected from 268 adolescents, using only the scree test as the criteria to determine the number of factors to retain. Also, any item with a factor loading $<.4$ was not retained. This criteria was not expressed by Maltby (1999) but was added by the authors as it is the common cutoff when retaining items in exploratory factor analysis. Using these methods two factors were indicated: Intrinsic and Extrinsic-Social. Of the two factors that were retained, the Intrinsic factor contained five of the original six items used to measure intrinsic motivation ("I have often had a strong sense of God's presence" loaded separately); the Extrinsic-Social factor contained all three of the original AUIES12 items. None of the Extrinsic-Personal items met the set criteria to be retained (factor loading > .4); however, all of the items did load together. These findings differed from Maltby (1999) in that he concluded that a three-factor solution was appropriate; whereas Banister et al. (2011a) determined a two-factor solution was more suitable. Following their replication of Maltby (1999), Banister et al. (2011a) also analyzed the original AUIES-12 items using different methods that the literature (Hayton, et al., 2004; O'Conner, 2000) recommends as being more appropriate in determining the number of factors when undertaking scale development. This analysis consisted of using principal axis factoring (PAF) with direct oblimin rotation and using both the scree test and parallel analysis (PA) to determine number of factors to retain. A PA (O'Conner, 2000) was conducted with 1,000 data sets and a criterion of 95 th percentile to confirm the number of factors to retain. The means from the PA were also considered. This procedure is a recommended method for determining how many factor to retain (Hayton, et al., 2004; 
O'Conner, 2000) and is more restrictive than the traditional Kaiser greater-than-one eigenvalue threshold criteria (Rudasill \& Callahan, 2008). In Banister et al.'s (2011a) analyses, the scree test and percentiles from the PA both suggested two factors, whereas the means from the PA suggested three factors. With the agreement of the scree test and percentiles, and following the direction of Hayton et al. (2004) to give precedence to the percentiles over the means in PA, two factors again were retained.

When using the new methods and examining a two-factor solution as found in the original ROS measure (intrinsic and extrinsic) and suggested by the scree plot and PA found in Banister et al. (2011a), two distinct factors emerged. The first factor contained five of the six items used in the AUIES-12 to measure Extrinsic-Social and ExtrinsicPersonal religious motivation. One Extrinsic-Personal item ("I pray mainly to gain relief and protection.") was not retained because its factor loading (.254) was insufficient. The second factor contained five of the original six items used in the AUIES-12 to measure Intrinsic religious motivation.

Also, due to the bifurcation of the extrinsic scale in the AUIES-12 by Maltby (1999), the new methods were used to examine a three-factor solution. Banister et al. (2011a) found that Intrinsic and Extrinsic-Social loaded as separate factors containing the same items as found in the Maltby (1999) replication. One item from the ExtrinsicPersonal scale loaded on a third factor, with the second ("I pray mainly to gain relief and protection.") and third items ("What religion offers me most is comfort in times of trouble and sorrow.") from the Extrinsic-Personal scale having factor loadings below the .4 threshold. The third factor, Extrinsic-Personal, was not retained due to having a singular item measure the Extrinsic-Personal construct, a construct that is not 
theoretically founded. Furthermore, it is not recommended to use a single item in measuring psychological attributes (McIver \& Carmines, 1981; Nunnally \& Bernstein, 1994; Spector, 1992). Mclver and Carmines (1981) state that the most fundamental problem with single item scales is that they tend to be less valid, less accurate, and less reliable than multiple items scales. McIver and Carmines (1981) also add that the degree of validity, reliability, and accuracy is often indeterminable due to a single items inability to provide sufficient information to estimate their measurement properties. Therefore, regardless of if using Maltby's (1999) methods or the new methods, two factors, not three, were retained.

\section{Appropriateness of Use of Intrinsic/Extrinsic Measures among Religious and Non- Religious Samples}

An emerging issue in the measurement of intrinsic/extrinsic religious motivation is whether it is appropriate to use an intrinsic/extrinsic measure of religious motivation with non-religious, as well as religious samples (Maltby \& Lewis, 1996). The ROS, from which the AUIES-12 is derived, was intended to measure the "extrinsic and intrinsic tendencies in a person's religious life" (Allport \& Ross, 1967, p. 435), specifically of the Christian faith. This implies that a prerequisite of the measurement of intrinsic/extrinsic religious motivation is that an individual possesses a "religious life." Prior to Maltby and Lewis other researchers, and even Maltby himself two years earlier (Maltby, McCollam, \& Millar, 1994), advocated that non-religious persons be excluded when using intrinsic/extrinsic scales to measure religious motivation because of the absence of their participation in religious beliefs and practices (Batson \& Gray, 1981; Maltby et al., 1994; 
Spilka et al., 1985). Similarly, Kirkpatrick (1989) determined that intrinsic and extrinsic scales are not appropriate for use with non-Christian/non-religious respondents due to the assumption that a respondent must participate in religious behaviors for the scale to be appropriate. Maltby et al. (1994), before their introduction of the AUIES-12, determined that non-religious persons could not be included in any psychometric analysis of intrinsic/extrinsic measures, as such persons are unable to fully answer intrinsic/extrinsic questionnaires, in turn potentially diminishing the internal reliability of the measure.

One of Maltby and Lewis's (1996) goals was to design an intrinsic/extrinsic measure that would be appropriate for use among both religious and non-religious samples. They argued that the changes made to the AUIES, particularly to the response format, made this appropriate. However, Maltby and Lewis omitted which specific criteria or criterion might differentiate the religious from the non-religious (e.g., affiliation with a Christian denomination, frequency of church attendance, personal importance of God) in their sample. The international sample they used for their study was associated highly with specific religious denominations, namely "mainstream Christian" (p. 939). If an affiliation with a Christian denomination would categorize a participant as religious, then Maltby and Lewis's sample in this study was made up of participants that would be considered religious (over 92\% affiliated with a Christian denomination, with only $8 \%$ claiming no religious affiliation). Nevertheless, Maltby and Lewis concluded from this sample that the AUIES was suitable for a non-religious population, even though they did not appear to use such a sample to make this determination. It does not appear appropriate for Maltby and Lewis to draw the conclusion from this sample that the AUIES is suitable for use among non-religious 
individuals because their sample does not contain a large quantity of nonreligious participants.

\section{A New Measure of Intrinsic/Extrinsic Religious Motivation: Development of the Measure of Religious Motivation}

Grounded in the aforementioned theoretical framework based on Allport (1950), Kohlberg (1969), Fowler (1981; 1991; 2004), Genia (1990) and Gibson (2004), Banister et al. (2011b) sought to develop and validate an addition to the AUIES-12, the ExtrinsicRules Keeping scale, along with additional extrinsic items consistent with Allport's original theory of intrinsic/extrinsic religious motivation that would improve internal consistency of the measure and enable further the study into intrinsic/extrinsic religious motivation and its potential impact on behavior, well-being, and overall mental health. In an attempt to strengthen the construct validity of Maltby's (1996) three-factor AUIES-12, they also added additional extrinsic items based on Maltby's definitions of ExtrinsicSocial and Extrinsic-Personal.

Banister et al. (2011b) developed the Measure of Religious Motivation (MRM), a revision of the AUIES-12. They administered the original AUIES-12 items along with 13 items developed to measure Extrinsic-Rules Keeping and 10 items added to measure extrinsic motivations to 268 adolescents. Based on an exploratory factor analysis (EFA), the items loaded on four factors: (a) Extrinsic-Rules Keeping, which contained six of the 13 new items added to measure "rules-keeping," $(\alpha=.751)$ (b) Intrinsic, which contained four of the six original AUIES-12 items and two additional items that were added to measure Extrinsic-Personal religious motivation $(\alpha=.681)$, (c) Extrinsic-Social, which 
contained all three of the original AUIES-12 items used to measure Extrinsic-Social religious motivation as well as all six additional items that were added to measure extrinsic-social religious motivation $(\alpha=.819)$, and (d) Extrinsic-Personal, which consisted of two of the three AUIES-12 items used to measure Extrinsic-Personal religious motivation as well as three new items $(\alpha=.597)$. The development of the Extrinsic-Rules Keeping scale supports Allport and Ross' (1967) claim that there are further factors to be identified between the extremes of intrinsic and extrinsic religious motivation.

The Extrinsic-Rules Keeping scale was designed to identify individuals that use their religion as a set of "celestial rules." That is, if they obey the rules of their religion, they are rewarded by God, and if they disobey, they are punished by God. ExtrinsicRules Keeping fits in Allport's (1950) theory of intrinsic/extrinsic religious motivation in that the use of religion is for an ulterior motive other than an internalized belief system. The Extrinsic-Rules Keeping scale is embedded in an exchange-based system of reciprocity (as described in the above theories) and differs from the Extrinsic-Social religious motivation in that it is not concerned with gaining or improving social relationships. It is also different from the Extrinsic-Personal motivation in that the Extrinsic-Rules Keeping motivation is not geared toward gaining comfort. The ExtrinsicRules Keeping factor is about avoiding punishment and gaining reward by adhering to religious practices. 


\section{Towards Defining and Refining the Study of Intrinsic/Extrinsic Religious}

\section{Motivation}

As expected, findings from Banister et al.'s (2011b) study, using both scree test and PA to determine the number of factors, indicated that Extrinsic-Rules Keeping emerged as a relevant factor to be considered when examining intrinsic/extrinsic religious motivation. Extrinsic-Rules Keeping represents religious motivation that is driven by avoiding punishment and/or gaining reward by following, or not breaking, a set of religious based rules. Extrinsic-Rules Keeping provides an aspect of intrinsic/extrinsic religious motivation that is set apart from Intrinsic, Extrinsic-Social or Extrinsic-Personal religiosity. Individual's found in fundamentalist sects, legalists, holders of totalitarian religious views, or participants in the Positive Confession movement ("name it-claim-it") may all potentially operate from an Extrinsic-Rules Keeping religious motivation.

Evidenced by Banister et al. (2011b), there are further areas of research that should be undertaken concerning Extrinsic-Rules Keeping. First, a new, more heterogeneous sample is needed to confirm the factor structure. A more heterogeneous sample will need to consist of greater variability in age, religious affiliation/denomination, and ethnicity from the sample used in the pilot study. Banister et al. (2011b) found that Extrinsic-Rules Keeping, which was theoretically founded on Fowler (1981; 1991; 2004), Genia (1990) and Gibson (2004), emerged as a valid factor. However, a measure of faith development should be given with the MRM to empirically test these theoretical underpinnings of the Extrinsic-Rules Keeping scale. 


\section{METHODOLOGY}

\section{Research Questions and Hypotheses}

The research questions and the hypotheses for this study are as follows:

1) Part A-Analyzing only the original AUIES-12 items, does the three-factor structure found by Maltby (1999), using a PCA with oblimin rotation and the scree test as the determining criteria to retain factors, result in a different factor structure when more appropriate, currently recommended statistical methods are utilized?

Part B-When comparing the three-factor structure of Maltby (1999) to the factor structure indicated by more appropriate, currently recommended methods, which model has less model misfit?

2) With regards to construct validity of the MRM, does the hypothesized four-factor model from Banister et al.'s study (2010b) fit the data with the new sample?

3) What is the relationship between the Rules-Keeping scale and Stage 2 through Stage 5 in Fowler's theory of faith development?

Hypothesis

1) Part A-As found in Banister et al. (2011a), it is expected that the three-factor structure found by Maltby (1999) will not hold when more stringent statistical methods are applied to the original AUIES-12 items, but rather a two-factor solution (Intrinsic and Extrinsic) will be more appropriate. 
Part B-It is expected that the two-factor structure found by Banister et al., (2011a) will have less model misfit than the three-factor structure found by Maltby (1999).

2) It is expected that the four-factor model of the MRM from the pilot study (Banister et al., 2011b) will fit the data with the overall new sample.

3) It is expected that there will be a positive relationship between the Rules-Keeping scale and Stage 2 of Fowler's theory of faith development. It is also expected that there will be no significant relationship between the Rules-Keeping scale and Fowlers stages three through five.

Participants. This study used a web-based sample. Research has found that webbased data collection does not statistically enhance, nor diminish, the consistency of responses, nor compromise the integrity of the test, and is a suitable alternative to more traditional methods of data collection (Riva, Teruzzi, \& Anolli, 2003). Meyerson and Tryon (2003) found that the reliability (internal consistency) of Internet data is comparable to the reliability of in-person data and that Internet validity coefficients are psychometrically equivalent to those obtained from in-person data. Their findings support the reliability and validity of Internet testing and indicate that the Internet is a valid forum for conducting psychological research. Participants were initially drawn through Facebook, and $U$ of L Today. On Facebook an individual page was created that briefly described the questionnaires and held an invitation for participation. A link to the questionnaires was available on that page that took each participant directly to the online questionnaire. Also, Johnson Bible College sent an e-mail to their alumni association 
requesting participation in the study. In addition, the University of Notre Dame's

Campus Ministry and Office of Multicultural Student Affairs sent e-mails explaining this study and inviting participation to the students, faculty and staff involved in their programs. Both Johnson Bible College and the University of Notre Dame included in their email's a link to the questionnaire.

The target sample size was 680 participants. That allowed for 10 participants per item of the Measure of Religious Motivation (MRM), the additional items from the AUIES-12 that were not retained in the MRM, and the Faith Development Stage Scale used to measure Stage 2 through Stage 5 of Fowler's theory of faith development.

A total of 1,121 subjects participated in the online survey. Of the 1,121 participants, 118 cases $(10.5 \%)$ were deleted because of missing data, and 42 cases (3.7\%) were not included in any analysis because the participants did not identify as "Christian." After screening the data, there were a total of 961 participants that identified as "Christian" and had no missing data, including 626 females (65.1\%) and 335 males (34.9\%). Age ranged from 18 years to 76 years $(M=40.33, M d n=38.00, S D=$ 13.14). Due to the multiple analyses used in this dissertation the 961 participants that identified as "Christian" and had no missing data were randomly split into two subsamples (Subsample 1, $N=476$; Subsample 2, $N=485$ ) using SPSS 17.0. Per Stevens (2002) this was determined to be an acceptable sample size for all analyses needed for this dissertation. Demographic variable information for all participants,

\footnotetext{
${ }^{4}$ In the demographic questionnaire participants were asked "Do you identify as Christian?" If the participant endorsed "yes," then they were included in the statistical analyses. If they endorsed "No," they were not included in the statistical analyses. Inclusion or exclusion in the study did not depend on what religious beliefs or denominational affiliation the participant endorsed.
} 
sample minus non-Christian participants, participants after listwise deletion, Subsample 1, and Subsample 2 are presented in Table 1.

Table 1

Sample Demographic Information

$\begin{array}{cccccc}\text { Baseline } & \text { Total } & \text { Sample } & \text { Sample } & \text { Subsample } & \text { Subsample } \\ \text { Characteristics } & \text { Sample } & \text { Minus Non- } & \text { after } & 1(N= & 2(N= \\ & (N= & \text { Christian } & \text { Listwise } & 476) & 485) \\ & 1,121) & \text { Participants } & \text { Deletion } & & \\ & & (N=1079) & (N=961) & \end{array}$

Gender

Male

33.5

35.6

34.9

35.9

33.8

Female

66.5

64.3

65.1

64.1

66.2

Race/Ethnicity

Asian

African

American

Caucasian

Hispanic/Latino

Native American

Other/Multiracial

Is God Important?
2.1

3.8

3.4

3.7

3.8

3.7

90.3

90.4

89.9

89.7

90.1

2.2

1.9

1.9

1.9

1.9

1.0

0.7

0.7

1.9

1.5

2.3

1.9

2.6

1.4

1.8 


\begin{tabular}{|c|c|c|c|c|c|}
\hline No & 5.6 & 0.4 & 0.4 & 0.4 & 0.4 \\
\hline A little bit & 2.3 & 1.0 & 1.0 & 1.3 & 0.8 \\
\hline Some & 6.7 & 5.8 & 5.5 & 4.8 & 6.2 \\
\hline A Lot & 13.1 & 13.8 & 13.6 & 12.8 & 14.4 \\
\hline Very Important & 72.2 & 79.0 & 79.4 & 80.7 & 78.1 \\
\hline \multicolumn{6}{|l|}{$\begin{array}{l}\text { Frequency of } \\
\text { Church Attendance }\end{array}$} \\
\hline Never & 9.3 & 3.7 & 3.9 & 4.4 & 3.3 \\
\hline Once a year & 5.0 & 3.3 & 3.3 & 2.5 & 4.1 \\
\hline $\begin{array}{l}\text { A few times a } \\
\text { year }\end{array}$ & 14.4 & 14.0 & 13.6 & 13.0 & 14.2 \\
\hline Once a month & 3.2 & 3.3 & 3.3 & 3.4 & 3.3 \\
\hline $\begin{array}{l}\text { A few times a } \\
\text { month }\end{array}$ & 8.5 & 8.8 & 9.3 & 9.7 & 8.9 \\
\hline Once a week & 23.9 & 26.6 & 26.6 & 26.7 & 26.8 \\
\hline $\begin{array}{l}\text { More than once a } \\
\text { week }\end{array}$ & 35.6 & 40.2 & 40.0 & 40.5 & 39.4 \\
\hline \multicolumn{6}{|l|}{$\begin{array}{l}\text { Association of } \\
\text { Religious Beliefs }\end{array}$} \\
\hline Agnostic & 3.7 & 0.6 & 0.5 & 0.6 & 0.4 \\
\hline $\begin{array}{l}\text { Assemblies of } \\
\text { God }\end{array}$ & 0.5 & 0.5 & 0.5 & 0.4 & 0.6 \\
\hline Baptist & 10.2 & 10.6 & 10.6 & 11.1 & 10.1 \\
\hline Catholic & 10.5 & 10.5 & 10.9 & 10.3 & 11.5 \\
\hline $\begin{array}{l}\text { Christian/Non- } \\
\text { denominational }\end{array}$ & 51.1 & 56.8 & 55.9 & 55.9 & 55.9 \\
\hline Disciples of & 1.2 & 1.0 & 1.0 & 1.1 & 1.0 \\
\hline
\end{tabular}


Christ

\begin{tabular}{|c|c|c|c|c|c|}
\hline Episcopal & 1.4 & 2.0 & 1.9 & 1.7 & 2.1 \\
\hline Evangelical Free & 2.3 & 2.3 & 2.6 & 2.5 & 2.7 \\
\hline Judaism & 0.9 & 0.3 & 0.3 & 0.4 & 0.2 \\
\hline Lutheran & 1.3 & 1.0 & 1.0 & 0.8 & 1.2 \\
\hline Mennonite & 0.5 & 0.6 & 0.5 & 0.4 & 0.6 \\
\hline Methodist & 3.8 & 3.9 & 3.7 & 4.2 & 3.3 \\
\hline Mormon & 0.4 & 0.3 & 0.3 & 0.4 & 0.2 \\
\hline Pentecostal & 1.7 & 1.6 & 1.5 & 1.1 & 1.9 \\
\hline Presbyterian & 2.5 & 2.2 & 2.4 & 3.2 & 1.6 \\
\hline $\begin{array}{l}\text { Seventh Day } \\
\text { Adventist }\end{array}$ & 1.8 & 1.9 & 2.1 & 2.1 & 2.1 \\
\hline Unitarian & 1.4 & 0.2 & 0.2 & 0.2 & 0.4 \\
\hline None & 4.6 & 0.9 & 1.0 & 1.5 & 0.6 \\
\hline Other & 7.4 & 2.9 & 2.9 & 2.3 & 5 \\
\hline
\end{tabular}

\section{Procedure}

Inclusion/Exclusion Criteria. Participants that identify themselves as "Christian" were included in the study. Participants were excluded from the study if they endorsed that they did not identify themselves as "Christian."

Measures. All measures were formatted as on-line questionnaires hosted at www.surveymonkey.com/MRMstudy.

Measure of Religious Motivation (MRM) (Banister et al., 2010b)-The MRM is a 26-item questionnaire designed to measure intrinsic/extrinsic religious motivation. The 
MRM contains four scales that measure different forms of religious motivation; Extrinsic-Rules Keeping, Extrinsic-Personal, Extrinsic-Social, and Intrinsic. The MRM contains six items to measure Extrinsic-Rules Keeping, six items to measure Intrinsic (four original AUIES-12 items), nine Extrinsic-Social items (including the original three AUIES-12 items), and five Extrinsic-Personal items (containing two of the three original AUIES-12 items). With a pilot sample, the MRM exhibited an internal consistency of $\alpha$ $=.747$. In addition to the MRM items, the original three items from the AUIES- 12 that did not load on any of the four MRM subscales were also included.

Faith Development Stage Scale (FDSS) (Leak \& Randall, 1995)-The FDSS is a 38-item brief global measure of faith maturity derived from Fowler's theory of faith development (1981), designed to measure Stage 2 through Stage 5. Respondents endorse items on a 5-point likert scale, ranging from strongly disagree to strongly agree. The items of the FDSS were based on the responses of six content validity judges. With the pilot sample, the alpha reliability estimates for the four subscales were $.55, .80, .72$, and .55 for Stage 2 through Stage 5, respectively (Leak, 2009). Although the values for Stage 2 and Stage 5 are low, they are consistent with results from Fowler's Faith Development Interview measure that indicate that specific stages in Fowler's theory are difficult to measure with a high degree of internal consistency (Leak, 2009). Jugel (1992) also provided evidence of criterion validity, finding that the FDSS relates to conventional, devout religiousness and an open flexible orientation to religious issues.

Demographics-Demographic questions included age, ethnicity, degree of religiousness, degree of spirituality, frequency of religious service attendance, marital status, level of education and denomination affiliation, 


\section{Statistical Analysis Plan}

To examine Research Question 1-part A, finding if the data that replicated the three-factor structure found by Maltby (1999) using PAF with direct oblimin rotation (Jennrich \& Sampson, 1966) and scree test (Cattell, 1966) as the criteria to retain factors, results in a different factor structure when compared to PCA with direct oblimin rotation and using the scree test, Kaiser's eigenvalues $>1.0$ rule (Kaiser, 1960), and PA (Hayton et al., 2004) as the determining criteria to retain factors. With the initial PAF the factors were determined by the scree test to replicate Maltby's study. Then a PAF was conducted using the scree test, Kaiser's eigenvalues $>1.0$ rule, and PA to determine if a different factor structure emerged. It was determined before either analysis was conducted that any item that loaded within 0.2 on any other item would be removed. Items would also be removed if their factor loadings were statistically significant on more than one factor. According to Stevens (2002), with a sample size of 485 a factor loading below .234 should not be retained.

For Research Question 1-part B, (does a two-factor structure as found in the pilot study have less model misfit than Maltby's (1999) three-factor structure) two CFA's, one reflecting each of the solutions from part A, were conducted. Then the model fits were compared. Using the results of the CFA, I investigated if the pattern coefficients were consistent with the hypothesized model; if they were moderate to high (i.e., .50 to .80 ); if the goodness-of-fit indices meet recommended levels; if the standardized residuals are not statistically significant; and the magnitude of the modification indices (MI's).

To examine Research Question 2, whether the hypothesized factor model from the pilot study (Banister et al., 2011b) fits the data with the new sample, a CFA was 
conducted using the 26 items from the results of the PAF from the pilot study. As stated above, using the results of the CFA, I investigated if the pattern coefficients were consistent with the hypothesized model; if they were moderate to high (i.e., .50 to .80 ); if the goodness-of-fit indices meet recommended levels; if the standardized residuals are not statistically significant; and the magnitude of the MI's.

All CFA's in this dissertation were performed using AMOS 17.0 using maximum likelihood procedures. For all models tested with CFA, multiple goodness-of-fit indices were used to test adequacy of model fit. The comparative fit index (CFI; Bentler, 1990), Tucker and Lewis index (TLI; McDonald \& Marsh, 1990), and root mean square error of approximation (RMSEA; Browne, \& Cudeck, 1993) were chosen based on their frequent use in the CFA literature. The CFI and TLI are normed indexes having lower bounds of zero and increasing toward unity with an improved fit of the model being tested. The RMSEA, an evaluation statistic used as a measure of approximate error, is suitable for assessing models of differing complexity (Browne \& Cudeck, 1993). The RMSEA also has the advantage in that it is relatively unaffected by the size of sample used. Although there are no definitive cut-off points for acceptable model fit for a particular model, the following criteria are frequently used to indicate the goodness-of-fit for a model; CFI > $0.90, \mathrm{TLI}>0.90$, and RMSEA $<0.08$ (Hu \& Bentler, 1999). Kline (2005) reported that an RMSEA $<0.05$ was considered to have a close sample-data fit, between 0.05 and 0.08 suggesting reasonable approximation, and $>0.1$ indicating a poor model fit. The $\chi^{2}$ is also reported to allow for the assessment of competing models if any exist. However, they can be problematic in that it becomes increasingly difficult to reject the $\mathrm{H}_{0}$ as the number of cases increase (Jöreskog, 1969). Finally, the Akaike Information Criterion (AIC; 
Akaike, 1987), a measure that estimate relative support for statistical models and provides a means for comparison among models, was also included.

In regards to Research Question 3, examining the relationship between the RulesKeeping scale and the different stages in Fowler's theory of faith development, correlations between the Rules-Keeping scale and the scores from the FDSS for each of Fowler's stages was calculated. T-tests were computed to determine if there was a significant difference between any of Fowler's stages on the Rules-Keeping scale. 


\section{RESULTS}

To test hypothesis 1-A, analyzing the 12 items of the AUIES-12 to find if the three-factor structure found by Maltby (1999) holds with the current sample, a PCA with direct oblimin rotation (Jennrich \& Sampson, 1966) was conducted. As used by Maltby only the scree test (Cattell, 1966) was used as the determining criteria to retain factors. Then to find if a different facture structure emerged when using more stringent, currently recommended statistical methods, a PAF with a direct oblimin rotation was conducted. Following the PAF the scree test, Kaiser's eigenvalues $>1.0$ rule (Kaiser, 1960), and PA (Hayton et al., 2004) were all used as the determining criteria to retain factors.

Both PCA and PAF were conducted with Subsample 2, which consisted of 485 participants (Table 1). This provided 40.4 cases per item, providing a more than adequate participant to item ratio (Kline, 2010). The Kaiser-Meyer-Olkin measure of sampling adequacy was .743 , above the recommended value of 0.6 , indicating that the data were appropriate for factor analysis. Bartlett's test of sphericity was significant $\left(\chi^{2}=\right.$ 913.699, $d f=66, p=<.001$ ), indicating that correlations among the variables existed. According to Stevens (2002), with a sample size of 485 a factor loading below .234 should not be retained. 


\section{Replicating Maltby}

The scree test from the PCA (Figure 1) suggested that three factors be retained, as it appeared that the scree test "leveled off" following the third factor. Table 2 shows that three factors containing 12 items were retained. All items had primary loadings over 0.5 , with no item loading significantly on any other factor or within 0.2 on more than one factor. Overall, $50.3 \%$ of the variance was explained by the three initial factors, $23.3 \%$ for Factor 1, 15.6\% for Factor 2, and $11.4 \%$ for Factor 3.

The items that load highest on Factor 1 make up the Intrinsic scale, containing all six of the original AUIES-12 Intrinsic items. Factor 2 consists of all three of the items used originally in the AUIES 12 to measure Extrinsic-Personal religious motivation. Factor 3 contains all three items from the AUIES-12 used to measure Extrinsic-Social religious motivation.

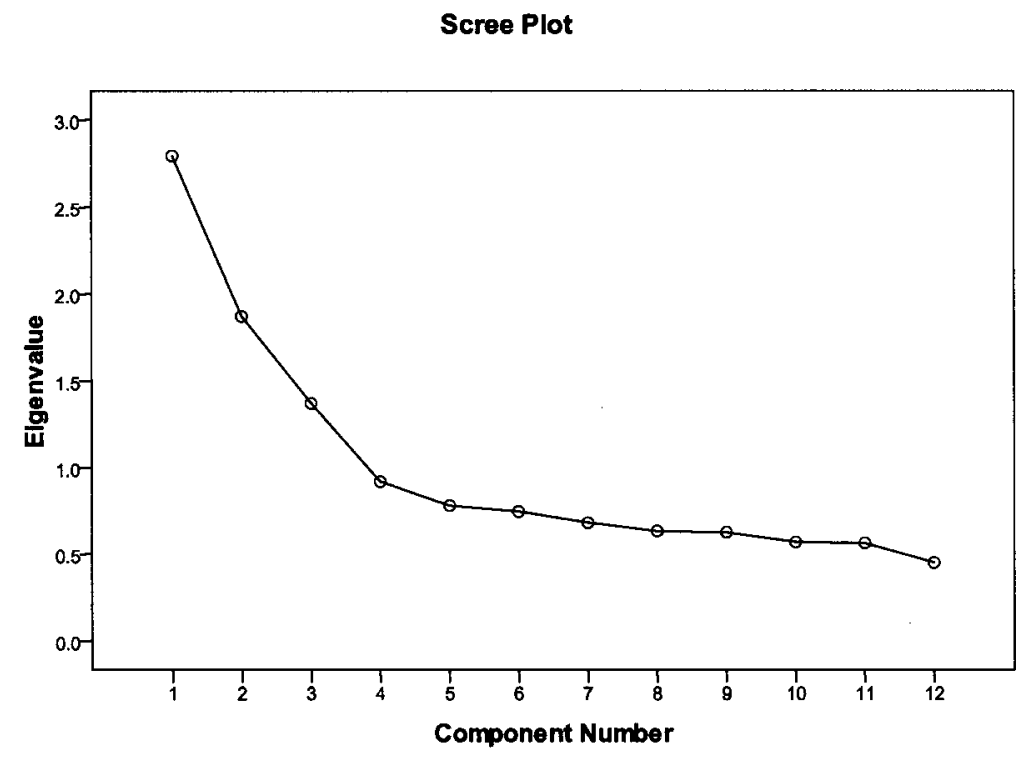

Figure 1. Scree Test from PCA with Maltby's Methods 
Table 2

Pattern Coefficients from the PCA and PAF with direct oblimin rotation for the 12 items of the AUIES-12 $(\mathrm{N}=485)$.

\begin{tabular}{|c|c|c|c|c|c|c|c|}
\hline \multirow[b]{2}{*}{$\begin{array}{l}\text { Item } \\
\#\end{array}$} & \multirow[b]{2}{*}{ Item } & \multicolumn{3}{|c|}{$\underline{\mathrm{PCA}}$} & \multicolumn{3}{|c|}{$\underline{\text { PAF }}$} \\
\hline & & Int & E-P & E-S & Int & E-P & E-S \\
\hline Q1 & I enjoy reading about my religion. & .70 & -.09 & -.06 & .62 & -.06 & .08 \\
\hline Q6 & $\begin{array}{l}\text { It is important to me to spend time in } \\
\text { private thought and prayer. }\end{array}$ & .69 & .05 & -.24 & .59 & .09 & -.12 \\
\hline Q8 & $\begin{array}{l}\text { I often have had a strong sense of God's } \\
\text { presence. }\end{array}$ & .58 & .03 & -.15 & .46 & .04 & -.06 \\
\hline Q13 & $\begin{array}{l}\text { I try hard to live my life according to my } \\
\text { religious beliefs. }\end{array}$ & .60 & -.06 & -.09 & .48 & -.02 & -.02 \\
\hline Q17 & $\begin{array}{l}\text { My religion is important because it } \\
\text { answers many questions about the } \\
\text { meaning of life. }\end{array}$ & .69 & .12 & .01 & .63 & .11 & .08 \\
\hline Q24 & $\begin{array}{l}\text { My whole approach to life is based on } \\
\text { my religion. }\end{array}$ & .68 & -.29 & -.10 & .60 & -.22 & .02 \\
\hline Q10 & $\begin{array}{l}\text { I pray mainly to gain relief and } \\
\text { protection. }\end{array}$ & -.09 & .74 & .12 & -.06 & .58 & .01 \\
\hline Q14 & $\begin{array}{l}\text { What religion offers me most is comfort } \\
\text { in times of trouble and sorrow. }\end{array}$ & .05 & .74 & .13 & .07 & .59 & .03 \\
\hline Q19 & Prayer is for peace and happiness. & -.06 & .74 & .12 & -.03 & .59 & .015 \\
\hline Q3 & I go to church because it helps me to & -.24 & .03 & .66 & .05 & .05 & .41 \\
\hline
\end{tabular}


make friends.

Q22 I go to church mostly to spend time with $\quad \begin{array}{ccccccc}-.12 & .20 & .77 & -.10 & -.10 & \mathbf{. 6 7}\end{array}$ my friends.

$\begin{array}{lllllllll}\text { Q26 I go to my church mainly because I } & & -.01 & .12 & \mathbf{7 5} & .00 & .07 & \mathbf{. 6 0}\end{array}$ enjoy seeing people I know there.

Notes. Int $=$ Intrinsic Scale items drawn from factor 1; E-P = Extrinsic-Personal Scale items drawn from factor 2; E-S = Extrinsic-Social Scale items drawn from factor 3; Items in boldface indicate the highest factor loading of each item.

\section{Analyzing the AUIES-12 with New Methods}

Following the replication of Maltby (1999) a PAF with direct oblimin rotation was conducted on the 12 items of the AUIES-12. In this analysis the number of factors to extract was determined on the basis of several criteria, including examination of the scree test (Cattell, 1966), Kaiser's eigenvalues $>1.0$ rule (Kaiser, 1960), and PA (Hayton et al., 2004).

The scree test from the PAF (Figure 2) suggested that three factors be retained, as it appeared that the scree test "leveled off" following the third factor. The Kaiser rule indicated three factors with eigenvalues greater than one, and both the 95 th percentiles and the mean eigenvalues from the PA suggested three factors (Table 3). Therefore, three factors containing 12 items were retained (Table 2). All items had primary loadings over 0.4 , with no item loading significantly on any other factor or within 0.2 on more than one factor. Overall, $50.3 \%$ of the variance was explained by the three initial factors, $23.3 \%$ for Factor 1, 15.6\% for Factor 2, and 11.4\% for Factor 3. 


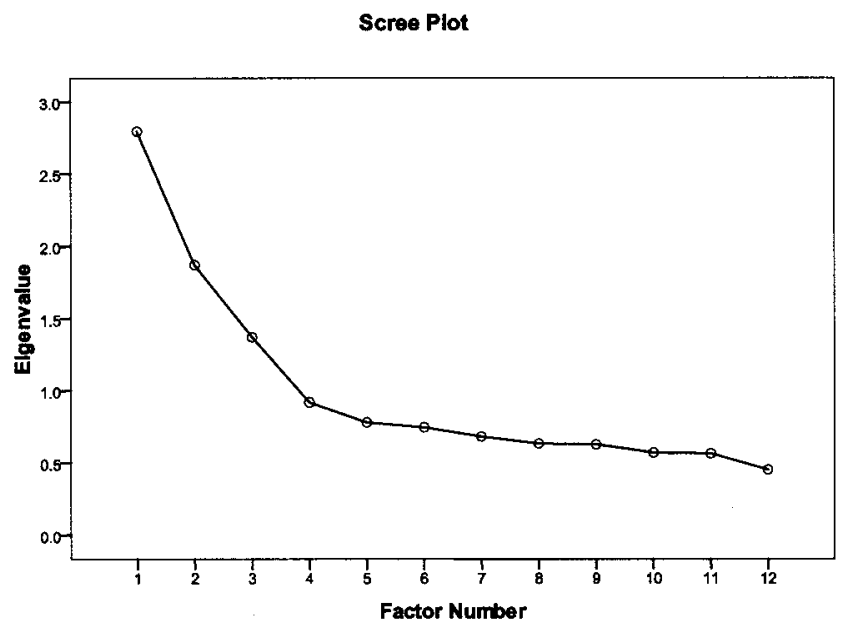

Figure 2. Scree Test from PAF with New Methods

Table 3

Eigenvalues and Parallel Analysis Results

\begin{tabular}{lccc}
\hline Factor & Eigenvalue & Means & $95^{\text {th }}$ Percentiles \\
\hline Factor 1 & 2.79 & 1.26 & 1.33 \\
Factor 2 & 1.87 & 1.19 & 1.24 \\
Factor 3 & 1.37 & 1.14 & 1.18 \\
Factor 4 & 0.92 & 1.10 & 1.18 \\
\hline
\end{tabular}

As found in the previous analysis that replicated Maltby, the PCA indicated that the items that load highest on Factor 1 make up the Intrinsic scale, containing all six of the original AUIES-12 Intrinsic items. Factor 2 consists of all three of the items used originally in the AUIES 12 to measure Extrinsic-Personal religious motivation. Factor 3 
contains all three items from the AUIES-12 used to measure Extrinsic-Social religious motivation.

Internal consistency analysis was conducted for each of the three factors retained. As found in both the PCA and the PAF, the items that load highest on Factor 1 make up the Intrinsic scale, containing all six of the original AUIES-12 Intrinsic items. Reliability analysis revealed that the internal consistency of the Intrinsic scale is $\alpha=.719$, judged to be acceptable (George \& Mallery, 2003).

Factor 2 consists of all three of the items used originally in the AUIES 12 to measure Extrinsic-Personal religious motivation. The internal consistency of the Extrinsic-Personal scale is .613, considered to be questionable (George and Mallery, 2003). Using the Spearman-Brown Prophecy, it was determined that adding five items with similar psychometric properties to the scale for a total of eight items should increase the reliability to the level of .80 .

The items that load highest on Factor 3 make up the Extrinsic-Social scale. Again, all of the three original Extrinsic-Social items used in the AUIES-12 were retained. The internal consistency of the Extrinsic-Social scale is .525 , deemed to be poor (George and Mallery, 2003). Using the Spearman-Brown Prophecy, it was determined that adding eight items with similar psychometric properties to the scale for a total of 11 items should increase the reliability to the level of .80 .

Overall, both analyses indicated that three distinct factors, Intrinsic, ExtrinsicPersonal, and Extrinsic-Social, were underlying the samples responses to the items of the AUIES-12. As Maltby (1999) found, all of the 12 items of the AUIES-12 were retained, with no item loading statistically significant on more than one factor. These factors 
ranged from acceptable to poor internal consistency. Spearman-Brown Prophecy indicates that an additional five items for the Extrinsic-Personal scale and eight items for the Extrinsic-Social scale are needed to allow each scale to reach good internal consistencies.

To test hypothesis 1-B, to examine which model of the AUIES-12 (a two-factor model or a three-factor model) has less model misfit, two CFAs were conducted to test which model, a two-factor model or a three-factor model fit the data more appropriately. Even though the eigenvalues, scree test, and PA in the exploratory analysis suggested three factors, as Maltby found (1999), it was deemed advantageous to proceed with testing both a two-factor model and three-factor model of the AUIES-12 due to the criticisms (Kirkpatrick, 1989; Kirkpatrick \& Hood, 1990) made of Maltby separating the extrinsic factor into two separate factors (Extrinsic-Personal and Extrinsic-Social) with no theoretical basis to do so as well as the results found by Banister et al. (2011a) with an adolescent sample.

Brown (2006) recommended a minimum of five to 10 cases to every parameter that is estimated when using SEM. Given this criterion, with 39 parameters being estimated in the two-factor model and 42 parameters being estimated in the three-factor model, a minimum sample size of 195 to 210 participants was needed to achieve adequate power. Therefore, the subsample used, Subsample $1(\mathrm{~N}=476)$ provided adequate power for these analyses. 


\section{Two-Factor model of the AUIES-12}

The first model tested was the two-factor model of religious motivation as measured by the AUIES-12 (Figure 3). The latent variables of this model were Intrinsic religious motivation and Extrinsic religious motivation. The observed variables for the Intrinsic latent variable consisted of the six items that loaded on Factor 1 (Intrinsic) in the PAF that was conducted with the other subsample (Subsample 2) prior to testing these models. The observed variables for the latent construct Extrinsic religious motivation were the six items combined from Factor 2 (Extrinsic-Social) and Factor 3 (ExtrinsicPersonal) that loaded on separate factors in the previous PCA and PAF used above. It was appropriate that one variable from each factor be arbitrarily chosen as a marker variable (Kline, 2011) and accordingly Q24 from the Intrinsic factor and Q26 from the Extrinsic factor were selected. 

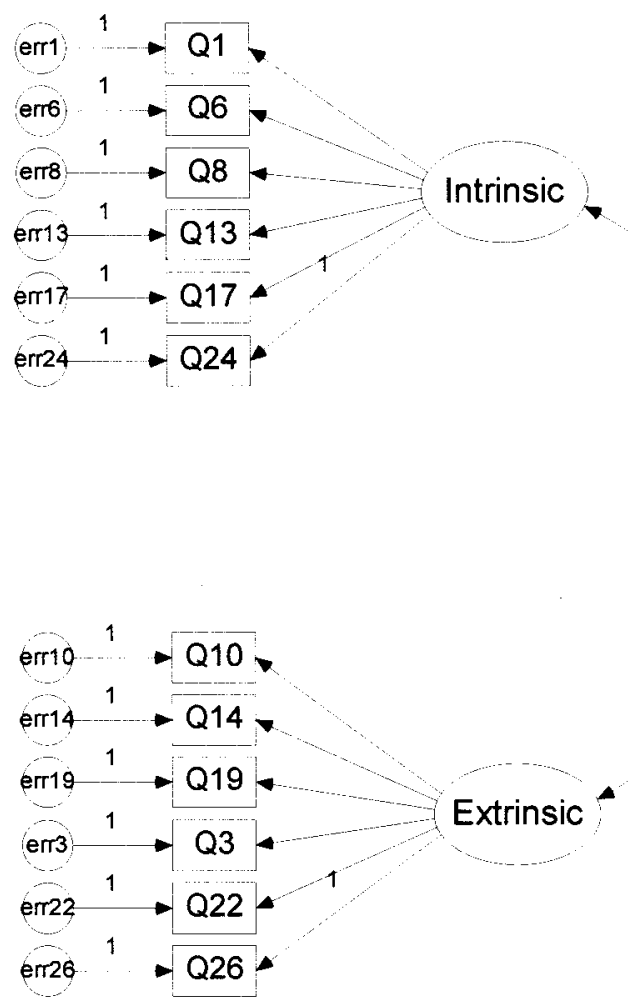

Figure 3. Two-Factor Model of the AUIES-12

Examination of the path coefficients revealed that all unstandardized regression weights were statistically significant. All standardized regression weights (Table 4), except two items on the Extrinsic factor: Q3 (.246) and Q19 (.284), were in the preferred range between .3 and .9. The Intrinsic items had standardized regression weights between .509 and .620 , and the four items of the extrinsic factor that were above .3 were between .307 and .621 . The covariance between the factors was statistically significant, and the correlation of factors was small $(-.181)$. 
Table 4

Standardized and Unstandardized Pattern Coefficients for Two Confirmatory Factor Analysis Models of the AUIES-12

\begin{tabular}{|c|c|c|c|c|c|c|c|c|c|c|}
\hline \multirow{3}{*}{ Variable } & \multicolumn{6}{|c|}{ Three-Factor Model } & \multicolumn{4}{|c|}{ Two-Factor Model } \\
\hline & \multicolumn{2}{|c|}{ Intrinsic } & \multicolumn{2}{|c|}{$\begin{array}{l}\text { Extrinsic- } \\
\text { Personal }\end{array}$} & \multicolumn{2}{|c|}{$\begin{array}{c}\text { Extrinsic- } \\
\text { Social }\end{array}$} & \multicolumn{2}{|c|}{ Intrinsic } & \multicolumn{2}{|c|}{ Extrinsic } \\
\hline & Stan & Unstan & Stan & Unstan & Stand & Unstan & Stan & Unstan & Stan & Unstan \\
\hline Q1 & .511 & .577 & - & - & - & - & .509 & .570 & - & - \\
\hline Q6 & .551 & .462 & - & - & - & - & .543 & .452 & - & - \\
\hline Q8 & .544 & .670 & - & - & - & - & .543 & .664 & - & - \\
\hline Q13 & .553 & .554 & - & - & - & - & .556 & .553 & - & - \\
\hline Q17 & .536 & .773 & - & - & - & - & .537 & .770 & - & - \\
\hline Q24 & .615 & 1.00 & - & - & - & - & .620 & 1.00 & - & - \\
\hline Q10 & - & - & .662 & 1.033 & - & - & - & - & .591 & 3.273 \\
\hline Q14 & - & - & .612 & 1.021 & - & - & - & - & .571 & 3.341 \\
\hline Q19 & - & - & .592 & 1.00 & - & - & - & - & .284 & 3.257 \\
\hline Q3 & - & - & - & - & .554 & 1.040 & - & - & .246 & 1.045 \\
\hline Q22 & - & - & - & - & .634 & .588 & - & - & .307 & .447 \\
\hline Q26 & - & - & - & - & .602 & 1.00 & - & - & .621 & 1.00 \\
\hline
\end{tabular}

Notes: Stan = standardized pattern coefficients; Unstan = unstandardized pattern coefficients. Parameter estimates "fixed" to be 0 are reported as dashes ("-"). All pattern coefficients are statistically significant $(p<.05)$. 
Interpretation of the model fit revealed that the two-factor model, which had a $\chi^{2}$ of 249.987 and $d f$ of 53 , did not fit the data. The $\chi^{2} / d f$ ratio of 4.717 was greater than 2.0 . The TLI (.712) and CFI (.768) did not meet the minimum standard of .9. The RMSEA $\left(.088, \mathrm{CI}_{90}=.078-.100\right)$ also was noticeably greater than .05 (see Table 5).

Following the examination of this model, and considering MI values, correlations between Q3 ("I go to church because it helps me to make friends.") and Q22 ("I go to church mostly to spend time with my friends."), Q3 and Q26 ("I go to my church mainly because I enjoy seeing people I know there."), and Q22 and Q26 of the Extrinsic scale were added due to high MI values (> 53) (Figure 4). These three items were the items used to measure Extrinsic-Social religious motivation in the three-factor model of the AUIES-12. A chi-square difference test comparing both two-factor models $\left(\Delta \chi^{2}\right.$ of 131.406 and $\Delta d f$ of 3 ) indicated that the two-factor model with correlation between the Extrinsic-Social items provided a statistically significantly $(p<.001)$ better fit to the data than does the two-factor model that did not allow correlation among the Extrinsic-Social items. Additionally, the AIC of the two-factor model was 299.987 while the AIC of the two-factor model with correlations was 168.494 , indicating that the two-factor model with correlations represented a better fit of the hypothesized model. However, adding these correlations did not improve the model fit to an acceptable level. The $\chi^{2} / d f$ ratio of 2.25 was greater than 2.0 . The TLI (.838) and CFI (.877) did not meet the minimum standard of .9. The RMSEA $\left(.061, \mathrm{CI}_{90}=.049-.074\right)$ also was greater than .05 (Table 5). After allowing for these correlations, the modification indices indicated that additional paths would not significantly alter the fit of the model (all MI values $<9$ ). 

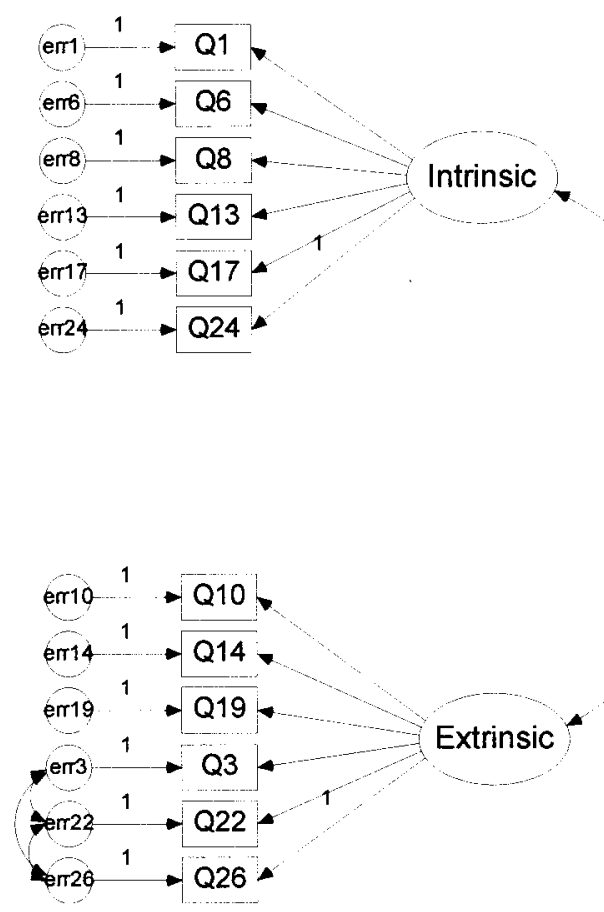

Figure 4. Two Factor Model with Correlations Allowed

Table 5

Fit Statistics: Confirmatory Factor Analysis of the Two-Factor and Three-Factor Models of the AUIES-12

Fit Indices

\begin{tabular}{lcccccc} 
Model & $\chi^{2}$ & CFI & TLI & RMSEA & $\begin{array}{c}\text { RMSEA- } \\
\text { LO-HI }\end{array}$ & AIC \\
\hline 2-Factor & $249.9(53)$ & .712 & .768 & .088 & $.078-.100$ & 299.987 \\
2-Factor with & & & & & & \\
Correlations & $118.494(50)$ & .838 & .877 & .061 & $.049-.074$ & 168.494 \\
3-Factor & $106.5(51)$ & .916 & .935 & .048 & $.035-.061$ & 160.504 \\
\hline
\end{tabular}

Notes. $\chi^{2}=$ Chi Square; TLI $=$ Tucker $\&$ Lewis Index; CFI = comparative fit index; 
RMSEA $=$ root mean square error of approximation; AIC = Akaike Information

Criterion.

\section{Three-Factor model of the AUIES-12}

The second model tested was the three-factor model (Figure 5) that was found by Maltby (1999) and indicated by both the PCA and PAF conducted to test hypothesis 1-A. The latent variables in this model were Intrinsic, Extrinsic-Personal, and Extrinsic-Social. The Intrinsic latent variable was measured with six observed variables, and both Extrinsic-Personal and Extrinsic-Social latent variables had three observed variables as indicators. The marker variable arbitrarily chosen for the Intrinsic factor was Q24, for the Extrinsic-Personal factor was Q19, and for the Extrinsic-Social factor was Q26. 


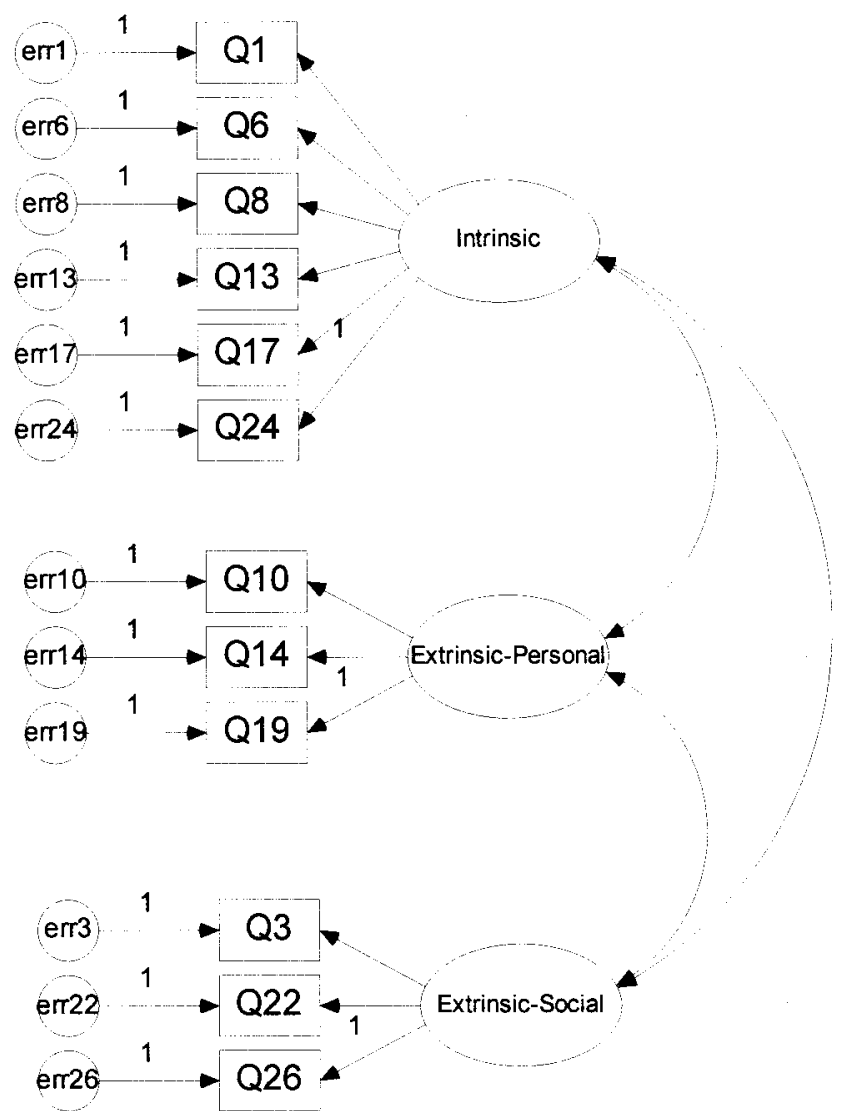

Figure 5. Three-Factor Model of the AUIES-12

Examination of the path coefficients revealed that all unstandardized regression weights were statistically significant. All standardized regression weights (Table 4) were in the preferred range between .3 and .9. All intrinsic items had standardized regression weights between .511 and .615 . The three items of the Extrinsic-Personal factor had standardized regression weights between .592 and .662 , and the standardized regression weights for the Extrinsic-Social scale ranged from .554 to .634 . The covariance between Extrinsic-Personal and Extrinsic-Social was statistically significant but exhibited a weak association; $(r=.266$; Cohen, 1988 . The covariances between Intrinsic and Extrinsic- 
Personal $(r=-.130)$ and Extrinsic-Social $(r=-.233)$ were not statistically significant and also exhibited a weak association (Cohen, 1988).

Model fit indices indicated that the three-factor model, which had a $\chi^{2}$ of 106.504 and $d f$ of 51, exhibited good model fit. The $\chi^{2} / d f$ ratio of 2.088 was fractionally greater than 2.0 but acceptable. The TLI (.916) and the CFI (.935) exceeded the minimum standard of .9. The RMSEA $\left(.048, \mathrm{CI}_{90}=.035-.061\right)$ was also less than .05 (see Table 5). The AIC of the two-factor model was 299.987 , the two-factor model with correlations was 168.494 and the three-factor model was 160.504 , indicating the threefactor model had a better fit to the data.

Based on the results of the analysis of both the two-factor model and three-factor model, including measures of model fit and the model fit indices, the three-factor model exhibited less model misfit with the data. A chi-square difference test also suggested that the three-factor model provided a significantly $(p<.001)$ better fit to the data than did either of the two-factor models (Two-factor model: $\Delta \chi^{2}$ of 143.4 and $\Delta d f$ of 2; Twofactor model with correlations: $\Delta \chi^{2}$ of 11.964 and $\Delta d f$ of 1$)$.

Moving beyond Maltby (1999), the MRM that was developed from the pilot study (Banister et al., 2011b) that incorporated nine items from the AUIES-12 with additional items to increase the reliability of the three factors of the AUIES-12 and also introduced a new extrinsic scale, Extrinsic-Rules Keeping, was tested to find if all four factors that were retained in the pilot study emerged when using a larger, more diverse adult sample. 


\section{Model One: Initial Four-Factor Model of the MRM}

To test Hypothesis 2, whether the hypothesized factor model from the pilot study (Banister et al., 2011b) fits the data with the new sample, a CFA was conducted to test the four-factor model of the Measure of Religious Motivation (MRM; Figure 6). The four latent variables in the model were Intrinsic, Extrinsic-Personal, Extrinsic-Rules Keeping, and Extrinsic-Social. Intrinsic was measured by six observed variables (including four items from the AUIES-12), Extrinsic-Personal measured by five observed variables (including two items from the AUIES-12), Extrinsic-Rules Keeping measured by six observed variables, and Extrinsic-Social measured by nine observed variables (including three items from the AUIES-12). Therefore, 26 items were included in the model, and as found in the pilot study (Banister et al., 2011b) nine of the items from the AUIES-12 were included and three items from the AUIES-12 were excluded in the MRM four-factor model. Subsample $1(N=476)$ was used for the CFA. Given this criterion with 84 parameters being estimated a minimum sample size of 420 to 840 participants was needed to achieve adequate power. The marker variables were Intrinsic Q28, Extrinsic-Personal Q19, Extrinsic-Rules Keeping Q29, and Extrinsic-Social Q27. 


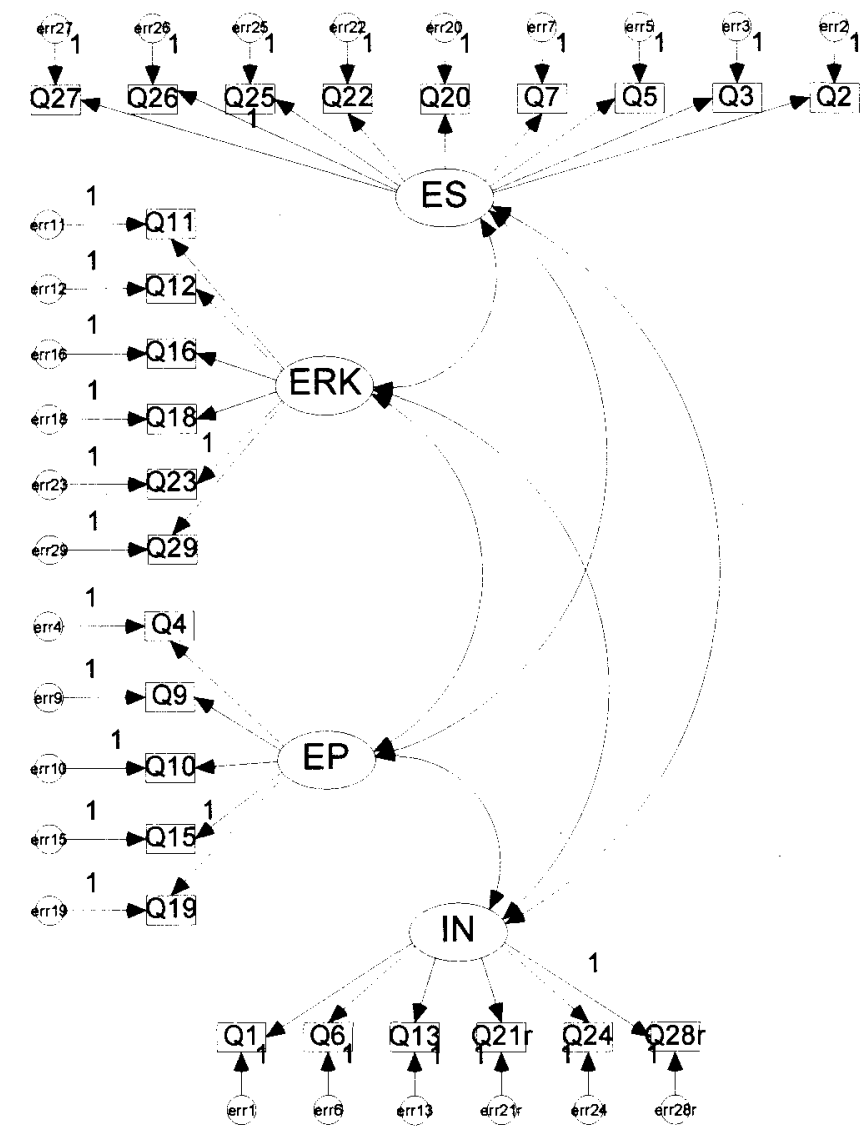

Figure 6. CFA of Model One, the four-factor model of the Measure of Religious Motivation as found in Banister et al. (2011b). IN = Intrinsic; EP = Extrinsic-Personal; ERK $=$ Extrinsic-Rules Keeping; ES $=$ Extrinsic Social.

Investigation of the path coefficients revealed that all unstandardized regression weights were statistically significant. All standardized regression weights (Table 6) were in the targeted range of between .3 and .9. Intrinsic items had standardized regression weights between .445 and .671 . Extrinsic-Personal had standardized regression weights between .364 and .854 . Extrinsic-Rules keeping items had standardized regression weights between .328 and .793 . Extrinsic-Social had standardized regression weights between .493 and .622 . The covariances between the factors were statistically 
significant. The relationships between Intrinsic and Extrinsic-Rules Keeping (-.221) and Intrinsic and Extrinsic-Personal (-.117) were weak (Cohen, 1988). The relationships between Intrinsic and Extrinsic-Social (-.347), Extrinsic-Personal and Extrinsic-Rules Keeping (.371), Extrinsic-Personal and Extrinsic-Social (.349) and Extrinsic-Rules Keeping and Extrinsic-Social (.342) were moderate (Cohen, 1988; Table 7).

Table 6

Standardized and Unstandardized Pattern Coefficients for Confirmatory Factor Analysis of Model One of the MRM

\section{Model One}

$\underline{\mathrm{IN}} \underline{\underline{\mathrm{N}}} \quad \underline{\mathrm{ERK}} \quad \underline{\mathrm{ES}}$

\begin{tabular}{lcccccccc} 
Variable & Stan & Unstan & Stan & Unstan & Stan & Unstan & Stan & Unstan \\
\hline Q1 & .445 & .702 & - & - & - & - & - & - \\
Q6 & .515 & .604 & - & - & - & - & - & - \\
Q13 & .505 & .707 & - & - & - & - & - & - \\
Q21r & .470 & .750 & - & - & - & - & - & - \\
Q24 & .671 & 1.523 & - & - & - & - & - & - \\
Q28r & .459 & 1.00 & - & - & - & - & - & - \\
Q4 & - & - & .854 & 2.453 & - & - & - & - \\
Q9 & - & - & .823 & 2.215 & - & - & - & - \\
Q10 & - & - & .364 & .967 & - & - & - & - \\
Q15 & - & - & .581 & 1.295 & - & - & - & - \\
Q19 & - & - & .347 & 1.00 & - & - & - & -
\end{tabular}




\begin{tabular}{|c|c|c|c|c|c|c|c|c|}
\hline Q11 & - & - & - & - & .694 & 1.454 & - & - \\
\hline Q12 & - & - & - & - & .328 & 1.167 & - & - \\
\hline Q16 & - & - & - & - & .405 & .832 & - & - \\
\hline Q18 & - & - & - & - & .801 & 1.437 & - & - \\
\hline Q23 & - & - & - & - & .793 & 1.457 & - & - \\
\hline Q29 & - & - & - & - & .517 & 1.00 & - & - \\
\hline Q2 & - & - & - & - & - & - & .493 & .482 \\
\hline Q3 & - & - & - & - & - & - & .500 & .986 \\
\hline Q5 & - & - & - & - & - & - & .585 & .749 \\
\hline Q7 & - & - & - & - & - & - & .526 & .948 \\
\hline Q20 & - & - & - & - & - & - & .622 & 1.184 \\
\hline Q22 & - & - & - & - & - & - & .611 & .594 \\
\hline Q25 & - & - & - & - & - & - & .542 & .364 \\
\hline Q26 & - & - & - & - & - & - & .574 & 1.001 \\
\hline Q27 & - & - & - & - & - & - & .599 & 1.00 \\
\hline
\end{tabular}

Notes: $\mathrm{IN}=$ Intrinsic; $\mathrm{EP}=$ Extrinsic-Personal; ERK = Extrinsic-Rules Keeping; ES = Extrinsic Social; Stan = standardized pattern coefficients; Unstan = unstandardized pattern coefficients. Parameter estimates "fixed" to be 0 are reported as dashes ("-"). All pattern coefficients are statistically significant $(p<.05)$. 
Table 7

Pearson Correlation Matrix for Factor Correlation of the MRM

\begin{tabular}{lllll}
\hline Factor & IN & EP & ERK & ES \\
\hline IN & --- & $-.117^{*}$ & $-.221^{*}$ & $-.347^{*}$ \\
EP & --- & -- & $.371^{*}$ & $.349^{*}$ \\
ERK & --- & --- & $-342^{*}$ \\
ES & --- & --- & -- &. \\
\hline
\end{tabular}

Notes: $\mathrm{IN}=$ Intrinsic; EP = Extrinsic-Personal; ERK = Extrinsic-Rules Keeping; ES = Extrinsic

Social; ${ }^{*}=$ statistical significance $p<.05$.

Interpretation of the model fit for Model One with Subsample 1 revealed poor model fit for the four-factor model of the MRM $\left(\chi^{2}\right.$ of $\left.954.883 ; d f=293\right)$. The $\chi^{2} / d f$ ratio of 3.259 was greater than 2.0. The TLI (.775) and CFI (.797) did not meet the minimum standard of .9. The RMSEA $(.069, \mathrm{CI}=.064-.074)$ was greater than .05 but less than .08 , making it acceptable at this level (see Table 8). The AIC value of Model One was 1122.883 .

\section{Model One-B: Initial Four-Factor Model of the MRM with Correlations Added}

Due to elevated MI values ( $>45$ ) it was determined that it would be beneficial, as well as theoretically appropriate, to add four correlations and test Model One-B (Figure 7). The correlations allowed were between Q10 and Q19 of the Extrinsic-Personal scale, Q16 and Q29 of the Extrinsic-Rules Keeping scale, and Q7 and Q26, as well as Q20 and 
Q27 of the Extrinsic-Social Scale. Items Q10 ("I pray mainly to gain relief and protection.") and Q19 (“Prayer is for peace and happiness.") are the two original Extrinsic-Personal scale items from the AUIES-12 that were included in the MRM. Both items frame prayer as a vehicle to bring personal comfort. Items Q16 ("If I read my Bible often enough, I get what I want.") and Q29 ("If I pray enough, I get what I want."), of the Extrinsic-Rules Keeping scale, involve an "exchange of goods." Items Q7, Q20, Q26, and Q27 are items from the Extrinsic-Social scale. Items Q7 ("I go to church activities mostly because my friends are there.") and Q26 ("I go to my church mainly because I enjoy seeing people I know there.") both share the theme of attending a religious service to be with friends. Both Q20 ("I go to church to make my family happy.") and Q27 ("Going to church is important to me because it is expected by my family.") both concern attending religious services due to familial expectations and keeping the family "happy."

By allowing these correlations Model One-B $\left(\chi^{2}\right.$ of $\left.681.251 ; d f=289\right)$ it appeared the model fit improved, however it did not improve the goodness-to-fit indices to acceptable levels. The $\chi^{2} / d f$ ratio of 2.357 was greater than 2.0 . The TLI (.865) and CFI (.880) did not meet the minimum standard of .9. The RMSEA $(.053, \mathrm{CI}=.048-.059)$ was greater than .05 but less than .08 , making it acceptable at this level (see Table 8). The AIC value of Model One-B with the added correlations was 857.251. After further examination of the MI values of Model One-B, with correlations added, were all acceptable $(<14)$, leading to the decision that no further correlation of items would be appropriate. A chi-square difference test also suggested that Model One-B provided a 
significantly $(p<.001)$ better fit to the data than did Model One ( $\Delta \chi^{2}$ of 273.632 and $\Delta$ $d f$ of 4$)$.

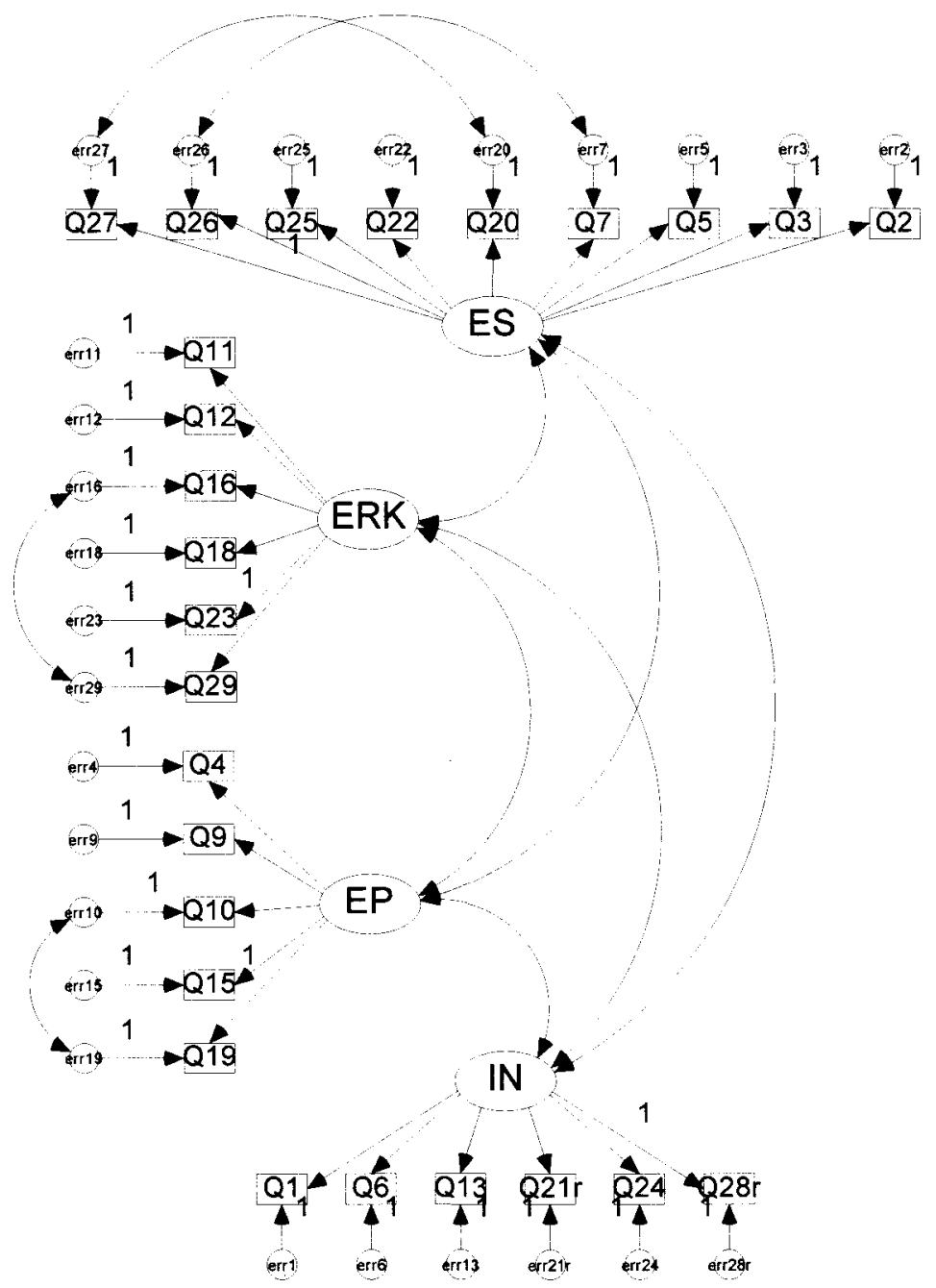

Figure 7. CFA of Model One-B, the four-factor model of the Measure of Religious Motivation with correlations added between items. $\mathrm{IN}=$ Intrinsic; $\mathrm{EP}=$ ExtrinsicPersonal; ERK = Extrinsic-Rules Keeping; ES = Extrinsic Social. 
Table 8

Fit Statistics for All Confirmatory Factor Analysis Models of the MRM

\begin{tabular}{|c|c|c|c|c|c|c|c|}
\hline Model & Description & $x^{2}$ & CFI & TLI & RMSEA & LO-HI & AIC \\
\hline $\begin{array}{l}\text { Model } 1 \mathrm{w} / \\
\text { Subsample } 1\end{array}$ & $\begin{array}{l}\text { 4-Factor } \\
\text { model from } \\
\text { the Pilot } \\
\text { Study }\end{array}$ & $954.9(293)$ & .797 & .775 & .069 & $\begin{array}{l}.064- \\
.074\end{array}$ & 1122.883 \\
\hline $\begin{array}{l}\text { Model } 1 \mathrm{w} / \\
\text { Subsample } 2\end{array}$ & $\begin{array}{c}\text { 4-Factor } \\
\text { model from } \\
\text { the Pilot } \\
\text { Study }\end{array}$ & $952.7(293)$ & .795 & .772 & .068 & $\begin{array}{l}.063- \\
.073\end{array}$ & 1120.669 \\
\hline $\begin{array}{l}\text { Model 1-B w/ } \\
\text { Subsample } 1\end{array}$ & $\begin{array}{c}\text { 4-Factor } \\
\text { from the } \\
\text { Pilot Study } \\
\text { w/ } \\
\text { correlations } \\
\text { allowed }\end{array}$ & $681.251(293)$ & .880 & .865 & .053 & $\begin{array}{l}.048- \\
.059\end{array}$ & 857.251 \\
\hline $\begin{array}{l}\text { Model 1-B w/ } \\
\text { Subsample } 2\end{array}$ & $\begin{array}{c}\text { 4-Factor } \\
\text { from the } \\
\text { Pilot Study } \\
\text { w/ } \\
\text { correlations } \\
\text { allowed }\end{array}$ & $758.754(289)$ & .854 & .836 & .058 & $\begin{array}{l}.053- \\
.063\end{array}$ & 934.754 \\
\hline $\begin{array}{l}\text { Model } 2 \text { w/ } \\
\text { Subsample } 1\end{array}$ & $\begin{array}{c}\text { MRM } \\
\text { Four- } \\
\text { Factor } \\
\text { Model with } \\
\text { all AUIES- } \\
12 \text { Items }\end{array}$ & $1172.4(371)$ & .781 & .760 & .067 & $\begin{array}{l}.063- \\
.072\end{array}$ & 1358.419 \\
\hline $\begin{array}{l}\text { Model } 2 \text { w/ } \\
\text { Subsample } 2\end{array}$ & $\begin{array}{c}\text { MRM } \\
\text { Four- } \\
\text { Factor } \\
\text { Model with } \\
\text { all AUIES- } \\
12 \text { Items }\end{array}$ & $1149.3(371)$ & .781 & .760 & .066 & $\begin{array}{l}.062- \\
.070\end{array}$ & 1335.263 \\
\hline $\begin{array}{l}\text { Model 2-B w/ } \\
\text { Subsample } 1\end{array}$ & $\begin{array}{l}\text { Final 4- } \\
\text { Factor }\end{array}$ & $641.8(310)$ & .904 & .891 & .046 & $\begin{array}{l}.041- \\
.052\end{array}$ & 831.8 \\
\hline
\end{tabular}


model

Model 2-B w/

Final 4-

$621.8(310)$

$.904 \quad .889$

.046

$.041-$

846.7

Subsample 2

Factor

.051

model

Notes. $\chi^{2}=$ Chi Square; TLI $=$ Tucker $\&$ Lewis Index; CFI = comparative fit index;

RMSEA = root mean square error of approximation; LO-HI = RMSEA LO-HI; AIC = Akaike Information Criterion.

\section{Model Two: Four-Factor Model of the MRM with all AUIES-12 Items Included}

Due to the lack of fit of the initial model and the indication of the SpearmanBrown Prophecy in Research Question 1-A that suggested adding additional items to each scale to increase internal consistency, an additional CFA was performed with Subsample 1. This four-factor model, Model Two (Figure 8), contained 26 items from the MRM as found in the pilot study (Banister et al., 2011b), as well as the three items from the AUIES-12 that were excluded from the earlier CFA due to the findings of the pilot study.

Of those three items, two were original items used to measure Intrinsic religious motivation in the AUIES-12, and one item was originally used to measure ExtrinsicPersonal in the AUIES-12. The decision was made to include them into the MRM because the earlier EFA and CFA from Research Question 1-A indicated that all of the original AUIES-12 items were retained on Maltby's original factors, as well as the findings from the Spearman-Brown Prophecy conducted previously. As explained more fully below, although the addition of these items did not provide an improved model fit, it did increase each of the scale reliabilities (Extrinsic-Personal increased from .743 to .761 
and Intrinsic from .676 to .715). Because Model One, Model One-B, and Model Two contain a different number of items, meaning they are not nested models, a chi-square difference test to compare these models is prohibited.

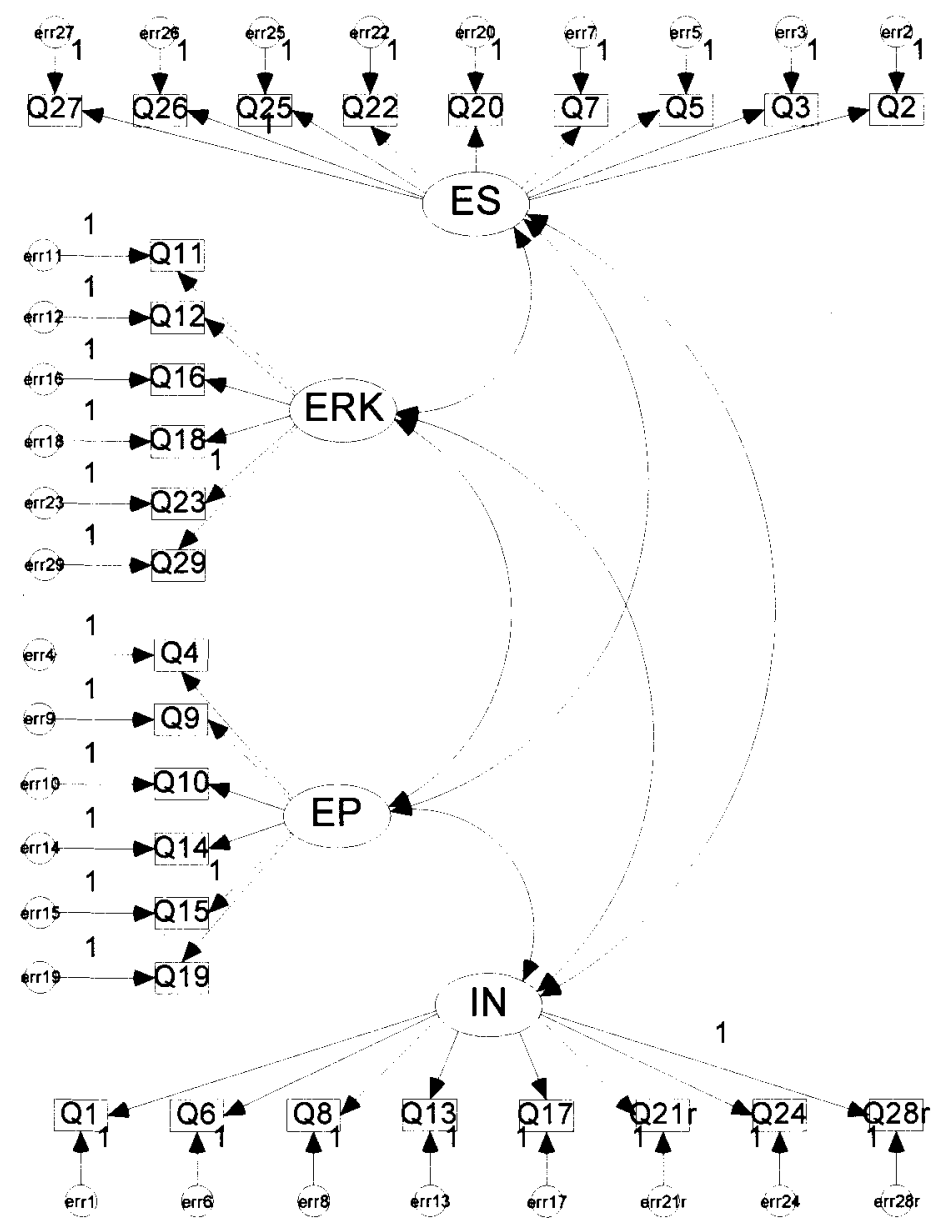

Figure 8. CFA of Model Two, a four-factor model of the Measure of Religious Motivation with all AUIES-12 items included. IN = Intrinsic; EP = Extrinsic-Personal; ERK $=$ Extrinsic-Rules Keeping; ES = Extrinsic Social.

Exploration of the path coefficients revealed that all unstandardized regression weights were statistically significant. All standardized regression weights (Table 9) were 
in the acceptable range between .3 and .9. Intrinsic items had standardized regression weights between .402 and .666. Extrinsic-Personal had standardized regression weights between .371 and .849 . Extrinsic-Rules keeping items had standardized regression weights between .328 and .793 . Extrinsic-Social had standardized regression weights between .494 and .621 . The covariances between the factors were statistically significant, and the correlations of the factors were all low to very low (Table 10).

Table 9

Standardized and Unstandardized Pattern Coefficients for Confirmatory Factor Analysis of Model Two of the MRM

\begin{tabular}{|c|c|c|c|c|c|c|c|c|}
\hline \multirow[b]{2}{*}{ Variable } & \multicolumn{2}{|c|}{$\underline{\mathrm{IN}}$} & \multicolumn{2}{|c|}{$\underline{\mathrm{EP}}$} & \multicolumn{2}{|c|}{$\underline{\mathrm{ERK}}$} & \multicolumn{2}{|c|}{$\underline{\mathrm{ES}}$} \\
\hline & Stan & Unstan & Stan & Unstan & Stan & Unstan & Stan & Unstan \\
\hline Q1 & .480 & .791 & - & - & - & - & - & - \\
\hline Q6 & .530 & .649 & - & - & - & - & - & - \\
\hline Q8 & .512 & .920 & - & - & - & - & - & - \\
\hline Q13 & .540 & .791 & - & - & - & - & - & - \\
\hline Q17 & .534 & 1.126 & - & - & - & - & - & - \\
\hline Q21r & .402 & .670 & - & - & - & - & - & - \\
\hline Q24 & .667 & 1.582 & - & - & - & - & - & - \\
\hline Q28r & .440 & 1.00 & - & - & - & - & - & - \\
\hline Q4 & - & - & .849 & 2.280 & - & - & - & - \\
\hline Q9 & - & - & .809 & 2.035 & - & - & - & - \\
\hline Q10 & - & - & .390 & .971 & - & - & - & - \\
\hline
\end{tabular}




\begin{tabular}{lcccccccc} 
Q14 & - & - & .356 & .972 & - & - & - & - \\
Q15 & - & - & .592 & 1.235 & - & - & - & - \\
Q19 & - & - & .371 & 1.00 & - & - & - & - \\
Q11 & - & - & - & - & .694 & 1.453 & - & - \\
Q12 & - & - & - & - & .328 & 1.166 & - & - \\
Q16 & - & - & - & - & .405 & .832 & - & - \\
Q18 & - & - & - & - & .801 & 1.437 & - & - \\
Q23 & - & - & - & - & .793 & 1.455 & - & - \\
Q29 & - & - & - & - & .517 & 1.00 & - & - \\
Q2 & - & - & - & - & - & - & .494 & .485 \\
Q3 & - & - & - & - & - & - & .501 & .991 \\
Q5 & - & - & - & - & - & - & .586 & .752 \\
Q7 & - & - & - & - & - & - & .527 & .951 \\
Q20 & - & - & - & - & - & - & .621 & 1.185 \\
Q22 & - & - & - & - & - & - & .611 & .596 \\
Q25 & - & - & - & - & - & - & .543 & .367 \\
Q26 & - & - & - & - & - & - & .572 & 1.001 \\
Q27 & - & - & - & - & - & - & .597 & 1.00 \\
\hline
\end{tabular}

Notes: $\mathrm{IN}=$ Intrinsic; $\mathrm{EP}=$ Extrinsic-Personal; $\mathrm{ERK}=$ Extrinsic-Rules Keeping; ES = Extrinsic Social; Stan = standardized pattern coefficients; Unstan $=$ unstandardized pattern coefficients. Parameter estimates "fixed" to be 0 are reported as dashes ("--"). All pattern coefficients are statistically significant $(p<.05)$. 
Table 10

Pearson Correlation Matrix for Model Two

\begin{tabular}{lllll}
\hline Factor & $\mathrm{IN}$ & $\mathrm{EP}$ & $\mathrm{ERK}$ & $\mathrm{ES}$ \\
\hline $\mathrm{IN}$ & --- & $-.067^{*}$ & $-.207^{*}$ & $-.319^{*}$ \\
$\mathrm{EP}$ & --- & --- & $.370^{*}$ & $.356^{*}$ \\
ERK & --- & --- & -- & $.342^{*}$ \\
ES & --- & --- & -- \\
\hline
\end{tabular}

$\mathrm{IN}=$ Intrinsic; $\mathrm{EP}=$ Extrinsic-Personal; ERK = Extrinsic-Rules Keeping; ES = Extrinsic Social; $* p<.05$.

Interpretation of the model fit showed that the Model Two, the four-factor model of the MRM with the additional AUIES-12 items, exhibited a poor fit of the model to the data. The model had a $\chi^{2}$ of 1172.419 with $d f$ of 371 . The $\chi^{2} / d f$ ratio of 3.160 was greater than 2.0. The TLI (.760) and CFI (.781) did not meet the minimum standard of .9. The RMSEA (.06) was greater than .05 but less than .08 , making it acceptable at this level (see Table 8). However, based on theory and modification indices, it was determined that further model respecifications could be beneficial prior to comparing the model to the final version of Model One.

\section{Model Two-B: Final Four-Factor Model of the MRM with Subsample 1}

As a final model, Model Two-B (Figure 9), post hoc respecification of Model Two, was analyzed with Subsample 1. Several methods were considered in determining 
a model that would provide a better fit to the data than the above models, including deleting items, moving items from one latent construct to another and adding correlations between items.

Items Q21r and Q28r were deleted from the Intrinsic scale due to the fact that they were items that were added in the pilot study (Banister et al., 2011b) intended to measure Extrinsic-Personal religious motivation and not Intrinsic religious motivation. There were no other items in the pilot study that loaded on the "wrong" factor. This resulted in $\chi^{2}$ of 1022.9(318), TLI $=.774, \mathrm{CFI}=.795, \mathrm{AIC}=1196.895$, and $\mathrm{RMSEA}=$ .068. The AIC value indicated that Model Two-B was a better fit than Model One ( $\Delta$ AIC $=291.083)$. This model, Model Two-B, was also a better fit than Model Two as indicated by the AIC values $(\triangle \mathrm{AIC}=526.619)$. Also, by subtracting these two items and adding Q8 and Q17, the two Intrinsic items from the AUIES-12 that were not retained in the pilot study but added in Research Question 1-B, the internal consistency rose from .676 to .739 . 


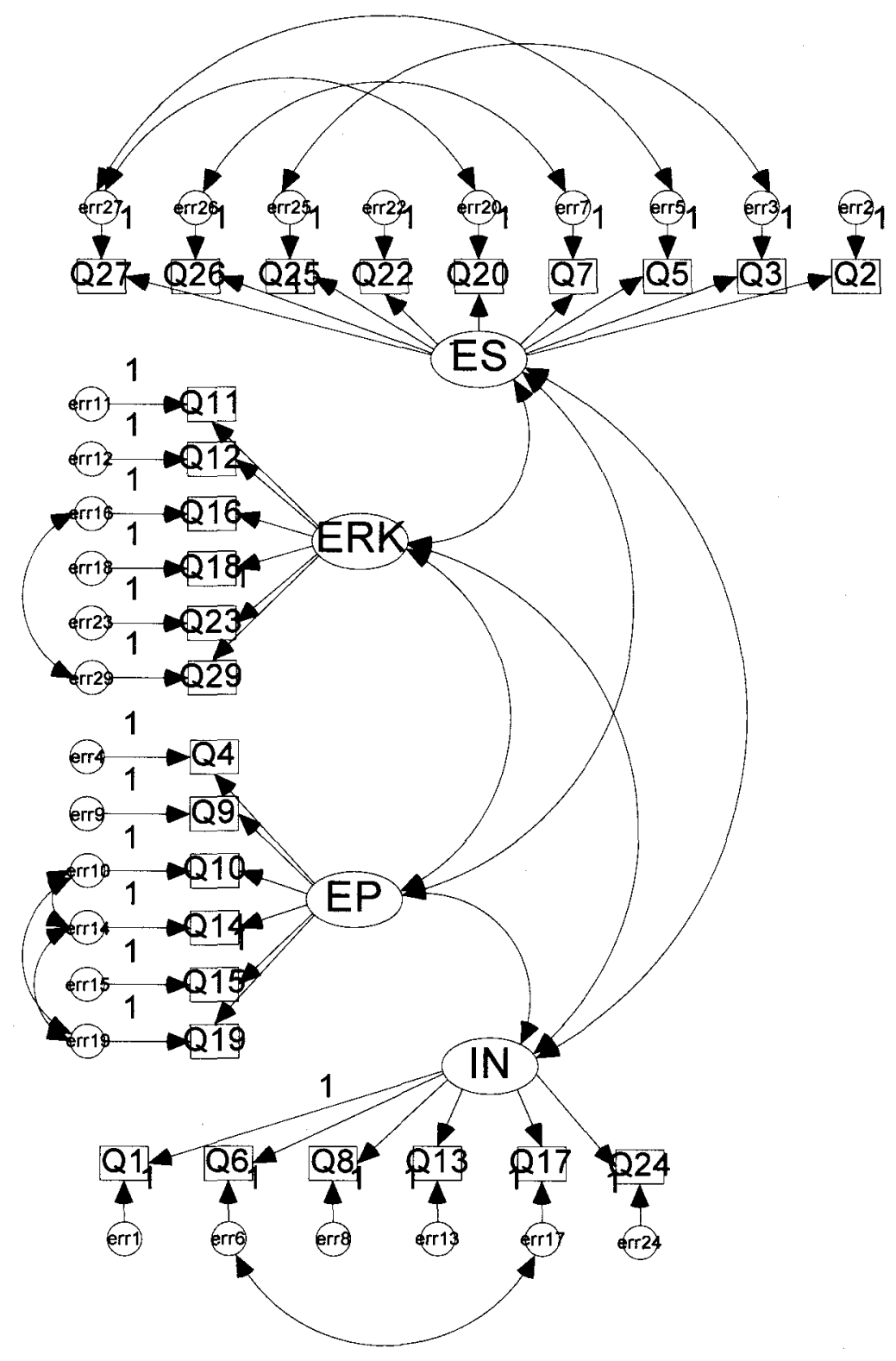

Figure 9. CFA of Model Two-B, a four-factor model of the Measure of Religious Motivation following model respecifications. $\mathrm{IN}=$ Intrinsic; $\mathrm{EP}=$ Extrinsic-Personal; ERK $=$ Extrinsic-Rules Keeping; ES = Extrinsic Social. 
After examining the data, correlations between Q10 and Q14 of the ExtrinsicPersonal scale were added due to high MI values (> 31). Also correlations between Q7 and Q26 and Q20 and Q27 of the Extrinsic-Social scale were added due to high MI values $(>47)$. Theoretically adding these correlations were deemed appropriate in view of the nature of each question. Q10 ("I pray mainly to gain relief and protection.") and Q14 ("What religion offers me most is comfort in times of trouble and sorrow.") were both items that related to direct personal comfort and protection from distress. These two items are two of the three original Extrinsic-Personal items used in the AUIES-12. Both Q7 ("I go to church activities mostly because my friends are there.") and Q26 ("I go to my church mainly because I enjoy seeing people I know there.") both share the theme of attending a religious service to be with friends. Finally, Q20 ("I go to church to make my family happy.") and Q27 ("Going to church is important to me because it is expected by my family.") both concern attending religious services due to familial expectations and keeping the family "happy." This resulted in $\chi^{2}$ of $803.4(315), \mathrm{TLI}=.842, \mathrm{CFI}=.858$, $\mathrm{AIC}=983.388$, and $\mathrm{RMSEA}=.057$. The AIC values reflected that allowing the correlations improved the model fit $(\Delta \mathrm{AIC}=213.507)$. A $\chi^{2}$ difference test $\left(\Delta \chi^{2}\right.$ of 219.5 and $\Delta d f$ of 3$)$ revealed that this model provided a significantly $(p<.001)$ better fit to the data.

After further examination, in addition to the added correlations described above, correlations between Q3 and Q25 and Q5 and Q27 of the Extrinsic-Social scale were allowed. As well as correlations between Q10 and Q19 and Q14 and Q19 of the Extrinsic-Personal scale and Q16 and Q29 from the Extrinsic-Rules Keeping scale. These items all had high MI values (> 27). From a theoretical standpoint, items Q10 ("I 
pray mainly to gain relief and protection."), Q14 ("What religion offers me most is comfort in times of trouble and sorrow."), and Q19 ("Prayer is for peace and happiness.") of the Extrinsic-Personal scale are the original three items used to measure ExtrinsicPersonal in the AUIES-12. Each item incorporates an aspect of personal protection or comfort into this type of religious motivation. Concerning the Extrinsic-Social items, both Q3 ("I go to church because it helps me to make friends.") and Q25 ("I go to church to make my friends happy.") concern going to church to make friends as well as to keep friends "happy.", indicating that both questions contain some aspect of building and maintaining friendships. Both Q5 ("Going to church is important to me because it is expected by my friends.") and Q27 ("Going to church is important to me because it is expected by my family.") share a theme of going to church services because it is expected by individuals that the participant views as important in their lives (friends and family). Although Q5 and Q27 correlate and Q20 and Q27 correlate, Q5 and Q20 do not correlate. Item Q5 refers to attending religious services because it is expected by friends whereas Q20 refers to attending religious services to make family "happy." In regards to the Extrinsic-Rules Keeping items, Q16 ("If I read my Bible often enough, I get what I want.") and Q29 ("If I pray enough, I get what I want.") involve an "exchange of goods." In both questions the theme of participating in a religious tradition or practice is directly rewarded. Therefore, the additions of these correlations were deemed theoretically appropriate. This resulted in a chi-square of $641.8(310), \mathrm{TLI}=.891, \mathrm{CFI}=.904, \mathrm{AIC}=$ 831.842, and RMSEA $=.047(.042-.053)$. The allowance of these correlations further improved the fit of the model as indicated by a lower AIC value than any of the previous 
models tested $(\triangle \mathrm{AIC}=151.546)$. Also, the $\chi^{2}$ difference test $\left(\Delta \chi^{2}\right.$ of 161.6 and $\Delta d f$ of $5 ; p$ $=<.001)$ indicated that this model was a better fit than the previous model tested.

Investigation of the path coefficients for the final model illustrated previously (Figure 7) revealed that all unstandardized regression weights were statistically significant. All standardized regression weights (Table 11) were in the permissible range between .3 and .9. Intrinsic items had standardized regression weights between .499 and .626. Extrinsic-Personal had standardized regression weights between .323 and .868 . Extrinsic-Rules keeping items had standardized regression weights between .332 and .811. Extrinsic-Social had standardized regression weights between .458 and .654 . The covariances between the factors were statistically significant, and the correlations of the factors were all low to very low (Table 12).

Table 11

Standardized Pattern Coefficients for Confirmatory Factor Analysis of Model Two-B w/ Subsample 1

$\underline{\mathbb{N}} \quad \underline{E P} \quad \underline{E R K} \quad \underline{E S}$

$\begin{array}{lllllllll}\text { Variable } & \text { Sub1 } & \text { Sub 2 } & \text { Sub 1 } & \text { Sub 2 } & \text { Sub 1 } & \text { Sub } & \text { Sub 1 } & \text { Sub }\end{array}$

\begin{tabular}{|c|c|c|c|c|c|c|c|}
\hline Q1 & .499 & .612 & - & - & - & - & - \\
\hline Q6 & .626 & .625 & - & - & - & - & - \\
\hline Q8 & .527 & .490 & - & - & - & - & - \\
\hline Q13 & .540 & .500 & - & - & - & - & - \\
\hline Q17 & .599 & .575 & - & - & - & - & - \\
\hline
\end{tabular}




\begin{tabular}{|c|c|c|c|c|c|c|c|c|}
\hline Q24 & .573 & .576 & - & - & - & - & - & - \\
\hline $\mathrm{Q} 4$ & - & - & .868 & .892 & - & - & - & - \\
\hline Q9 & - & - & .823 & .859 & - & - & - & - \\
\hline Q10 & - & - & .339 & .331 & - & - & - & - \\
\hline Q14 & - & - & .317 & .320 & - & - & - & - \\
\hline Q15 & - & - & .572 & .475 & - & - & - & - \\
\hline Q19 & - & - & .323 & .396 & - & - & - & - \\
\hline Q11 & - & - & - & - & .700 & .674 & - & - \\
\hline Q12 & - & - & - & - & .332 & .330 & - & - \\
\hline Q16 & - & - & - & - & .360 & .438 & - & - \\
\hline Q18 & - & - & - & - & .796 & .873 & - & - \\
\hline Q23 & - & - & - & - & .811 & .895 & - & - \\
\hline Q29 & - & - & - & - & .484 & .557 & - & - \\
\hline Q2 & - & - & - & - & - & - & .527 & .368 \\
\hline Q3 & - & - & - & - & - & - & .569 & .407 \\
\hline Q5 & - & - & - & - & - & - & .601 & .371 \\
\hline Q7 & - & - & - & - & - & - & .506 & .444 \\
\hline Q20 & - & - & - & - & - & - & .508 & .337 \\
\hline Q22 & - & - & - & - & - & - & .654 & .742 \\
\hline Q25 & - & - & - & - & - & - & .592 & .478 \\
\hline Q26 & - & - & - & - & - & - & .523 & .514 \\
\hline Q27 & - & - & - & - & - & - & .458 & .323 \\
\hline
\end{tabular}


Notes: $\mathrm{IN}=$ Intrinsic; $\mathrm{EP}=$ Extrinsic-Personal; ERK = Extrinsic-Rules Keeping; ES = Extrinsic Social; Sub $1=$ Subsample 1; Sub 2 = Subsample 2. Parameter estimates "fixed" to be 0 are reported as dashes ("-"). All pattern coefficients are statistically significant.

Table 12

Pearson Correlation Matrix for Factor Correlation of Model Two-B of the MRMw/ Subsample 1

\begin{tabular}{lcccc}
\hline Factor & $\mathrm{IN}$ & EP & ERK & ES \\
\hline IN & --- & $-.009^{*}$ & $-.219^{*}$ & $-.268^{*}$ \\
EP & --- & --- & $.363^{*}$ & $.306^{*}$ \\
ERK & --- & -- & --- & $.335^{*}$ \\
ES & --- & $-\cdots$ & --- & --- \\
\hline
\end{tabular}

Notes. $\mathrm{IN}=$ Intrinsic; EP = Extrinsic-Personal; ERK = Extrinsic-Rules Keeping; ES = Extrinsic Social; ${ }^{*} p<.05$.

Interpretation of the model fit showed that the respecified four-factor model of the MRM, Model Two-B, displayed a reasonable model fit to the data. The model had a $\chi^{2}$ of 624.095 and $d f$ of 309 with a $\chi^{2} / d f$ ratio of 2.0 that was acceptable as it was no greater than the 2.0 cutoff criterion. In Model Two-B both the TLI and CFI increased from Model Two to acceptable levels. The TLI (.891) was marginally lower than the 0.9 recommended value, but the CFI (.904) met the minimum standard of .9. The RMSEA (.046 $\mathrm{CI}_{90}, .041$ to .052$)$ was less than .05 indicating that the model overall was a good fit 
to the data (see Table 8). Moreover, as shown in Table 8, Model Two-B exhibited better model fit on all indices compared to Models One and Two.

After the final model, Model Two-B, internal reliability analyses were calculated (Table 13). Reliability analysis revealed that the internal consistency of the ExtrinsicPersonal scale is .761, the Extrinsic-Rules Keeping scale is .760, the Extrinsic-Social scale is .806, and the Intrinsic scale is .744. The addition of these items respectively increased the reliabilities of these scales to acceptable levels where previously they were unacceptable. Internal reliability coefficients for all four scales are judged to be acceptable (George \& Mallery, 2003).

Table 13

Internal Reliabilities of the Four Factors of the MRM (Model Two-B)

\begin{tabular}{lcc}
\hline Factor & Subsample 1 & Subsample 2 \\
\hline IN & .744 & .719 \\
EP & .761 & .708 \\
ERK & .760 & .756 \\
ES & .806 & .764 \\
\hline
\end{tabular}

Notes. IN = Intrinsic; EP = Extrinsic-Personal;

ERK $=$ Extrinsic-Rules Keeping; ES = Extrinsic-Social.

\section{Testing of the Models with Subsample 2}

Split-sample validation was used to test the above models of the MRM (Figures 6-9). Randomly splitting the overall sample collected for this dissertation allowed for further independent validation (Tashakkori \& Teddlie, 1998) and the reduction of the 
possibility of over-fitting the model (Brown, 2006) by testing the model fit with a different group of participants.

A CFA of Model One (Figure 6), containing four-factors and 26 items, was performed using Subsample 2. The examination of the path coefficients revealed that all unstandardized regression weights were statistically significant. All standardized regression weights were in the acceptable range between .3 and .9. Intrinsic items had standardized regression weights between .485 and .615 . Extrinsic-Personal had standardized regression weights between .303 and .847 . Extrinsic-Rules keeping items had standardized regression weights between .322 and .885 . Extrinsic-Social had standardized regression weights between .318 and .740 . The covariances between the factors were statistically significant, and the correlations of the factors were all low to very low.

Examination of the model fit for Model One with Subsample 2 (see Table 8) revealed poor model fit ( $\chi^{2}$ of $952.7 ; d f=293$ ). The $\chi^{2} / d f$ ratio of 3.251 was greater than 2.0. The TLI (.772) and CFI (.795) did not meet the minimum standard of .9. The RMSEA $\left(.068, \mathrm{CI}_{90}=.063-.073\right)$ was greater than .05 but less than .08 , making it acceptable at this level (see Table 8). The AIC value of Model One with Subsample 2 was 1120.669 (see Table 8 ).

Model One-B (Figure 7), the initial four-factor model of the MRM with four correlations added, was tested with Subsample 2. Although the goodness-to-fit indices improved $\left(\chi^{2}\right.$ of $758.754 ; d f=289 ; \mathrm{TLI}=.865 ; \mathrm{CFI}=.880 ; \mathrm{RMSEA}=.058\left(\mathrm{CI}_{90}=.048-\right.$ $.059 ; \mathrm{AIC}=934.754)($ see Table 8$)$, Model One-B was still rejected due to TLI, CFI, and RMSEA values being below the predetermined cutoff criteria. 
Model Two (Figure 8), containing four-factors and 27 items, was examined using Subsample 2. The examination of the path coefficients revealed that all unstandardized regression weights were statistically significant. As with Subsample 1, all standardized regression weights were in the acceptable range between .3 and .9. Intrinsic items had standardized regression weights between .466 and .658 . Extrinsic-Personal had standardized regression weights between .325 and .885 . Extrinsic-Rules keeping items had standardized regression weights between .331 and .890 . Extrinsic-Social had standardized regression weights between .301 and .631 . The covariances between the factors were statistically significant, and the correlations of the factors were all low to very low as well.

Inspection of the model fit for Model Two with Subsample 2 (see Table 8) revealed poor model fit as well $\left(\chi^{2}\right.$ of $\left.1149.3 ; d f=371\right)$. The $\chi^{2} / d f$ ratio of 3.098 was greater than 2.0. The TLI (.781) and CFI (.760) did not meet the minimum standard of .9. The RMSEA $\left(.06, \mathrm{CI}_{90}=.062-.070\right)$ was greater than .05 but less than .08 , making it acceptable at this level (see Table 8). The AIC value of Model Two with Subsample 2 was 1335.263.

Finally, a CFA of Model Two-B (Figure 9), containing four-factors and 27 items, was performed using Subsample 2 (see Table 8). The examination of the path coefficients revealed that all unstandardized regression weights were statistically significant. All standardized regression weights were in the acceptable range between .3 and .9. Intrinsic items had standardized regression weights between .490 and .625 . Extrinsic-Personal had standardized regression weights between .318 and .852 . Extrinsic-Rules keeping items had standardized regression weights between .330 and 
.895. Extrinsic-Social had standardized regression weights between .337 and .742 . The covariances between the factors were statistically significant, and the correlations of the factors were all low to very low (Table 14).

Table 14

Pearson Correlation Matrix for Factor Correlation of Model Two-B of the MRMw/ Subsample 2

\begin{tabular}{lllll}
\hline Factor & IN & EP & ERK & ES \\
\hline IN & --- & $-.009^{*}$ & $-.212^{*}$ & $-.268^{*}$ \\
EP & --- & --- & $.363^{*}$ & $.306^{*}$ \\
ERK & --- & --- & -- & $.324^{*}$ \\
ES & --- & --- & - & - \\
\hline
\end{tabular}

Notes. $\mathrm{IN}=$ Intrinsic; EP = Extrinsic-Personal; ERK = Extrinsic-Rules Keeping; ES = Extrinsic Social; $*=$ statistical significance $p<.05$.

Interpretation of the model fit of the final four-factor model of the MRM (with Subsample 2) displayed a good model fit to the data. The model had a $\chi^{2}$ of 621.807 and $d f$ of 309 with a $\chi^{2} / d f$ ratio of 2.03 , CFI (.904), TLI (.889), RMSEA (.046 $\mathrm{CI}_{90}, .041$ to .051 ), and AIC Value of 846.7. All held similar values as found in the respecified model above that used Subsample 1 (see Table 8). This CFA indicates, as seen in Table 8, that the final model, Model Two-B and using Subsample 2, fits the data appropriately and provides a similar fit to the data as Model Two-B when using Subsample 1. 
Following analyses of Model Two-B with Subsample 2, internal reliability analyses were calculated (Table 13). Reliability analysis revealed that the internal consistency of the Extrinsic-Personal scale is .708, the Extrinsic-Rules Keeping scale is .756 , the Extrinsic-Social scale is .764, and the Intrinsic scale is .719. The alpha levels found for each of the four scales with Subsample 2 were similar to those found with Subsample 1. As with Subsample 1, internal reliability coefficients for all four scales are judged to be acceptable when using Subsample 2 (George \& Mallery, 2003).

To test hypothesis 3 , if a statistically significant relationship exists between the Extrinsic-Rules Keeping scale and Stage 2 through Stage 5 of Fowler's theory of faith development, using factor scores, a Pearson product-moment correlation coefficient was computed to assess the relationship between Extrinsic-Rules Keeping and Stage 2 through Stage 5 of Fowler's theory of faith development as measured by the FDSS.

Extrinsic-Rules Keeping religious motivation was built on the theory that individuals obey religious "rules" in exchange of a reward from God or to avoid divine punishment. Extrinsic-Rules Keeping was built in part on Stage 2 of Fowler's theory of faith development. To test this theory summed factor scores (Comrey \& Lee, 1992) from the items retained on the Extrinsic-Rules Keeping scale of the MRM were calculated. These summed factor scores were analyzed with the summed factor scores of the FDSS, the measure used to measure Stage 2 through Stage 5 of Fowlers theory, to find if a statistically significant relationship existed. 
As hypothesized, there was a statistically significant correlation between Extrinsic-Rules Keeping and Stage $2, r=-.435\left(\mathrm{Cl}_{90}=-.413\right.$ to -.457$), n=961, p<.001$ (Table 15). This is considered a moderate correlation (Cohen, 1988). A scatterplot summarizes these results (Figure 10). Overall, there was a moderate, negative correlation between scores on the Extrinsic-Rules Keeping scale and the Stage 2 scale of the FDSS. A lower score on the Extrinsic-Rules Keeping scale (range 6 to 18) indicates a higher identification with extrinsic-rules keeping religious motivation. A higher score on the Stage 2 scale of the FDSS (range 9 to 45 ) indicates a stronger identification with Stage 2 of Fowlers theory of faith development. Therefore, this correlation indicates that the more a participant identifies with the Extrinsic-Rules Keeping factor the higher the degree they endorse items that indicate that their faith development is in Stage 2 of Fowler's theory.

Table 15

Pearson Correlations Between Extrinsic-Rules Keeping and Stage 2 through Stage 5 of Fowlers Theory of Faith Development as Measured by the FDSS $n=961$

\begin{tabular}{lrccc}
\hline FDSS Stage & \multicolumn{1}{c}{ ERK } & Lower & Upper & $p$ \\
\cline { 2 - 5 } FDSS Stage 2 & .435 & .413 & .457 & $<.001$ \\
FDSS Stage 3 & .062 & .059 & .066 & .218 \\
FDSS Stage 4 & -.004 & -.003 & -.004 & .934 \\
FDSS Stage 5 & -.139 & -.132 & -.146 & .006 \\
\hline
\end{tabular}


Note. $\mathrm{ERK}=$ Extrinsic-Rules Keeping. Lower $=$ Lower Bound $\mathrm{CI}_{90}$. Upper $=$ Upper Bound $\mathrm{Cl}_{90}$. Cohen (1988) considers a $p$ value of $>0.5$ to be a large effect size; $0.3-0.5$ to be a moderate effect size; and $0.1-0.3$ to be a small effect size. Correlations were calculated with the items of the FDSS reverse scored.

Pearson product-moment correlation coefficients were computed to assess the relationship between the Extrinsic-Rules Keeping scale and Stages 3 through Stage 5 of Fowler's theory of faith development as measured by the FDSS. As expected, there was no correlation between Extrinsic-Rules Keeping and stage 3, $r=-.062, n=961, p=.218$ (Table 14) or Extrinsic-Rules Keeping and Stage 4 of Fowler's theory of faith development, $r=.004, n=961, p=.934$. Unexpectedly, a correlation between ERK and Stage 5 was found, $r=.139, n=961, p=.006$. Although a significant relationship was found between ERK and Stage 5, it is a small association (Cohen, 1988) and is considered to hold no practical significance. 

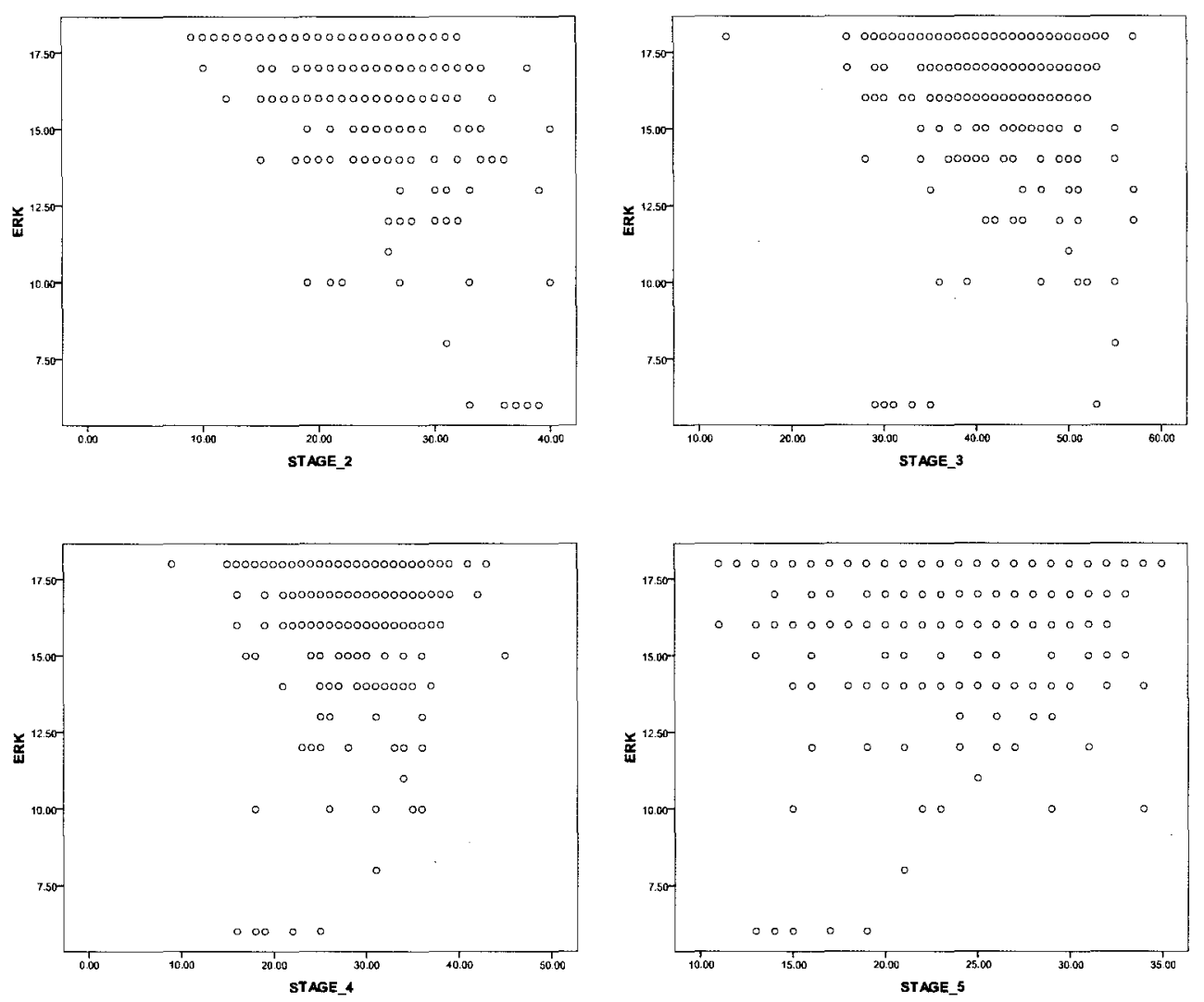

Figure 10. Scatterplot of Extrinsic-Rules Keeping and Stages 2 through 5 of Fowler's Theory of Faith Development visually representing the relationship between ExtrinsicRules Keeping and each of the stages of Fowler's Theory of Faith Development as measured by the FDSS. ERK = Extrinsic-Rules Keeping. 


\section{DISCUSSION}

Three research questions were investigated: (1) is a two-factor structure or a three-factor structure of the AUIES-12 more appropriate?; (2) does the data from the current sample fit the factor structure of the MRM that was found in the pilot study (Banister et al,. 2011b)?; and, (3) as expected, is there a positive relationship between the Rule-Keeping scale of the MRM and Stage 2 of Fowler's theory of faith development as measured by the FDSS?

The decision to pursue Research Question $1-A$ and $1-B$, determining the factor structure of the AUIES-12, came about for several reasons. The first reason was that the pilot study (Banister et al., 2011a) found that a two-factor structure emerged, opposed to the three-factor structure found by Maltby (1999). Coupled with the criticism of Maltby (1999) separating the Extrinsic scale into two separate scales with no a priori theoretical reason to do so, and the psychometric issues concerning scale reliabilities, it appeared important to determine whether a two-factor or three-factor structure of the AUIES-12 emerged. Secondly, although Maltby (2002) reported that he had confirmed the threefactor structure of the AUIES-12 via CFA, it appears that he used the same sample for the CFA that he had used in determining the three-factor structure through the initial EFA (Maltby, 1999). Therefore, it appears that there has not been a CFA conducted to confirm the factor structure of the AUIES-12. Lastley, with the frequent use of the AUIES-12 in current research (e.g., Aydin, 2010; Borynski, 2008; Coulter-Kern, 2010; 
Detember, 2007; Dezutter, 2006; Flere et al,, 2007; Flere \& Lavric, 2006; Flere \& Lavric, 2007, Joules, 2007; Lewis \& Cruise, 2006; Lewis et al.,2005; Lillios, 2010; Nelson et al., 2009; Pössel et al., 2011; Shreive-Neiger \& Edalstein, 2004; Wenger, 2005) and the claims made pertaining to the Christian population among multiple domains stemming from the AUIES-12, it warranted that the AUIES-12 be further evaluated and improved.

Research Question 2 spawned from the sense that the AUIES-12, and the scope of religious motivation measured within, was insufficient and stood in need in several important domains. Therefore the aim of Research Question 2 was threefold: 1) to develop a new measure of religious motivation, the MRM, that demonstrated a clear factor structure that was evidenced through both EFA and CFA; 2) introduce a new factor (Extrinsic-Rules Keeping) that was theoretically sound and psychometrically supported that would allow for an expansion in the research of extrinsic religious motivation (the development of the Extrinsic-Rules Keeping scale on sound theory is a step closer to bringing clarity to the murky theoretical foundations of which the AUIES-12 was established); and 3) to improve the scale reliabilities of the existing Intrinsic, ExtrinsicPersonal, and Extrinsic-Social scales by adding additional items to the Extrinsic-Personal and Extrinsic-Social scales from the AUIES-12 that allow for valid inferences. Historically, since the initial development of the ROS, scale reliabilities have been criticized with little improvement in the scale reliabilities found in the adaptations of the ROS (Banister et al., 2011a, Brewcynski, 2006; Genia, 1993; Gorsuch \& McPherson, 1989). The overall goal was to create a measure of intrinsic-extrinsic religious motivation that would be more theoretically sound than the AUIES-12, have scales that possessed acceptable reliabilities and allow for the expansion of the scientific study of 
religion by introducing a new extrinsic factor that enabled another dimension of extrinsic motivation to be measured and considered.

Research Question 3, determining the relationship between the Extrinsic-Rules Keeping scale and Fowler's theory of faith development, was a logical extension from the previous research question and a critical component in providing construct validity for the Extrinsic-Rules Keeping scale. Therefore, a measure of Fowler's theory of faith development, the FDSS, was given alongside the MRM in an effort to begin to sure up the theory surrounding intrinsic-extrinsic religious motivation, testing if the theory of which the Extrinsic-Rules Keeping scale claimed to stand upon was upheld.

\section{Research Question 1: Determining the Factor Structure of the AUIES-12}

The first set of analyses used both a PCA with direct oblimin rotation, as used by Maltby (1999), and a PAF with direct oblimin rotation, as used by Banister et al. (2011a), with the 12-items of the AUIES-12 to determine the factor structure of the AUIES-12. However the PCA and PAF used differing criteria to determine the number of factors to retain. With the PCA, in replication of Maltby (1999), the scree test was used to determine the number of factors to retain; whereas with the PAF, in replication of Banister et al. (2011a), the scree test, Kaiser's eigenvalues $>1$ rule, and PA were used. Differing from what was hypothesized, both the PCA and the PAF resulted in a threefactor solution retaining all 12 items, as found by Maltby (1999). Contrary to what was hypothesized, all items loaded on the original factors with Intrinsic having six items and both Extrinsic scales, Extrinsic-Personal and Extrinsic-Social, having three items each. 
Following the exploratory analyses, a two-factor model and a three-factor model were tested using CFA with a different sample to find which model more appropriately fit the data. These analyses were conducted because of the differing results from the pilot study (Banister et al., 2011a), as well as other criticisms given concerning the bifurcation of the Extrinsic scale by Maltby (1999) with no theoretical justification given. Following the testing of the two differing models it was found that the three-factor model had a better model fit to the data (Table 5). The three-factor model of the AUIES-12 consisted of all of the original items loading on all of the original factors (Intrinsic; six items, Extrinsic-Personal; three items and Extrinsic-Social; three items), as found by Maltby (1999) and the PAF from Research Question 1-A of this dissertation.

Surprisingly, these analyses indicated that regardless of the methods used, PAF, PCA or CFA, the items of the AUIES-12 loaded as three separate factors (ExtrinsicPersonal, Extrinsic-Social and Intrinsic), consisting of all of the original 12 items. The pilot study (Banister et al., 2011a) found that a two-factor solution was more appropriate. The differing results between these studies may lie in the samples used. The pilot study used a smaller sample of primarily adolescents $(n=268$; mean age 14.94 years, $S D=$ 2.09); whereas the current study used a large sample comprised of adults ( $n=961$; mean age $40.33, S D=13.14)$. The age difference $(\Delta$ mean age $=25.39$ years, $\Delta S D=11.05)$ gives a possible explanation for the differing factor structure found in the pilot study (Banister et al., 2011a). The age of the sample and the nature of the questions may play a significant role in how an adolescent may respond as compared to an adult. For example, the Intrinsic items that were not retained could reflect a mature belief system that may be more prevalent in a post-adolescent sample (Allport, 1950; Fowler, 1981; Fowler et al., 
2004; Milevsky \& Levitt, 2004). Also, the Extrinsic-Personal items that did not have high enough factor loadings to be retained ("What religion offers me most is comfort in times of trouble and sorrow." and "I pray mainly to gain relief and protection.") tap into the idea of religious belief/prayer as a function of stress reduction and/or protection from difficulties or harm (Flere \& Lavric, 2008; Trimble, 1997). It may very well be that the adult sample has experienced more life stressors and have experienced more difficulties/harm than the typical adolescent (Folkman et al., 1987; Orsega-Smith, 2004), shaping their extrinsic religious motivation to weigh more heavily these stressful, difficult experiences and seek personal refuge through their religious beliefs Flere \& Lavric, 2008; Trimble, 1997). It is possible that these youth are still in the developmental stages of their chosen belief system. However the AUIES-12 is a measure of religious motivation and not a measure of faith maturity, therefore it is impossible to say precisely from the findings of the pilot study (Banister et al., 2011a) if these youth were still in the developmental stages of their belief systems. If these youth were in the beginning stages of their belief system, it would be consistent with Fowler's view (1991) that the maturation and experience acquired through aging would move an individual to a higher faith stage. Fowler $(1981,1991)$ indicated that it is unlikely to find a pre-adult in a higher faith stage (stage four, five or six), but more probable that an adult would remain in a lower faith stage (stage one, two or three).

Aside from factor structure, there are two important issues concerning the AUIES-12 that warrant further discussion. The first is the poor internal consistency of both the Extrinsic-Personal and Extrinsic-Social scales. The second is the 
appropriateness of using the AUIES-12 in its original form with both adult and adolescent populations.

First, let us consider the unacceptable scale reliabilities of both the ExtrinsicPersonal and Extrinsic-Social scales. Both the Extrinsic-Personal and Extrinsic-Social scales have been found by Venable (1982), Genia (1993), Gorsuch McPherson (1989) and Banister et al., (2011a) to consistently have low scale reliabilities, indicating that neither extrinsic scale is psychometrically sound and do not allow for valid inferences and reliable scores to be made from them.

Results from Research Question 1-A support these consistent findings that the extrinsic scales hold inadequate reliabilities. Of the two scales used in the AUIES-12 to measure extrinsic religious motivation neither held acceptable reliabilities. The scale reliability of the Extrinsic-Personal scale, a three item scale, was considered questionable $(\alpha=.613)$ and the Extrinsic-Social scale, also a three item scale, had poor internal reliability $(\alpha=.525)$. However only the Intrinsic scale, a six item scale, had acceptable internal reliability $(\alpha=.719)$. These findings were consistent with findings from previous studies that the Intrinsic scale held acceptable reliabilities (Gorsuch \& McPherson, 1989; Gorsuch \& Venable, 1983; Griffin, Gorsuch \& Davis, 1987), but the Extrinsic-Personal and Extrinsic-Social scales had unacceptable reliabilities (Banister et al., 2011a; Genia, 1993; Goursuch \& McPherson, 1989; Venable, 1982). Due to Maltby (1999) not reporting scale reliabilities, it was impossible to compare the scale reliabilities from this dissertation to those of his original study.

A plausible explanation for the low reliabilities of the Extrinsic-Personal and Extrinsic-Social scales of the AUIES-12 lies in understanding that Cronbach's alpha is to 
a degree a function of the number of items in each scale (George \& Mallery, 2003), and each Extrinsic scale is a relatively short scale consisting of only three items each. Thus adding items to each scale will theoretically increase each of the scale reliabilities. Using the Spearman-Brown prophecy it was determined that adding five items to the ExtrinsicPersonal scale and eight items to the Extrinsic-Social scale would bring each scale's internal reliability near .80 . Trimble (1997) reported that doubling each scale would raise the Extrinsic-Personal scale to .78 and .77 for the Extrinsic-Social scale. However, before the pilot study neither scale had been lengthened. A longer scale tends to be more reliable than a shorter version of a scale if the items truly measure a one-dimensional construct. However, if reliabilities remain low even after the addition of similar items than there is an increased likelihood that the scale in question holds a more multidimensional structure than originally conceptualized (Nunnelly \& Bernstein, 1994). Also, let us consider the acceptability of using the AUIES-12 as is (a twelve item measure with three separate factors) with both adult and adolescent populations. If researchers conclude that using the AUIES-12 is acceptable in spite of the consistent findings that the extrinsic scales hold low reliabilities, and a lack of a priori theoretical definitions, they should not assume the factor structure will hold across both adult and adolescent populations. The present dissertation offered empirical support through both PAF and CFA that the factor structure among adults is a three-factor model. However, Banister et al. (2011a) reported that among adolescents a two-factor model was more appropriate. Within the two factor model the Extrinsic-Personal factor found by Maltby (1999) was not retained and the Intrinsic scale as found by Maltby (1999) lost two items, making it a four item scale. Banister et al. (2011a) did not perform a CFA to test the two- 
factor model among adolescents, and further research should be conducted to confirm the factor structure of the AUIES-12 with adolescents.

Regardless of the reason for the low reliability levels of the extrinsic scales (whether they are insufficient due to too few items or rather stemming from a lack of theoretical construction a priori), or the final factor structure of the instrument, from the perspective of practicing and conducting research with psychometrically sound measures, it seems unethical to make any assumptions of the Christian population from use of either of the Extrinsic scales, as found in the AUIES-12, due to their unacceptable reliabilities. As the AUIES-12 stands in its current manifestation as proposed by Maltby (1999), only scores from the Intrinsic scale should be considered reliable, from which the only meaningful data from the AUIES-12 can be drawn.

Tashakkori and Teddlie (1998) stated that the two most important questions to ask concerning measurement of specific constructs through scales are: 1) Do the constructs contain operational definitions that have been developed from theory; and 2) is what is intended to be measured truly being measured (measurement validity)? It appears that the AUIES-12 fails to answer both of these questions in a sufficient manner. At the conclusion of researching Research Question $1 A$ and $1 B$ it was apparent that the AUIES12 , although frequently used in current literature to measure intrinsic/extrinsic religious motivation (e.g., Baker \& Gorsuch, 1982; Benjamins \& Brown, 2004; Brewczynski \& McDonald, 2006: Chatters, 2000; Cohen, 2002; Cohen et al., 2005; D’Onofrio, et al., 1999; Donahue, 1984; Francis \& Kaldor, 2002; Forthun et al., 2003; Genia, 1996; Hackney \& Sanders, 2003; Kendler et al., 1997; Koenig, 1995, 2001; Leak \& Fish, 1989; Leak \& Randall, 1995; Maltby et al., 1999; Park et al., 1990; Pössel et al., 2011; Reyes- 
Ortiz, 2007; Smith et al., 2003; Yeager, 2006), was found to be a deficient instrument that clearly needed further revisions if it was to be used in future research concerning religious motivation. Fortunately, Research Question 2, and the development of the MRM addressed these shortcoming by providing a more reliable instrument that contains a clear factor structure and has a more solid theoretical foundation.

\section{Research Question 2: Determining the Factor Structure of the MRM}

After the findings of Research Question $1 A$ and $1 B$, and conclusions drawn from them, it seemed pertinent to develop a measure of religious motivation that reached beyond the capabilities of the AUIES-12, by constructing a measure that is psychometrically sound and that also attempts to more fully define the underlying theory. The MRM, which was developed by Banister et al. (2011b), provides an improved measure of intrinsic-extrinsic religious motivation by: 1) providing a unique extrinsic construct to be considered; 2) improving internal consistency of all scales (> .7; George $\&$ Mallery, 2003); 3) confirming the four-factor structure using two samples; and 4) further defining the theoretical issues that beset its predecessors. Using CFA, two hypothesized models were tested, revised, and then compared with a different sample. The final model of the MRM incorporate 27 items (including all items from the AUIES12), contains four factors (Extrinsic-Personal, Extrinsic-Rules Keeping, Extrinsic-Social and Intrinsic), is psychometrically sound, and allows for the expansion of the scientific study of religious motivation by improving scale reliabilities and offering a unique type of religious motivation, Extrinsic-Rules Keeping, to be considered. 
The development of the Extrinsic-Rules Keeping scale allows for a more comprehensive investigation of Christian religious motivation, as has been lacking in current non-theory based theories of religious motivation (Batson \& Ventis, 1982; Genia \& Shaw, 1991; Spilka, 1985), by theoretically defining a specific type of extrinsic religious motivation that is unique from the currently researched constructs of extrinsic religious motivation, that can be measured, observed and further researched to explore the relationship between Extrinsic-Rules Keeping religious motivation and its impact on mental and physical well-being. In addition, the development of the Extrinsic-Rules Keeping factor begins to further uncloak the "indiscriminately pro-religious" group identified by Allport and Ross (1967), allowing for the research of an aspect of religious motivation that has been to this point ignored, furthering the ability to scientifically examine religious motivation.

The MRM also has the strength of having its factor structure confirmed by use of split-sample validation. By splitting the dataset and testing the final model of the MRM through CFA using essentially two samples, the likelihood of over fitting the model was decreased (Brown, 2006) and independent validation of the model through two sets of participants was achieved (Tashakkori \& Teddlie, 1998). Considering Maltby's (1999) factor structure of the AUIES-12 had never been confirmed, as well as the criticisms of separating the extrinsic scale into two separate scales, validating the model through splitsample validation is a noteworthy improvement.

In addition to identifying a new type of religious motivation, Extrinsic-Rules Keeping, and validating the factor structure of the MRM through split-sample validation, an important issue that plagued the ROS, the AUIES, and the AUIES-12 was addressed: 
reliabilities of the extrinsic scales. The additional Extrinsic-Personal and Extrinsic-Social items included in the MRM raised the scale reliabilities of the two extrinsic factors of the AUIES-12 to $>.7$. The Extrinsic-Personal scale rose from an unacceptable .613 within the AUIES-12 to .743 within the MRM, and the Extrinsic-Social scale rose from a poor .525 within the AUIES-12 to .806 within the MRM. In addition, the reliability of the Intrinsic scale rose from .719 within the AUIES-12 to .739 within the MRM. The reliability of the Extrinsic-Rules Keeping scale within the MRM was .760, higher than any of the three scales of the AUIES-12 as seen in Research Question 1-A. As shown above, the addition of these items made a significant improvement to the three original scales of the AUIES-12, taking it from a measure where only one (Intrinsic) of three factors could be viewed as reliable, to a measure in the MRM where all scales, including the Extrinsic-Rules Keeping scale, have acceptable reliabilities $(>.7)$ that allowed for valid inferences and reliable scores.

The final issue to discuss is the theoretical support of the Extrinsic-Personal and Extrinsic-Social scales. Although there was no a priori theory given to the ExtrinsicPersonal and Extrinsic-Social factors, seemingly sufficient data has been collected over the past two decades to evidence the existence of two distinct factors that emerge from the concept of extrinsic religious motivation, allowing for a post hoc theory to be constructed. Many studies (e.g., Aydin, 2010; Baker \& Gorsuch, 1982; Benjamins \& Brown, 2004; Brewczynski \& McDonald, 2006; Borynski, 2008; Chatters, 2000; Cohen, 2002; Cohen et al., 2005; Coulter-Kern, 2010; D'Onofrio et al., 1999; Detemtor; 2007; Dezutter, 2006; Donahue, 1984; Flere et al., 2007; Flere \& Lavic, 2006, 2007; Francis \& Kaldor, 2002; Forthun et al., 2003; Genia, 1993, 1996; Gorsuch \& McPherson, 1989; 
Gorsuch \& Venable, 1983; Griffen et al., 1987; Hackney \& Sanders, 2003; Hoge, 1972; Kendler et al., 1997; Kirkpatrick, 1989; Koenig, 1995, 2001; Leak \& fish, 1989; Leak \& Randall, 1995; Lewis \& Cruise, 2005; Lewis et al., 2005; Lillioos, 2010; Maltby et al., 1999; Nelson et al., 2009; Park, Cohen \& Herb, 1990; Pössel et al., 2011; Reyes-Ortiz, 2007; Shreive-Neiger \& Edalstein, 2004; Smith et al., 2003; Trimble, 1987, 1996;

Wenger, 2005; Yeager, 2006) have used the different extrinsic scales and have found that each factor has differing correlations with several psychological, psychosocial, and/or subjective well-being variables, supporting that Extrinsic-Personal and Extrinsic-Social measure two separated constructs. Through factor analysis Kirkpatrick (1989) initially discovered that the extrinsic factor of the ROS was more suitable as a two factor construct, although he was not the first to make this discovery (Hoge, 1972). When Kirkpatrick differentiated between Extrinsic-Social and Extrinsic-Personal religious motivations following factor analysis he described them as two differing categories of religious motivation, both of which contained differing goals that were obtained through distinctively different types of religious motivation. He conceptualized ExtrinsicPersonal as a function of religious belief or participation in religious services/traditions as a mechanism to gain comfort, protection and a sense of security. Extrinsic-Social was conceptualized as a religious motivation that revolved around the goal of gaining social contact, improving social standing and increased social opportunity. Kirkpatrick (1989) reported that individuals that scored highly on the Extrinsic-Personal factor positively correlated with frequency of prayer, suggesting that prayer was used as a coping mechanism and source of personal comfort/security by the Extrinsic-Personal religiously motivated. Kirkpatrick (1989) also reported that individuals that scored highly on the 
Extrinsic-Social factor positively correlated with frequency in church attendance and negatively correlated with frequency of prayer. This was interpreted as those scoring highly on the Extrinsic-Social factor consistently participated in church services/activities, assumedly for social reasons, but did not seek personal gain or comfort through prayer as did the Extrinsic-Personal religiously motivated. These findings support that the Extrinsic-Personal items reflect a religious motivation that is concerned with using religion for security and personal need. Furthermore, the additional Extrinsic-Personal and Extrinsic-Social items that were added to the pilot study (Banister et al., 2011b) were constructed using the definitions provided by Kirkpatrick (1989). As indicated throughout the results and discussion of Research Question 2 the additional items did load with the original items from the two extrinsic factors, providing additional support that these constructs measure two separate types of extrinsic religious motivation; one that is concerned with personal gain and security and one that is concerned with social contact and advancement.

Masters (1991) stated that even though there was no strong a priori theoretical construction of the original Extrinsic-Personal and Extrinsic-Social concepts they should not be discarded as insignificant byproducts of statistical procedure. He asserts that the scientifically unexpected can at times be as important as the expected. In his argument he references Skinner's (1956) belief that when something of interest is uncovered, whether theory was laid down beforehand or not, it is highly important to then diligently study that which is uncovered. This may well be the philosophy that has led over six decades of researchers to continue to research and refine the original intrinsic-extrinsic concepts of Allport and Ross (1967). Masters' (1991) attitude towards the future research 
concerning Extrinsic-Personal and Extrinsic-Social religious motivation is "why not?" If continuing to research these concepts, and adding to them, allows the field to be more precise concerning the study of religious motivation, then it appears beneficial to move forward with the remnants of theory and quality research that does support their use in allowing further expansion of the study of religious motivation.

\section{Research Question 3: Relationship between the Extrinsic-Rules Keeping Scale and Fowler's Theory of Faith Development}

Upon examining the relationship between Extrinsic-Rules Keeping religious motivation and Stage 2 of Fowler's Theory a statistically significant, moderate correlation was found (Table 13). No statistically significant relationship between the Extrinsic-Rules Keeping scale and Stage 3 or Stage 4 of Fowler's theory was found. However, there was a statistically significant negative relationship, albeit small, found between Extrinsic-Rules Keeping and Stage 5. With a small association indicated, this statistically significant relationship could be a result of the large sample size and may hold no practical significance (Kirk, 1996). It is also possible that the statistically significant relationship between Extrinsic-Rules Keeping and Stage 5 of Fowler's theory may be resultant from theoretical reasons. Intuitively, it is understandable that an individual that is in Stage Two of Fowler's theory, seen as a less mature stage of faith, would have a negative association with Stage Five, a mature level of faith where individuals have internalized their belief systems. Thus, one can say, as hypothesized, the Rules-Keeping scale has a statistically significant positive correlation with Stage 2 of Fowler's theory and does not have statistically significant correlations with stages three 
and four of Fowler's theory of faith development. Extrinsic-Rules Keeping does have a statistically significant negative correlation with Stage 5. With such a small proportion of variance being explained (1.9\%), this statistically significant correlation could be due to sample size or due to theoretical factors. This finding endorses the theoretical proposition that the Extrinsic-Rules Keeping scale is consistent with a religious motivation that reflects an individual's concern with following "celestial rules" in order to receive reward and avoid punishment, as described in stage two of Fowler's theory of faith development. Extrinsic-Rules Keeping is a religious motivation that is an exchange based system where one is religiously obedient to the "rules of their religion" in order to receive a "blessing" and avoid punishment for acting in a way that would be contradictory to their religious system, a "Christian karma" of sorts.

Considering other studies findings that indicate that extrinsic religious motivation is consistently found to be a risk factor for a number of psychological maladies (i.e., depression, anxiety), low tolerance (Bergin, Master, \& Richards, 1987; Donahue, 1985), increased dogmatism (Donahue, 1985; Thompson, 1974) and decreased perceived subjective wellbeing (Baker \& Gorsuch, 1982; Byrd, Hageman \& Belle Isle, 2007; George, Ellison \& Larson, 2009; Larson, 2003; McCullough \& Larson, 1999; Maltby et al., 1999; Park et all, 1990; Smith et al., 2003), it would be likely that Extrinsic-Rules Keeping religious motivation would also be a potential risk factor. Extrinsic motivation is a function of secondary reinforcement (Byrd et al., 2007) where an individual participates in religious services or practices for a secondary gain. For example, attending religious services to increase social connections, praying in times of stress to alleviate anxiety, or following religious laws or rules to gain a reward or avoid a 
punishment. Extrinsic-Rules Keeping being a risk factor in the areas where ExtrinsicPersonal and Extrinsic-Social are known to be risk factors would be expected due to the nature of extrinsic religious motivation missing the internal payoff associated with intrinsic religious motivation, and the extrinsically motivated missing out on the positive aspects of their belief systems (Allport \& Ross, 1967).

Extrinsic-Rules Keeping religious motivation does not capture an individual that has internalized their belief system and lives it or someone using religion as a secondary gain of increased social benefit or personal gain. Rather, it identifies an individual that holds low tolerance for "breaking the rules." Such an individual would have increased dogmatism due to inflexibility concerning the observance of their religious rules and laws. Thompson (1974) reported that individuals that fell into the indiscriminately proreligious group when using the ROS demonstrated a higher degree of dogmatism than did those that scored highly on either the intrinsic or extrinsic factors. It is possible that many of these "indiscriminately pro-religious" would be identified through the ExtrinsicRules Keeping scale. Certainly the theory behind the Extrinsic-Rules Keeping scale indicates an individual that would be highly inflexible concerning breaking the rules of their religion, as would one who is highly dogmatic. It would be valuable and appropriate for future research to focus on replicating previous studies that have shown Extrinsic-Personal, Extrinsic-Social, and Intrinsic motivation to be either a risk or protective factor and include the Extrinsic-Rules Keeping factor to determine if it is a risk or a protective factor. It would also be interesting to replicate Thompson's (1974) study with the MRM to find if the Extrinsic-Rules Keeping factor helps in identifying those he found to be "indiscriminately pro-religious." 
Defining Extrinsic-Rules Keeping on solid theoretical footing a priori, and providing evidence that upholds that theory, is a step in the right direction for the further study of religious motivation. Extrinsic-Rules Keeping emerges as the only factor of religious motivation that can make that claim. As discussed previously, ExtrinsicPersonal and Extrinsic-Religious Motivation were constructed through more of a reversed process from that which is typical. Rather than stating theory on the front side and testing it through statistical analysis, they were initially a product of statistical analysis in the beginning and then theoretical construction afterwards. One may use the ExtrinsicRules Keeping factor with confidence that it was constructed on sound theory and then tested statistically, resulting in a reliable scale from which valid inferences can be made. This again sets the Extrinsic-Rules Keeping factor apart.

\section{Summary and Conclusions}

Through both PAF and CFA with two different samples the MRM has been validated and is seen as an appropriate measure to be incorporated into the scientific study of religious motivation. The MRM is a 27 -item measure of religious motivation that combines the three factors of the AUIES-12 with additional items to increase scale reliabilities to acceptable levels ( $>0.7$; George \& Mallery, 2003). Along with the three original factors of the AUIES-12 (Intrinsic, Extrinsic-Personal and Extrinsic-Social) a new fourth factor, Extrinsic-Rules Keeping, has been introduced.

Kahoe and Meadow's (1981) suggested that identifying the factors that made up the "indiscriminate" group would not only enlarge, but benefit the literature concerning intrinsic-extrinsic religious motivation. Identifying Extrinsic-Rules Keeping religious motivation is a response to the need to further define the "indiscriminate" group that was 
identified nearly a half century ago. Trimble (1997) called researchers to identify other types of extrinsic religious motivation to enable a more precise study of the extrinsically motivated. By identifying Extrinsic-Rules Keeping we can more comprehensively identify and study how individuals think differently about religion and what impact those differences have on social interactions and attitudes, psychological variables, health outcomes, views of subjective wellbeing, degrees of meaning in life and ethical behaviors (among other areas). By introducing Extrinsic-Rules Keeping, participants that are not intrinsically religiously motivated have an opportunity to identify with a religious motivation that consists of "rules keeping" to gain a "blessing" or to avoid "condemnation." Before the introduction of Extrinsic-Rules Keeping, religious motivation was only concerned with personal comfort or social gain. Extrinsic-Rules Keeping allows for a type of religious motivation that is neither concerned with social gain or personal comfort. It identifies individuals that would previously have been unidentified, likely falling into the "indiscriminate" group.

Extrinsic-Rules Keeping stands out from the other three types of religious motivation (Intrinsic, Extrinsic-Personal and Extrinsic-Social) as described by Allport (1950), Allport and Ross (1967) and Maltby (1999) in that it was developed on sound theoretical underpinnings. As hypothesized, a significant moderate correlation between Extrinsic-Rules Keeping and stage 2 of Fowler's Theory of Faith Development was discovered. It was hypothesized that this stage of Fowler's theory and Extrinsic-Rules Keeping would have a positive correlation, reflecting a religious motivation that was concerned with obedience to religious rules and systems in exchange for reward or the avoidance of punishment. The other three types of religious motivation were not 
developed on an overarching theory, but have been widely accepted and used in decades of research nonetheless (e.g., Baker \& Gorsuch, 1982; Benjamins \& Brown, 2004; Brewczynski \& McDonald, 2006: Chatters, 2000; Cohen, 2002; Cohen et al., 2005; D’Onofrio et al., 1999; Donahue, 1984; Francis \& Kaldor, 2002; Forthun 2003; Genia, 1996; Hackney \& Sanders, 2003; Kendler 1997; Koenig, 1995, 2001; Leak \& Fish, 1989; Leak \& Randall, 1995; Maltby, 1999; Park et al., 1990; Pössel et al., 2011; Reyes-Ortiz, 2007; Smith, 2003; Yeager, 2006). Allport and Ross (1967) gave operational definitions to the Intrinsic and Extrinsic factors from the original study that spawned the ROS, but these definitions were given ex post facto. Kirkpatrick (1989) followed suit by defining Extrinsic-Personal and Extrinsic-Social after he believed there were statistical reasons to do so. There was no theoretical hypothesization a priori.

The development of the MRM, along with the addition of the Extrinsic-Rules Keeping scale, is a move in advancing the study of religious motivation by providing an instrument from which valid inferences can be made and provides a scale that has a clearly defined theory and an understandable definition of a specific type of religious motivation (Extrinsic-Rules Keeping). Considering the evidence offered through this dissertation it appears that many of the studies that have used the ROS, AUIES, and/or AUIES-12 to measure intrinsic/extrinsic religious motivation likely did so with a measure that was not psychometrically sound and likely not suitable to make valid inferences from their use. Therefore, it would be beneficial to replicate studies concerning intrinsic/extrinsic religious motivation with the MRM. The MRM holds sound psychometric properties, scales with acceptable reliability, and a fourth factor, ExtrinsicRules Keeping, to be considered in future research of intrinsic-extrinsic religious 
motivation. The Intrinsic, Extrinsic-Personal, and Extrinsic-Social scales have been expanded upon and further defined with added scale items that have increased the scale reliabilities, making them useful in research.

\section{Limitations and Future Direction}

A limitation of this study concerns the sample used. Ideally, a greater degree of non-Caucasian participants would have been included. However, even after attempts to reach non-Caucasian participants through minority groups and organizations, there was a larger degree of Caucasian respondents used in the study. A replication of this study using a more ethnically diverse sample would be beneficial in ensuring that any ethnic component concerning religious motivation is fully considered. Ghorpade, Lackritz, and Sing, (2006) found that there were statistically significant differences concerning intrinsic religious motivation between African Americans, Asian Americans, Latinos, and Fillipinos. However, due to the low volume of participants from these minority groups this dissertation was unable to replicate this study to confirm or refute Ghorpade et al's (2006) findings. The lower percentage of minorities that participated in the study is concerning in terms of sampling bias, with the possibility that the sample is not completely representative of the entire population, in turn limiting the generalizability from the sample to the entire population, allowing for diminished external validity (Black, 1999).

It should further be noted that the sample used was comprised of volunteer consenters, making it a convenience sample. This again opens the door for criticism concerning sampling bias and the possibility that the sample is not actually representative 
of the entire population, again limiting the generalizability from the sample to the entire population, allowing for diminished external validity (Black, 1999). It is unknown what characteristic difference may exist between consenters and non-consenters, or how this may affect the results in this dissertation. With the large amount of participants drawn through social-media, participants were required to have memberships to the socialmedia sites and have access to a computer with internet access. Sampling bias could be minimized in a replicated study by collecting a sample with a greater number of participants using a mixed mode of data collection methods (i.e., online surveys, inperson data collection, phone-based surveys). This data collection strategy may draw a more representative sample of the overall population.

Concerning future direction, the Extrinsic-Rules Keeping factor should be used in research concerning its potential as a risk factor in regards to mental health. Research has shown that extrinsic religious motivation has historically been a risk factor (George et al., 2009; Larson, 2003; McCullough \& Larson, 1999; Maltby et al., 1999; Smith et al., 2003). However, additional research would be needed to speak further on what role Extrinsic-Rules Keeping motivation plays in ones mental health. Also, it would be advantageous to perform a CFA of the four-factor model of the MRM with an adolescent sample. Such a study would provide the information needed for the determination of if the current model of the MRM is appropriate to be used with an adolescent sample. It would also be advantageous to modify and validate a version of the MRM to fit different world religions. This would allow for the comparison of different religions to explore if they hold similar risk/protective factors as found in studying intrinsic-extrinsic religious motivation among Christians. By validating the MRM to be used in religious populations 
beyond Westernized Christianity, researchers can identify how motivation within multiple religious systems may impact the multitude of variables that have been identified over the course of this dissertation. 


\section{REFERENCES}

Akaike, H. (1987). Factor analysis and AIC. Psychometrika, 52, 317-332.

Allport, G. W. (1950). The individual and his religion. New York: McMillan.

Allport, G. W. \& Ross, M. J. (1967). Personal religious orientation and prejudice. Journal of Personality and Social Psychology, 5, 432-443.

Aydin, N., Fischer, P., \& Frey, D. (2010). Turning to God in the face of ostracism: Effects of social exclusion on religiousness. Personality and Social Psychology Bulletin, 36, 742-753.

Baker, M., \& Gorsuch, R. (1982). Trait anxiety and intrinsic-extrinsic religiousness. Journal for the Scientific Study of Religion, 21, 119-122.

Banister, A.W., Pössel, P., \& Adelson, J. (2011a). The development of the Measure of Religious Motivation (MRM). Unpublished manuscript.

Banister, A.W., Pössel, P., \& Adelson, J. (2011b). The development of the Measure of Religious Motivation (MRM). . Unpublished manuscript.

Barnes, M., Dennis, D., \& Johnson, B. (1989). The formulation of a Fowler scale: An empirical assessment among Catholics. Review of Religious Research, 30, 412420.

Batson, C.D., \& Ventis, W.L. (1982). The religious experience: A social-psychological perspective. New York: Oxford University Press. 
Batson, C.D., \& Gray, R.A. (1981). Religious orientation and helping behavior:

Responding to one's own to the victim's needs? Journal of Personality and Social Psychology, 40, 511-520.

Benjamins, M. R., \& Brown, C. (2004). Religion and preventative health care utilization among the elderly. Social Science \& Medicine, 58, 109-118.

Benson, P.L. (2004). Emerging themes in research on adolescent spiritual and religious development. Applied Developmental Science, 8, 47-50.

Bentler, P.M. (1990). Comparative fit indexes in structural models. Psychological Bulletin, 107, 238-246.

Bergin, A., Masters, K., Richards, P. (1987). Religiousness and mental health reconsidered: A study of an intrinsically religious sample. Journal of Counseling Psychology, 34, 197-204.

Bergman, R. (2002). Why be moral? A conceptual model from developmental psychology. Human Development, 45, 104-124.

Black, T. R. (1999). Doing quantitative research in the social sciences: An integrated approach to research design, measurement, and statistics. Thousand Oaks, CA: SAGE Publications, Inc.

Borynski, M. L. (2008). Factors related to reductions in alcohol consumption among college students: The role of religious involvement. Current Psychology, 22, 138148.

Brewczynski, J., \& MacDonald, D.A., (2006). Confirmatory factor analysis of the Allport and Ross Religious Orientation Scale with a Polish sample. The International Journal for the Psychology of Religion, 16, 63-76. 
Brown, T. A. (2006). Confirmatory factor analysis for applied research. New York: Guilford Press.

Browne, M.W. \& Cudeck, R. (1993). Alternative ways of assessing model fit. In Bollen, K.A. \& Long, J.S. [Eds.] Testing structural equation models. Newbury Park, CA: Sage, 136-162.

Cattell, R.B. (1966). The scree test for the number of factors. Multivariate Behavioral Research, 1, 245-276.

Chatters, L.M. (2000). Religion and health: Public health research and practice. Annual Review of Public Health, 21, 335-367.

Clay, R.A. (1996, August). Psychologists' faith in religion continues to grow. $A P A$ Monitor, 27(8), 1.

Cohen, J (1992). "A power primer". Psychological Bulletin, 112, 155-159.

Cohen, A.B. (2002). The importance of spirituality in the well-being of Jews and Christians. Journal of Happiness Studies, 3, 287-310.

Cohen, A.B., Pierce, J.D., Chambers, J., Meade, R., Gorvine, B.J., \& Koenig, H.G. (2005). Intrinsic and extrinsic religiosity, belief in the afterlife, death anxiety, and life satisfaction in young Catholics and Protestants. Journal of Research in Personality, 39, 307-324.

Colby, A., and Damon, W. (1983). Listening to a different voice. Merrill-Palmer Quarterly, 29,

$473-481$. 
Colby, A., Kohlberg, L., Gibbs, J., \& Lieberman, M. (1983). A longitudinal study of moral development. Monographs of the Society for Research in Child Development, 48, (1-2, Serial No. 200).

Comrey, A. L. and Lee, H. B., (1992), A First Course in Factor Analysis, Hillsdale, New Jersey: Erlbaum.

Crain, W. (2005). Theories of Development: Concepts and Applications, $5^{\text {in }}$ ed. Prentice Hall.

D’Onofrio, B.M., Murrelle, L., Eaves, L.J., McCullough, M.E., Landis, J.L., \& Maes, H.H. (1999). Adolescent religiousness and its influence on substance use: Preliminary findings from the Mid-Atlantic School Age Twin Study. Twin Research, 2, 156-168.

Dittes, J.E. (1969). Psychology of Religion. In G. Lindzey \& E. Aronson (Eds.), The handbook of social psychology. Reading, MA: Addison-Wesley.

Donahue, M.J. (1985). Intrinsic and extrinsic religiousness: Review and meta-analysis. Journal of Personality and Social Psychology, 48, 400-419.

Dorahy, M. J., Lewis, C. A., Schumaker, J. F., Akuamoah-Boateng, R., Duze, M. C., \& Sibiya, T. E. (1998). A cross-cultural analysis of religion and life satisfaction. Mental Health, Religion and Culture, 1, 37-43.

Duriez, B., \& Soenens, B. (2006). Religiosity, moral attitudes and moral competence: A critical investigation of the religiosity-morality relation. International Journal of Behavioral Development, 30, 76-83. 
Duzutter, J., Soenens, B., \& Hutsebaut, D. (2006). Religiosity and mental health: A further exploration of the relative importance of religious behaviors vs. religious attitudes. Personality and Individual Differences, 40, 807-818.

Eisenberg, N. (1995). Prosocial development: A multifaceted model. In W.M. Kurtines \& J.L. Gewirtz (Eds.), Moral development: An introduction (pp. 401-429). Boston: Allyn \& Bacon.

Ellis, A. (1983). The Case Against Religiosity. New York: Institute for Rational-Emotive Therapy.

Ellis, A. (2000). Can Rational Emotive Behavior Therapy (REBT) be effectively used with people who have devout beliefs in God and religion? Professional Psychology: Research and Practice, 31, 29-33.

Erikson, E.H. (1963). Childhood and society. New York: Norton.

Flere, S.J. \& Lavric, M. (2008). Is intrinsic religious orientation a culturally specific American Protestant concept? The fusion of intrinsic and extrinsic religious orientation among non-protestants. European Journal of Social Psychology, 38, $521-530$.

Forthun, L.F., Pidcock, J.L., \& Fischer, J.L. (2003). Religiousness and disordered eating: Does religiousness modify family risk? Eating Behaviors, 4, 7-26.

Fowler, J. (1981). Stages of faith. San Francisco: Harper and Row.

Fowler, J. W. (1987). Faith Development and Pastoral Care. Philadelphia: Fortress Press. 
Fowler, J. W. (1991). Stages in Faith Consciousness. In F. K. Oser \& W. G. Scarlett (Eds.), Religious Development in Childhood and Adolescence (pp. 27-45). San Francisco: Jossey-Bass.

Fowler, J. W. \& Dell, M. L. (2004). Stages of Faith and Identity: Birth to Teens. Child \& Adolescent Psychiatric Clinics of North America, 13, 17-33.

Fowler, J., Streib, H., \& Keller, B. (2004). Manual for faith development research. Atlanta: Center for Research in Faith and Moral Development.

Frame, M. (2003). Integrating religion and spirituality into counseling. Pacific Grove, CA: Brooks/Cole.

Francis, L.J., \& Kaldor, P. (2002). The relationship between psychological well-being and Christian faith and practice in an Australian population sample. Journal for the Scientific Study of Religion, 41, 179-184.

Freud, S. (1939). Moses and Monotheism. London: Hogarth Press.

Gartner, J., Larson, D.B., \& Allen, G.D. (1991). Religious commitment and mental health: A review of the empirical literature. Journal of Psychology and Theology, $19,6-25$.

Gathman, A. C. \& Nessan, C. L. (1997). Fowler's Stages of Faith Development in an Honors Science-and-Religion Seminar. Zygon, 32, 407-414.

Genia, V. (1990). Religious development: A synthesis and reformulation. Journal of Religion and Health, 29, 85-99.

Genia, V. (1995). Counseling and psychotherapy of religious clients: A developmental approach. Westport, CT: Praeger. 
Genia, V. (1996). I, E, Quest, and fundamentalism as predictors of psychological and spiritual well-being. Journal for the Scientific Study of Religion, 35, 56-64.

Genia, V. \& Shaw, D.G. (1991). Religion, intrinsic/extrinsic orientation, and depression. Review of Religious Research, 32, 274-283.

George, L. K., Ellison, G. C., \& Larson, D. B. (2009). Explain the relationships between religious involvement and health. Psychological Inquiry, 13, 190-200.

Gibson, T. S. (2004). Proposed levels of Christian maturity. Journal of Psychology and Theology, 32, 395-304.

Gilligan, C. (1982). In a different voice: Psychological theory and women's development. Cambridge: Harvard University Press.

Glover, R.J. (1997). Relationships in moral reasoning and religion among members of conservative, moderate, and liberal religious groups. The Journal of Social Psychology 137, 247-254.

Gold, J. M. (2010). Counseling and spirituality: Integrating spiritual and clinical orientations. Upper Saddle River, NJ: Pearson Education.

Gorsuch, R.L. (1988). Psychology of religion. Annual Review of Psychology, 39, 201221.

Gorsuch, R.L. \& McPherson, S.E. (1989). Intrinsic/extrinsic measurement; I-E revised and single item scales. Journal for the Scientific Study of Religion, 28, 348-354.

Gorsuch, R.L. \& Venable, G.D (1983). Development of an "Age Universal” I-E Scale. Journal for theScientific Study of Religion, 22, 181-187.

Greeno, G.C. \& Maccoby, E.E. (1986). How different is the "Different Voice"? Signs, $11,310-316$. 
George, D., \& Mallery, P. (2003). SPSS for Windows step by step: A simple guide and reference. 11.0 update $\left(4^{\text {th }}\right.$ edition). Boston: Allyn \& Bacon.

Hackney, C.H., \& Sanders, G.S. (2003). Religiosity and mental health: A meta-analysis of recent studies. Journal for the Scientific Study of Religion, 42, 43-55.

Hayton, J.C., Allen, D.G., \& Scarpello, V. (2004). Factor retention decisions in EFA: A tutorial on parallel analysis. Organizational Research Methods, 7, 191-205.

Hernandez, K.M. (2006). Spirituality and moral development among students at a Christian College. Spirituality and Moral Development, 5, 41-46.

Hill, P.C., \& Hood, R.W. (1999). Measures of Religiosity. Birmingham: Religious Education Press.

Hill, P.C., Pargament, K.I., Hood, R.W., McCullough, M.E., Swyers, J.P., \& Larson, D. (2000). Conceptualizing religion and spirituality: Points of commonality, points of departure. Journal for the Theory of Social Behaviour, 30, 51-77.Hu, L. \& Bentler, P. (1999). Cutoff criteria for fit indices in covariance structure analysis: Conventional criteria versus new alternatives. Structural Equation Modeling, 6, 155.

Huber, S., Reich, K.H., \& Schenker, D. (2003). Studying empirically religious development: Interview, repertory grid, and specific questionnaire techniques. Arhiv für Religionspsychologie, 24, 180-201.

Idler, E.L. (1987). Religious involvement and the health of the elderly: Some hypotheses and an initial test. Social Forces, 66, 226-238.

Jennrich, R. I., \& Sampson, P. F. (1966). Rotation for simple loadings. Psychometrika, 32, 313-323. 
Johnson, D.P., \& Mullins, L.C. (1989). Religiosity and loneliness among the elderly. Journal of Applied Gerontology, 8, 110-131.

Jöreskog, K.G. (1969). A general approach to confirmatory maximum likelihood factor analysis. Psychometrika, 34, 183-202.

Jorgensen, G. (2006). Kohlberg and Gilligan: duet or duel? The Journal of Moral Education, 35, 179-196.

Jung, C. (1933). Modern Man in Search of a Soul. New York: Hartcourt, Brace and World.

Kahoe, R.D. (1985). The development of intrinsic and extrinsic religious orientations. Journal for theScientific Study of Religion, 24, 408-412.

Kahoe, R.D. \& Meadow, M.J. (1981). A developmental perspective on religious orientation dimensions. Journal of Religion and Health, 20, 8-17.

Kaiser, H. F. (1960). The application of electronic computers to factor analysis. Educational and Psychological Measurement, 20, 141-151.

Kendler, K.S., Gardner, C.O., Prescott, C.A. (1997) Religion, psychopathology, and substance use and abuse; a multi-measure, genetic-epidemiologic study. American Journal of Psychiatry, 154, 322-329.

Kirk, R. E. (1996). Practical significance: A concept whose time has come. Educational and Psychological Measurement, 56, 746-759.

Kirkpatrick, L. (1989). A psychometric analysis of the Allport, Ross, and Feagin measures of intrinsic and extrinsic religious orientation. Research in the Social Scientific Study of Religion, 1, 1-31. 
Kirkpatrick, L.A., \& Hood, R.W. (1990). Intrinsic-extrinsic religious orientation: The boon or bane of contemporary psychology of religion. Journal for the Scientific Study of Religion, 29, 442-462.

Kline, R. B. (2010). Principles and practice of structural equation modeling (3rd ed.). New York: The Guildford Press.

Koenig, H.G. (1995). Use of acute hospital services and mortality among religious and non-religious copers with medical illness. Journal of Religious Gerontology, 9, 121.

Koenig, H.G., Larson, D.B., \& Larson, S.S. (2001). Religion and coping with serious medical illness. Annals of Pharmacotherapy, 35, 352-359.

Koenig, H.G., McCullough, M.E., and Larson, D.B. (2001). Handbook of Religion and Health. New York: Oxford University Press.

Kohlberg, L.R. (1958). The Development of Modes of Thinking and Choices in Years 10 to 16. Ph.D. Dissertation, University of Chicago.

Kohlberg, L.R. (1963). The development of children's orientations toward a moral order: Sequence in the development of moral thought. Vita Humana, 6, 11-33.

Kohlberg, L.R. (1966). Moral education in the schools: A developmental view. The School Review, 74, 1-30.

Kohlberg, L. (1984). The essay in moral development. Psychology of Moral

Development, 2. New York, NY: Harper \& Row.

Kohlberg, L.R. (1969). Stages in the development of moral thought and action. New York: Holt, Rinehart \& Winston.

Kohlberg, L.R. (1981). Essays on Moral Development. San Francisco: Harper \& Row. 
Kohlberg, L.R., \& Gilligan, C. (1971). The adolescent as the philosopher. The discovery of the self in a postconventional world. Daedahus, 100, 1051-1086.

Kohlberg, L.R., \& Kramer, J. (1969). Continuities and Discontinuities in childhood and adult moral development. Human Development, 1, 92-120.

Kohlberg, L.R., LeVine, C., \& Hewer, A. (1983). Moral Stages: The Current Formulation of Kohlberg's Theory and a Response to Critics. Basel: Karger.

Kohlberg, L.R., \& Turiel, E. (1972). Moralization, the Cognitive-Developmental Approach. New York; Holt, Rinehart \& Winston.

Lambert, N.M., Dollahite, D.C. (2006). How religiosity helps couples prevent, resolve, and overcome marital conflict. Family Relations, 55, 439-449.

Larson, D. B. (2003). Spirituality's potential relevance to physical and emotional health: A brief review of quantitative research. Journal of Psychology and Theology, 31, $37-51$.

Leak, G.K. (2009). An assessment of the relationship between identity development, faith development, and religious commitment. Identity, 9, 201-218.

Leak, G.K., \& Fish, S.B. (1999). Development and initial validation of a measure of religious maturity. International Journal of Psychology and Religion, 9, 83-103.

Leak, G. K., Louks, A. A., \& Bowlin, P. (1999). Development and Initial Validation of an Objective Measure of Faith Development. International Journal for the Psychology of Religion, 9, 105-124.

Leak, G.K., \& Randall, B. A. (1995). Clarification of the link between right-wing authoritarianism and religiousness: The role of religious maturity. Journal for the Scientific Study of Religion, 34, 245-252. 
Ledesma, R.D., \& Valero-Mora, P. (2007). Determining the number of factors to retain in EFA: An easy-to-use computer program for carrying out Parallel Analysis. Practical Assessment Research \& Evaluation, 12, 1-12. Available online: http://pareonline.net/getvn.asp? $v=12 \& n=2$

Leong, F.T. \& Zachar, P. (1990). An evaluation of Allport's religious orientation scale across one Australian and two United States samples. Educational and Psychological Measurement, 50, 359-368.

Lewis, C. A. \& Cruise, S. M. (2006). Religious and happiness: Consensus, contradictions, comments and concerns. Mental Health, Religion \& Culture, 9, 213-225.

Lewis, A.L., Maltby, J., \& Day, L. (2005). Religious orientation, religious coping and happiness among UK adults. Personality and Individual Differences, 38, 11931202.

Lownsdale, S. (1997). Faith Development Across the Life Span: Fowler's Integrative Work. Journal of Psychology and Theology, 25, 49-63.

McClure, R.F., \& Loden, M. (1982). Religious activity, denomination membership and life satisfaction. Psychology: A Quarterly Journal of Human Behavior, 9(4), 1217.

McCullough, M. E. \& Larson, D. B. (1999). Religion and depression: A review of the literature. Twin Research, 2, 126-136.

McDonald, R.P. \& Marsh, H.W. (1990). Choosing a multivariate model: Noncentrality and goodness of fit. Psychological Bulletin, 107, 247-255. 
McIver, J. P., \& Carmines, E. G. (1981). Unidimensional scaling. Thousand Oaks, CA: Sage.

Maltby, J. (1999). The internal structure of a derived, revised, and amended measure of the religious orientation scale: The 'Age-Universal' I-E Scale-12. Social Behavior and Personality, 27, 407-412.

Maltby, J. (2002). The Age Universal I-E Scale-12 and orientation toward religion: Confirmatory factor analysis. The Journal of Psychology: Interdisciplinary and Applied, 136, 555-560.

Maltby, J., \& Lewis, C.A. (1996). Measuring intrinsic and extrinsic orientation toward religion: Amendments for its use among religious and non-religious samples. Personality and Individual Differences, 21, 937-946.

Maltby, J., Lewis, C.A., \& Day, L. (1999). Religious orientation and psychological wellbeing-The role of the frequency of personal prayer. British Journal of Health Psychology, 4, 363-378.

Maltby, J., McCollam, P., \& Millar, D. (1994). Religiosity and obsessionality: A refinement. Journal of Psychology, 128, 609-611.

Masters, K. S. (1991). Of boons, banes, babies, and bath water: A reply to the Kirkpatrick and Hood discussion of intrinsic-extrinsic religious orientation. Journal for the Scientific Study of Religion, 30, 312, 317.

Meyerson, P. \& Tryon, W.W. (2003). Validating internet research: A test of the psychometric equivalence of internet and in-person samples. Behavior Research Methods, Instruments, \& Computers, 35, 614-620. 
Muss, R. E. (1988). The feminist perspective: Carol Gilligan's revised theory of sex differences in moral reasoning. In Theories of adolescence. (pp. 224-237). New York, NY: McGraw Hill.

Narvaez, D. (in press). The Neo-Kohlbergian Tradition and Beyond: Schemas, Expertise and Character. In C. Pope-Edwards \& G. Carlo (Eds.), Nebraska Symposium on Motivation, Vol. 51: Moral Motivation through the Lifespan. Lincoln, NE: University of Nebraska Press.

Nelson, C., Jacobson, C., Weinberger, M., Bhaskaran, V., Breibart, W., \& Roth, A. (2009). The role of spirituality in the relationship between religiosity and depression in prostate cancer. Annals of Behavioral Medicine, 38, 105-114.

Nunnally, J. C., \& Bernstein, I. H. (1994). Psychometric theory (3rd ed.). New York: McGraw-Hill.

O'Conner, B.P. (2000). SPSS and SAS programs for determining the number of components using parallel analysis and Velicer's MAP test. Behavior Research Methods. Instrumentation, and Computers, 32, 396-402.

Paloutzian, R.F., \& Park, C.L. (2005). Handbook of the Psychology of Religion and Spirituality. New York: Guilford Press.

Pargament, K.I. (1999). The psychology of religion and spirituality? Yes and no. International Journal for the Psychology of Religion, 9, 3-16.

Park, C., Cohen, L. H. \& Herb, L. (1990). Intrinsic religiousness and religious coping as life stress moderators for Catholics versus Protestants. Journal of Personality and Social Psychology, 59, 562-574.

Parker, S. (2010). Research in Fowler's faith development theory: A review article. 
Review of Religious Research, 51, 233-252.

Piaget, J. (1948). The Moral Judgment of the Child. Glencoe, IL; Free Press.

Pössel, P., Martin, N.C., Garber, J., Banister, A.W., \& Pickering, N.K. (2011).

Bidirectional Relations of Religious Orientation and Depressive Symptoms in Adolescents: A Short-Term Longitudinal Study. Psychology of Religion and Spirituality, 3, 24-38.

Preacher, K.J., \& MacCallum, R.C. (2003). Repairing Tom Swift's electric factor analysis machine. Understanding Statistics, 2, 13-43.

Rest, J. (1986). In Rest, J. (Ed.) Moral development: Advances in research and theory (pp. 1-39). Boston: Praeger Publishers.

Rest, J., Thoma, S. J., \& Edwards, L. (1997). Devising and validating a measure of moral judgment: Stage preference and stage consistency approaches. Journal of Educational Psychology, 89, 5-28.

Reyes-Ortiz, C.A., Pelaez, M., Koenig, H.G., \& Mulligan, T. (2007). Religiosity and selfrated health among Latin American and Caribbean elders. International Journal of Psychiatry in Medicine, 37, 425-443.

Riva, G., Teruzzi, T., \& Anolli, L. (2003). The use of the internet in psychological research: Comparison of online and offline questionnaires. CyberPsychology and Behavior, 6, 73-80.

Rudasill, K.M., \& Callahan, C.M. (2008). Psychometric characteristics of the Harter Self -Perception Profiles for Adolescents and Children for use with gifted populations. Gifted Child Quarterly, 52, 70-86.

Rychlak, J.F. (1977). The psychology of rigorous humanism. New York: The Free Press. 
St. George, A., \& McNamara, P.H. (1984). Religion, race and psychological well-being. Journal for the Scientific Study of Religion, 23, 351-363.

Sapp, G.L., \& Gladding, S.T. (1989). Correlates of religious orientation, religiosity and moral judgment. Counseling and Values, 33, 140-145.

Schapman, A.M., \& Inderbitzen-Nolan, H. M. (2002). The role of religious behavior in adolescent depressive and anxious symptomology. Journal of Adolescence, 25, 631-643.

Schlaefli, A., Rest, J.R., \& Thoma, S.J. (1985). Does moral education improve moral judgment? A meta-analysis of intervention studies using the Defining Issues Test. Review of Educational Research, 55, 319-352.

Shreve-Neiger, A. K. \& Edalstein, B. A. (2004). Religion and anxiety: A critical review of the literature. Clinical Psychology Review, 24, 379-397.

Siegel, K., Anderman, S.J, \& Schrimshaw, E.W. (2001). Religion and coping with healthrelated stress. Psychology and Health, 16, 631-653.

Skinner, B. F. (1956). A case history in scientific method. American Psychologist, 11, 221-233.

Smith, T.B., McCullough, M.E., \& Poll, J. (2003). Religiousness and depression: Evidence for a main effect and the moderating influence of stressful life events. Psychological Bulletin, 129, 614-636

Spector, P. (1992). Summated rating scale construction. Thousand Oaks, CA: Sage. Spilka, B., R.W. Hood, and R. L. Gorsuch. 1985. The psychology of religion: An empirical approach. Englewood Cliffs, NJ: Prentice Hall. 
Spilka, B., Kojetin, B., \& McIntosh, D. (1985). Forms and measures of personal faith: Questions correlates and distinctions. Journal for the Scientific Study of Religion, $24,437-442$.

Straughan, H.H. (2002). In Hugen, B. \& Scales, T. (Eds.) Christianity and Social Work. Spiritual Development: Readings on the integration of Christian faith and social work practice (pp. 145-165). Botsford, CT.

Streib, Heinz. 2002. Faith development at twenty years. In Faith Development and Public Life, ed. Rick Osmer and Friedrich Schweitzer. St Louis, MO: Chalice Press.

Stevens, J. (2002). Applied Multivariate Statistics for the Social Sciences. New Jersey: Psychology Press.

Subbotsky, E. (2000). Phenomalistic Perception and Rational Understanding in the Mind of an Individual: A Fight for Dominance. In K. S. Rosengren, C. N. Johnson, \& P. L. Harris (Eds.), Imagining the Impossible: Magical, Scientific, and Religious Thinking in Children (pp. 35-74). New York: Cambridge University Press. Tashakkori, A. \& Teddlie, C. (1998). Mixed Methology: Combining Qualitative and Qualitative Approaches. Thousand Oaks, CA: SAGE Publications, Inc.

Thompson, A. D. (1974). Open-mindedness and indiscrimination antireligious orientation. Journal for the Scientific Study of Religion, 13, 471-477.

Trimble, D. E. (1997). The Religious Orientation Scale: Review and meta-analysis of social desirability effects. Educational and Psychological Measurment, 57, 970986.

Turiel, E. (1983). The development of social knowledge: Morality and convention. Cambridge, England: Cambridge University Press. 
Turiel, E. (1997). The development of morality. In W. Damon (Ed.), Handbook of child psychology (Fifth Edition), Vol. 3. In N. Eisenberg (Ed.), Social, emotional, and personality development, Chapter 13. New York: Wiley.

Vine, I. (1986). Moral maturity in a socio-cultural perspective; Are Kohlberg's stages universal? In S. Modgil \& C. Mogdil (Eds.), Lawrence Kohlberg: Consensus and controversy (430-450). London: The Falmer Press.

Walker, L. (1984). Sex differences in the development of moral reasoning: A critical review. Child Development, 55, 667-691.

Walker, L., \& Taylor, J.H. (1991). Family interactions and the development of moral reasoning. Child Development, 62, 264-283.

Wallwork, E. (1980). Morality, religion, and Kohlberg's theory. In Munsey, B. (Ed.), Moral development, moral education, and Kohlberg: Basic issues in philosophy, psychology, religion, and education (pp. 269-297). Birmingham, AL: Religious Education Press.

Weaver, A.J., Pargament, K.I., Flannelly, K.J., \& Oppenheimer, J.E. (2006). Trends in the scientific study of religion, spirituality, and health: 1965-2000. Journal of Religion and Health, 45, 208-214.

Wenger, J. L. (2005). Religious individuals: Evaluating their intrinsic awareness and extrinsic motivations at the implicit level of awareness. The Journal of Social Psychology, 145, 5-16.

White Jr., R.D. (1999). Are women more ethical? Recent findings on the effects of gender upon moral development. Journal of Public Administration Research and Theory, 3, 459-471. 
Worthington, E. L. Jr. (1989). Religious faith across the life span: Implications for counseling and research. The counseling Psychologist, 17, 555-612.

Yeager, D.M., Gleia, D.A., Melanie, A., Lind, H.S., Sloane, R.P., \& Weinsteinf, M. (2006). Religious involvement and health outcomes among older persons in Taiwan. Social Science \& Medicine , 63, 2228-2241.

Zinnbauer, B., Pargament, K.I., Cole, B., Rye, M., Butter, E., Belavich, T., Hipp, K.M., Scott, A.B., and Kadar, J.L. (1997). Religion and spirituality: Unfuzzying the fuzzy. Journal for the Scientific Study of Religion, 36, 549-564.

Zwick, W.R., \& Velicer, W.F. (1986). Factors influencing five rules for determining the number of components to retain. Psychological Bulletin, 99, 432-442. 


\title{
CURRICULUM VITAE
}

\author{
Aaron W. Banister \\ Schneck Medical Center \\ 411 West Tipton Street \\ Seymour, IN 47274
}

Tel-812-522-5739

Fax-812-522-5615

\section{EDUCATIONAL HISTORY}

09/2007 - Present Doctoral Candidate, Counseling Psychology

Department of Educational and Counseling Psychology

College of Education and Human Development

University of Louisville, Louisville, KY

01/2006 - 05/2008 Master of Education, Counseling Psychology

Department of Educational and Counseling Psychology

College of Education and Human Development

University of Louisville, Louisville, KY

09/1991 - 05/1996 Bachelor of Science, Biblical Studies \& Education

Johnson Bible College, Knoxville, TN

\section{SUPERVISED TRAINING AND CLINICAL EXPERIENCE}

10/2011 - Present Fellow in Health Psychology and Behavioral Medicine Schneck Medical Center, Seymour IN

Supervisor: Brenda Smith, Psy.D.

08/2010-8/2011

Psychology

\section{APA Accredited Predoctoral Internship in Professional \\ University of Notre Dame \\ University Counseling Center, University of Notre Dame, Notre Dame, IN}


Specialization: Mind/Body Therapeutic Approaches

Training Director: Maureen Lafferty, Ed.D.

Supervisors: Peter Barnes, Ph.D., Karen Baer-Barkley, Ph.D., Rita Donley, Ph.D., Wendy Settle, Ph.D.

\author{
09/2008 - 05/2010 Advanced Practicum Counselor \\ University Counseling Center \\ University of Louisville Student Counseling Center, Louisville, \\ KY \\ Supervisor: Terri White, Ph.D.
}

09/2008 - 05/2010 Practicum Supervisor

Department of Educational and Counseling Psychology

College of Education and Human Development

University of Louisville, Louisville, KY

Supervisor: Nancy Cunningham, Ph.D.

$09 / 2008-12 / 2008$

Advanced Practicum Counselor

Pediatric Assessment

Weisskopf Child Evaluation Center, Louisville, KY

University of Louisville Medical School, Dept. of Pediatrics

Supervisor: Eva Markham, Ph.D.

\author{
09/2007 - 08/2008 Advanced Practicum Counselor \\ Urban Community Women's Mental Health Practicum \\ Nechole's Place, Louisville, KY \\ Lifehouse Maternity Center, Louisville, KY \\ Supervisors: James Kassel, Psy.D., Dennis Kauffman, Ph.D. \\ 05/2007-08/2007 Practicum Counselor \\ Rural Community Mental Health Practicum \\ Samaritan Behavioral Healthcare, Scottsburg, IN \\ Supervisor: Kathleen Kirby, Ph.D.
}


05/2007-08/2007 Practicum Counselor

Assessment Practicum

Wellstone Regional Hospital, Jeffersonville, IN

Supervisor: Kathleen Gallagher, Psy.D.

TEACHING EXPERIENCE

01/2007-05/2007 Graduate Instructor

Department of Educational and Counseling Psychology

University of Louisville

Course Taught: Introduction to Counseling and Psychotherapy

(Graduate students)

\section{RESEARCH EXPERIENCES}

08/2007-07/2010 Research Team Member

Department of Educational and Counseling Psychology

University of Louisville

Research Mentor: Patrick Pössel, Ph.D.

Responsibilities: Assisted in design and implementation of quantitative research, data collection, and reviewed current literature.

09/2006-05/2007 Research Team Member

Department of Educational and Counseling Psychology

University of Louisville

Research Mentor: Michael Steger, Ph.D.

Responsibilities: Assisted in design and implementation of quantitative research, data collection, and reviewed current literature.

05/2005 - 7/2010 Graduate Research Assistant

National Research Center on Career and Technical Education University of Louisville

Research Mentor: Jeff Valentine, Ph.D.

Responsibilities: Assisted in meta-analysis projects, as well as research various quantitative research projects. 


\section{PUBLICATIONS \& PAPERS}

Valentine, J. C., Hirschy, A., S., Bremer, C., Novillo, W., Castellano, M., \& Banister, A.W. (2011). Keeping at-risk students in school: A systematic review of college retention programs. Educational Evaluation and Policy Analysis.

Pössel, P., Martin, N.C., Garber, J., Banister, A.W., \& Pickering, N.K. (2010). Bidirectional relations of religious orientation and depressive symptoms in adolescents: a short-term longitudinal study. Psychology of Religion and Spirituality.

Valentine, J. C., Hirschy, A., S., Bremer, C., Novillo, W., Castellano, M., \& Banister, A.W. (2009). Systematic Reviews of Research: Postsecondary Transitions Identifying Effective Models and Practices. University of Louisville: National Research Center on Career and Technical Education.

Valentine, J. C., Pan, Y., Richardson, G. B., \& Banister, A.W. (2009). Professional development programming for post-secondary faculty. University of Louisville: National Research Center on Career and Technical Education.

\section{SUBMITTED MANUSCRIPTS}

Valentine, J.C., Banister, A.W, \& Goodwin, S. (Submitted). Consenters and nonconsenters in studies in education. Submitted to The Journal of Experimental Education.

\section{PRESENTATIONS}

Mitchell, N. G., Wyrick, A. J., Nichols, A. J., Carrier, J. W., \& Banister, A. W. (2008, August). Social stigmatization of obesity in African American preschool children. Poster presented at the 2008 American Psychological Association Annual Convention, Boston, MA.

Banister, A.W. \& Adams, E. F. (2008, March). Religious beliefs, dysfunctional attitudes, and the development of depressive symptoms in adolescents. Poster presented at the 2008 Kentucky Psychological Association Student Conference.

Adams, E. F., Banister, A.W., \& Steger, M. F. (2007, August). Seeking and finding meaning in the context of the sacred. Poster presented at the 2007 American Psychological Association Annual Convention, San Francisco, CA. 
Adams, E. F., Banister, A.W., \& Steger, M. F. (2007, April). Seeking and finding meaning in the context of the sacred. Poster presented at the 2007 Kentucky Spring Research Conference, Lexington, KY.

Adams, E. F., Banister, A.W., \& Steger, M. F. (2007, March). Seeking and finding meaning in the context of the sacred. Poster presented at the 2007 Kentucky Psychological Student Conference.

\section{MEMBERSHIPS IN PROFESSIONAL SOCIETIES}

American Psychological Association

\section{PROFESSIONAL SERVICE}

$2006-2007$

Student Representative

Graduate Student Association

College of Education \& Human Development

University of Louisville

$2007-2009$

Secretary

Doctoral Student Organization

College of Education \& Human Development

University of Louisville

SERVICE AWARDS

2006

Outstanding Hoosier Citizen Award

Awarded by the State of Indiana for services performed in Mississippi following Hurricane Katrina.

\section{PROFFESIONAL REFERENCES}

Available upon request 